\title{
The Catalytic Mechanisms of Binuclear Metallohydrolases
}

\author{
Nataša Mitić, ${ }^{\dagger}$ Sarah J. Smith, ${ }^{\dagger}$ Ademir Neves, ${ }^{\ddagger}$ Luke W. Guddat,${ }^{\dagger}$ Lawrence R. Gahan, ${ }^{\dagger}$ and Gerhard Schenk ${ }^{*, \dagger}$ \\ School of Molecular and Microbial Sciences, The University of Queensland, Brisbane, QLD 4072, Australia, and Departamento de Química, \\ Universidade Federal de Santa Catarina, Campus Trindade, Florianópolis, SC 88040-900, Brazil
}

Received November 18, 2005

\section{Contents}

1. Introduction

2. Purple Acid Phosphatases

2.1. Biochemical Characterization and Function

2.2. Structural Characterization

2.3. Catalytic Mechanism

2.4. Biomimetics of PAPs

3. Ser/Thr Protein Phosphatases

3.1. Biochemical Characterization and Function

3.2. Structural Characterization

3.3. Catalytic Mechanism

4. 3'-5' Exonucleases

4.1. Biochemical Characterization and Function

4.2. Structural Characterization

4.3. Catalytic Mechanism

5. 5'-Nucleotidases

5.1. Biochemical Characterization and Function

5.2. Structural Characterization

5.3. Catalytic Mechanism

6. Conclusions

7. Abbreviations

8. Acknowledgments

9. References

3338

3338

3338

3341

3344

3345

3347

3347

3348

3350

3351

3351

3352

3354

3355

3355

3356

3357

3358

3359

3359

3359

\section{Introduction}

Binuclear metallohydrolases are a structurally diverse group of enzymes that use binuclear metal ion centers to catalyze the hydrolysis of amides and esters of carboxylic and phosphoric acids. Representatives are listed in Table 1, together with their metal ion composition and, if known, their metabolic role(s). Several of these enzymes are either targets for drug design against a wide variety of human disorders, including osteoporosis, cancer, cystic fibrosis, and depression, or are of significance in bioremediation since they can be modified to degrade pesticides or organophosphorus nerve gases.

In 1996, Wilcox summarized the then current knowledge about the structure, function, and mechanism of all known binuclear metallohydrolases. ${ }^{1}$ In subsequent years more specialized articles followed, ${ }^{2}$ focusing on the binuclear manganese-containing arginases, catalases, and enolases, ${ }^{3}$ the Ser/Thr protein phosphatases (in particular calcineurin), ${ }^{4-6}$

\footnotetext{
* To whom correspondence should be addressed. Phone: ++61 73365 4144. Fax: ++6173365 4273. E-mail: schenk@uq.edu.au.

$\dagger$ University of Queensland.

$\doteqdot$ Universidade Federal de Santa Catarina.
}

aminopeptidases, ${ }^{7}$ and the purple acid phosphatases.$^{8-10}$ Despite their structural versatility and variations in metal ion specificity (Table 1), binuclear metallohydrolases employ variants of a similar basic mechanism. Similarities in the first coordination sphere are found across the entire family of enzymes (Figure 1), but in the proposed models for catalysis, the identity of the attacking nucleophile, the stabilization of reaction intermediates, and the relative contribution of the metal ions vary substantially.

Here, an updated review of the current understanding of metallohydrolase-catalyzed reactions is presented. The motivation is to present, compare, and critically assess current models for metal ion assisted hydrolytic reaction mechanisms. The focus here is on four systems, purple acid phosphatases (PAPs), Ser/Thr protein phosphatases (PPs), $3^{\prime}-5^{\prime}$ exonucleases, and $5^{\prime}$-nucleotidases (5'-NTs), which have contributed to major advancement of our current understanding of the catalytic mechanisms that operate in such enzymes. Although three of the four enzymes (PAPs, PPs, and $5^{\prime}$-NTs) are evolutionarily related, ${ }^{11}$ the enzymes selected for this review are diverse with respect to their structure, metal ion composition, and function. The authors have concentrated mainly on references covering the past decade; however, relevant earlier literature is included where appropriate. We extend our apologies to researchers whose contributions may not have been covered by this review.

In terms of the catalytic mechanism, the identity of the reaction-initiating nucleophile and the roles of the metal ions in catalysis are addressed. Where possible, predicted structures of transition states and their stabilization are discussed. Each description of an enzyme family concludes with an illustration of the currently accepted model for its catalytic mechanism. The various models proposed for the hydrolytic reaction mechanism are compared in context with observed variations in physicochemical and functional properties. Similar to Wilcox's review, this article reflects the recent achievements of bioinorganic chemists. However, since many binuclear metallohydrolases are targets for the development of drugs, pesticides and anti-warfare agents, structural biologists and those involved in drug discovery and development will find this review useful and timely.

\section{Purple Acid Phosphatases}

\subsection{Biochemical Characterization and Function}

PAPs (E.C. 3.1.3.2) are the only binuclear metallohydrolases where the necessity for a heterovalent active site (Fe(III)-M(II), where $\mathrm{M}=\mathrm{Fe}, \mathrm{Zn}$, or $\mathrm{Mn}$ ) for catalysis has been established. PAPs are glycosylated, resistant to inhibition by L-tartrate, and catalyze the hydrolysis of a broad range 


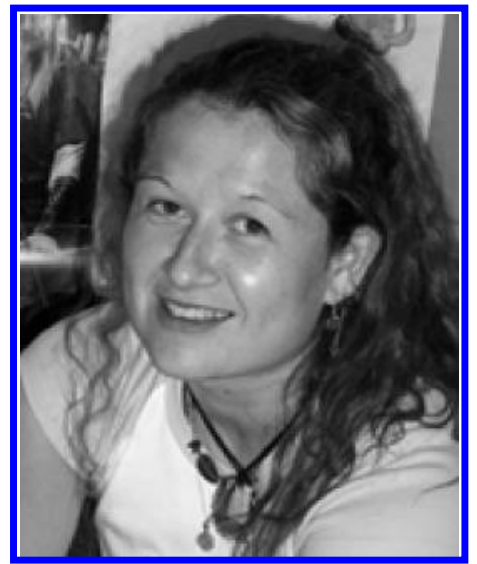

Nataša Mitić (Ph.D. in Chemistry from Yale University, New Haven, CT) was a graduate student with Prof. John P. Caradonna working on spectroscopic and kinetic characterization of the enzyme phenylalanine hydroxylase (PAH) and its implication in the genetic disorder known as phenylketonuria (PKU). From 2001 to 2003, Nataša was a postdoctoral fellow in the group of Prof. Edward I. Solomon at Stanford University, working on the binuclear non-heme iron enzymes methane monooxygenase and ribonucleotide reductase, and specifically on the characterization of their oxygen intermediates. In 2004, she was awarded a postdoctoral research fellowship from the University of Queensland (Brisbane, Australia), and since then has been working on binuclear metallohydrolases. Her current research interests also involve bacterial and human cytochrome P450 enzymes. When not at work, Nataša loves outdoor activities and enjoys spending her free time in the rugged Australian outback and on the beach.

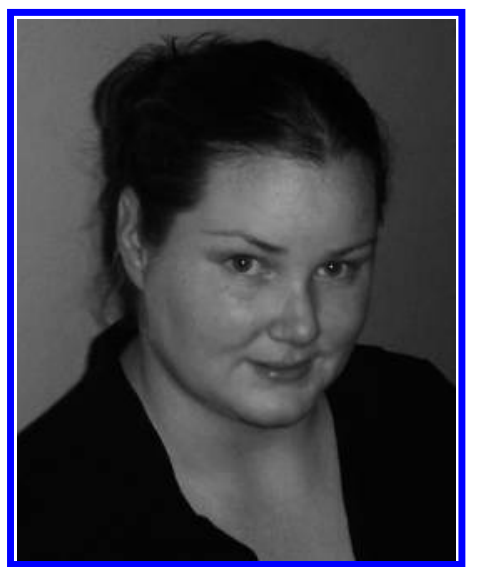

Sarah Smith received her Honors degree (First Class) in Chemistry at the University of Queensland (Australia) in 2004. She is currently pursuing her Ph.D. under the supervision of Lawrence Gahan and Gerhard Schenk at the University of Queensland. Her current research is focused on the mechanism of purple acid phosphatases and biomimetics of binuclear metalloenzymes. Sarah is also known in the laboratory for her infectious and vibrant laughter, and is a talented sushi maker.

of phosphorylated substrates at acidic to neutral $\mathrm{pH} .{ }^{8,10,12,13}$ The enzyme isolated from mammals (pig, bovine, mouse, rat, and human ${ }^{14-20}$ ) is a $\sim 35 \mathrm{kDa}$ monomeric protein with an $\mathrm{Fe}$ (III)-Fe(II) center; the amino acid sequences of animal PAPs are highly conserved with at least $85 \%$ identity. ${ }^{21}$ The characteristic color of PAPs is due to a charge-transfer transition $\left(\lambda_{\max }=510-560 \mathrm{~nm} ; \epsilon=\sim 3000-4000 \mathrm{M}^{-1}\right.$ $\mathrm{cm}^{-1}$ ) in the active site from a conserved tyrosine ligand to the ferric ion. ${ }^{2-24}$ Interestingly, mammalian PAPs can easily (and reversibly) be oxidized to the inactive diferric form due to the low redox potential ( $~ 340 \mathrm{mV}$ ) of the divalent iron. ${ }^{25,26}$ It has thus been suggested that PAP activity may be regulated in vivo by reversible oxidation/reduction of the active site. ${ }^{25}$

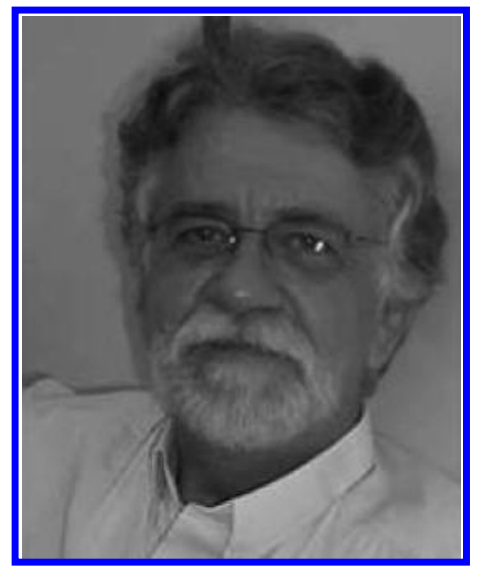

Ademir Neves is a Professor of Chemistry in the Department of Chemistry, Universidade Federal de Santa Catarina (UFSC), Brazil. He obtained his Ph.D. in Inorganic Chemistry (summa cum laude) in 1983 at the University of Bochum, Germany, under the supervision of Professor Karl Wieghardt. From 1984 to 1986, he joined the faculty of chemistry at UFSC as an assistant professor of chemistry. After a one year postdoctoral stay at the University of Bochum in 1987, again in the laboratory of Karl Wieghardt, he became a full professor of bioinorganic chemistry at UFSC. His current research is related to the design of unsymmetrical small molecules as synthetic and functional models for the active site of metalloenzymes, including catechol oxidases and purple acid phosphatases. The research also includes the application of these transition metal complexes as tools to probe recognition and reactions of double helical DNA and the design of novel chemotherapeutics.

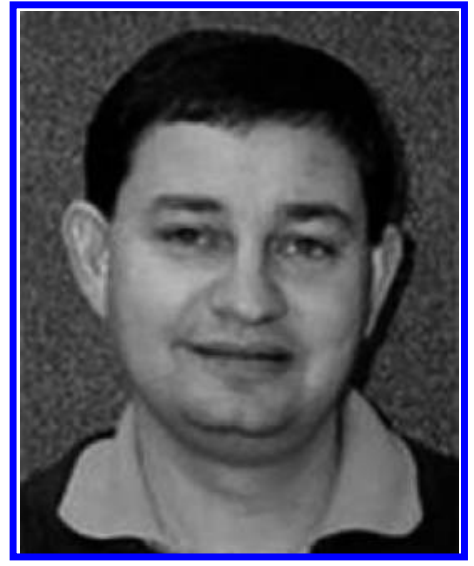

Luke Guddat was born in Melbourne, Australia, and received his undergraduate degree from Monash University, and his Ph.D. from Melbourne University in 1990. He then pursued graduate work with Professor Allen Edmundson at the Harrington Cancer Center, Amarillo, TX. Upon returning to Australia, he spent 4 years as a research fellow in the Centre for Drug Design and Development at the University of Queensland before being appointed to the School of Molecular and Microbial Sciences, also at the University of Queensland, where he is now a Senior Lecturer. His research interests include structural studies on binuclear metallohydrolases, enzymes in the branched chain amino acid biosynthesis pathway, antimalarial drug design, and discovery of novel components of Australian snake venoms.

Oxidation of the heterovalent di-iron site is also accompanied by a change in color from pink $\left(\lambda_{\max }=515 \mathrm{~nm}\right)$ to purple $\left(\lambda_{\max }=560 \mathrm{~nm}\right) \cdot{ }^{16,22,24,27-29}$

Plant PAPs have been extracted from red kidney bean, soybean, sweet potato, duckweed, and tomato. ${ }^{30-35}$ Most characterized plant PAPs are homodimers with a subunit molecular weight of $\sim 55 \mathrm{kDa}^{30-32,35} \mathrm{~A}$ heterodimeric intracellular PAP has recently been reported for tomato, ${ }^{33}$ with 63 and $57 \mathrm{kDa}$ subunits. The same organism also has two secreted, monomeric isoforms with molecular weights of 84 and $57 \mathrm{kDa}^{34}$ The amino acid sequences of homo- 


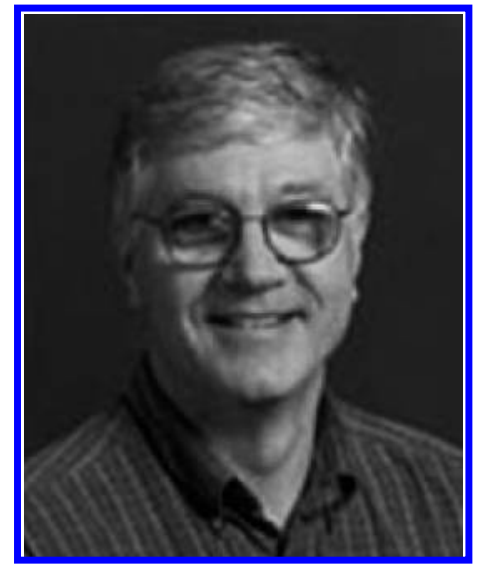

Lawrence Gahan is an Associate Professor of Chemistry in the School of Molecular and Microbial Sciences at the University of Queensland, Brisbane, Australia. He obtained his Ph.D. in Inorganic Chemistry at La Trobe University, Melbourne, Australia, and, after postdoctoral positions in the United States and England, joined the group of Professor Alan Sargeson at the Research School of Chemistry at the Australian National University, Canberra, Australia. In 1984, he joined the Chemistry Department at the University of Queensland. Current research is related to the design of synthetic and functional models for the active site of metalloenzymes and the design of radiopharmaceutical compounds.

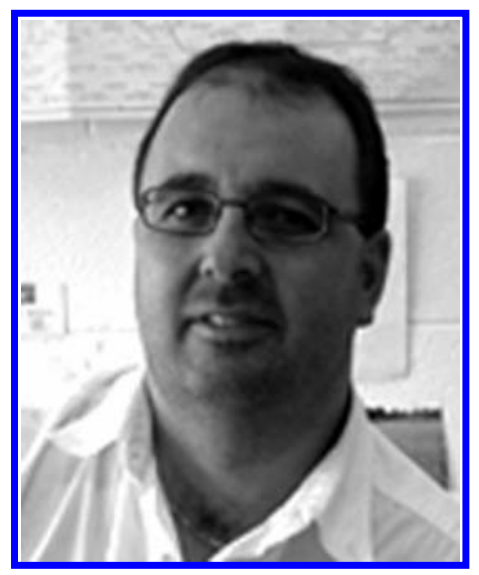

Gerhard Schenk is a Senior Lecturer of Biophysical Chemistry in the School of Molecular and Microbial Sciences at the University of Queensland, Brisbane, Australia. He obtained a Diploma in Chemistry from the University of Berne, Switzerland, and was awarded a Ph.D. in Biochemistry from the University of Queensland in 1997. Following a postdoctoral position in the same institution, Dr. Schenk spent several months as a visiting research fellow in Prof. A. Geoffrey Sykes' laboratory at the University of Newcastle-upon-Tyne, England (2000). In 2001, he joined the group of Professor Edward I. Solomon in the Department of Chemistry at Stanford University. He has been a member of the Academic Staff at the University of Queensland since 2003. Current research is related to the investigation of the mechanism of binuclear metalloenzymes and the design of anti-osteoporotic compounds. Outside work Gerhard enjoys exploring the South Pacific islands.

dimeric plant PAPs are homologous, sharing at least $65 \%$ identity. ${ }^{21}$ However, sequence conservation between plant and mammalian PAPs is low ( $<20 \%$ sequence homology) and is limited predominantly to residues in the catalytic center (vide infra). ${ }^{21}$ The metal ion composition in plant PAPs is the $\mathrm{Fe}(\mathrm{III})-\mathrm{M}(\mathrm{II})$ type, where $\mathrm{M}$ is zinc or manganese. ${ }^{30-32,35,36}$ Thus, while plant PAPs have a chromophoric center similar to that of their animal counterparts $\left(\lambda_{\max }=\sim 550 \mathrm{~nm}\right)$ their activity cannot be regulated by reversible oxidation/reduction. Interestingly, a sequence database search has revealed that plants contain a second type of PAP that resembles the mammalian enzymes. ${ }^{21}$ The metal ion composition and physiochemical properties of this novel plant PAP have not yet been determined.

A monomeric fungal PAP has been identified in Aspergillus ficuum with a molecular weight of $\sim 85 \mathrm{kDa} .{ }^{37}$ The metal ion composition is unknown. No bacterial PAP has yet been characterized, but evidence has accumulated that indicates the occurrence of this enzyme in only a limited number of microorganisms. ${ }^{38}$

The proposed biological roles for PAP are diverse and dependent on the organism. Mammalian PAPs have been implicated in iron transport during pregnancy ${ }^{39}$ and macrophage-specific generation of reactive oxygen species (ROS) through Fenton chemistry in response to the invasion of the host organism by pathogens. ${ }^{40-42}$ Of particular interest is the observation that, in animals, PAP is secreted into the boneresorptive space where it may be required for normal bone turnover. ${ }^{10}$ PAP levels are elevated in patients with metabolic bone diseases such as osteoporosis and cancers with bone metastases. ${ }^{43}$ A transgenic mouse in which the enzyme is overexpressed $^{44}$ exhibits increased bone resorption leading to a mild form of osteoporosis, while the transgenic mouse knock-out ${ }^{45}$ exhibits the opposite phenotype (osteopetrosis). It has been speculated that PAP participates in bone resorption by dephosphorylation of bone matrix proteins such as osteopontin. ${ }^{46}$ Because of its high expression levels, PAP has become the most commonly used histochemical marker for osteoporosis, ${ }^{10}$ making it a major target for the development of chemotherapeutic agents. ${ }^{47}$

Although only one PAP-encoding gene has been identified in mammals ${ }^{48,49}$ two isoforms have been observed, 5a and 5 b. ${ }^{50,51}$ The $5 \mathrm{a}$ isoform represents the intact polypeptide chain, while isoform $5 \mathrm{~b}$ is the product of a proteolytic cleavage in an exposed loop, sometimes referred to as the repression loop, close to the active site. ${ }^{10,52-57}$ Since proteolysis significantly increases the activity of the enzyme, it has been proposed that isoform $5 \mathrm{a}$, expressed in osteoclasts, effectively represents a proenzyme which, upon secretion into the bone-resorptive space, is activated by proteolytic cleavage. ${ }^{52,56,57}$ Importantly, proteolytic cleavage does not only increase the reactivity of PAP but also alters its preference for substrates. In particular, since the cleaved isoform efficiently catalyses the dephosphorylation of ATP, whereas the intact enzyme displays a preference for ADP, 56 it has been proposed that isoform $5 \mathrm{~b}$ may act as an ATPase.

Plant PAPs may play a crucial role in mobilizing organic phosphate esters in the soil during germination. ${ }^{58}$ However, the study of the physiological function(s) of plant PAPs is greatly complicated by the fact that plants contain a multitude of genes encoding different isoforms of this enzyme. ${ }^{21}$ For example, Arabidopsis thaliana was shown to have at least 29 different isoforms. ${ }^{59}$ Evidence has accumulated which suggests that different isoforms may be expressed in different tissue types in response to a variety of environmental factors. ${ }^{60,61}$ In tomato, phosphate starvation induces the expression of one intracellular and two secreted PAPs. ${ }^{33,34}$ Interestingly, in addition to acid phosphatase activity, each of these isoforms can also act as an alkaline peroxidase. It has been hypothesized that PAPs with peroxidase activity may be involved in the generation of ROS, ${ }^{33,34}$ and that the extracellular production of ROS is associated with the oxidative burst that occurs during the plant's response to pathogen attack, ${ }^{34}$ while the intracellular ROS production may be connected to an increase in respiratory electron transport and $\mathrm{O}_{2}$ uptake during biotic and abiotic stresses. ${ }^{33}$ 
Table 1. Representative Group of Binuclear Hydrolytic Enzymes ${ }^{a}$

\begin{tabular}{|c|c|c|c|}
\hline enzyme & metal center & metabolic role(s) & pharmacology \\
\hline purple acid phosphatases* & $\begin{array}{l}\mathrm{Fe}(\mathrm{III})-\mathrm{Fe}(\mathrm{II}) \\
\mathrm{Fe}(\mathrm{III})-\mathrm{Zn}(\mathrm{II}) \\
\mathrm{Fe}(\mathrm{III})-\mathrm{Mn}(\mathrm{II})\end{array}$ & $\begin{array}{l}\text { bone resorption, iron transport, } \\
\text { generation of reactive } \\
\mathrm{O}_{2} \text { species }\end{array}$ & $\begin{array}{l}\text { target for anti- } \\
\quad \text { osteoporotic drugs }\end{array}$ \\
\hline Ser/Thr phosphatases $* b$ & $\begin{array}{l}\mathrm{Fe}(\mathrm{II})-\mathrm{Fe}(\mathrm{II}) \\
\mathrm{Fe}(\mathrm{II})-\mathrm{Zn}(\mathrm{II}) \\
\mathrm{Mn}(\mathrm{II})-\mathrm{Mn}(\mathrm{II})\end{array}$ & $\begin{array}{l}\text { glycogen metabolism, muscle } \\
\text { contraction, signal transduction, } \\
\text { neuronal activities, cell cycle } \\
\text { progression, RNA splicing }\end{array}$ & $\begin{array}{l}\text { targets for } \\
\text { development of } \\
\text { immunosuppressants }\end{array}$ \\
\hline ureases & $\mathrm{Ni}(\mathrm{II})-\mathrm{Ni}(\mathrm{II})$ & hydrolysis of urea & $\begin{array}{l}\text { target for pesticides and drugs } \\
\text { against pyelonephritis, kidney stones, } \\
\text { and peptic ulcers }\end{array}$ \\
\hline leucine aminopeptidase & $\mathrm{Zn}(\mathrm{II})-\mathrm{Zn}(\mathrm{II})$ & $\begin{array}{l}\text { protein degradation, } \\
\text { amino acid biosynthesis }\end{array}$ & $\begin{array}{l}\text { target for drugs against myeloid leukemia, } \\
\text { cystic fibrosis, and eye lens aging }\end{array}$ \\
\hline $3^{\prime}-5^{\prime}$ exonucleases* & $\mathrm{Mn}(\mathrm{II})-\mathrm{Mn}(\mathrm{II})$ & $\begin{array}{l}\text { correction of errors during } \\
\text { DNA replication }\end{array}$ & \\
\hline EcoRV endonuclease & $\operatorname{Mg}(\mathrm{II})-\mathrm{Mg}(\mathrm{II})$ & DNA metabolism & \\
\hline $5^{\prime}$-nucleotidases $* b$ & $\begin{array}{l}\mathrm{Zn}(\mathrm{II})-\mathrm{Zn}(\mathrm{II}) \\
\mathrm{Co}(\mathrm{II})-\mathrm{Co}(\mathrm{II})\end{array}$ & $\begin{array}{l}\text { maintenance of balanced } \\
\text { nucleotide concentrations }\end{array}$ & \\
\hline phosphotriesterase $^{b}$ & $\begin{array}{l}\mathrm{Zn}(\mathrm{II})-\mathrm{Zn}(\mathrm{II}) \\
\mathrm{Cd}(\mathrm{II})-\mathrm{Cd}(\mathrm{II}) \\
\mathrm{Zn}(\mathrm{II})-\mathrm{Cd}(\mathrm{II}) \\
\mathrm{Co}(\mathrm{II})-\mathrm{Co}(\mathrm{II})\end{array}$ & $\begin{array}{l}\text { removal of organophosphates } \\
\text { as response to toxic stress }\end{array}$ & $\begin{array}{l}\text { target for development of } \\
\text { biocatalyst to remove } \\
\text { organophosphorus nerve agents } \\
\text { (e.g., Sarin) }\end{array}$ \\
\hline metallo- $\beta$-lactamases & $\begin{array}{l}\mathrm{Fe}(\mathrm{II})-\mathrm{Fe}(\mathrm{II}) \\
\mathrm{Zn}(\mathrm{II})-\mathrm{Zn}(\mathrm{II})\end{array}$ & virulence factors & $\begin{array}{l}\text { potential antibiotic } \\
\text { and/or vaccine targets }\end{array}$ \\
\hline inositol monophosphatase & $\operatorname{Mg}(\mathrm{II})-\mathrm{Mg}(\mathrm{II})$ & signal transduction & $\begin{array}{l}\text { target for development of drugs against } \\
\text { manic-depressive disorders }\end{array}$ \\
\hline
\end{tabular}

${ }^{a}$ Metal ion compositions, metabolic roles, and pharmacological potential are indicated. The "*" indicates systems that are discussed in detail in this review. ${ }^{b}$ The in vivo metal ion composition for these enzymes is not established.

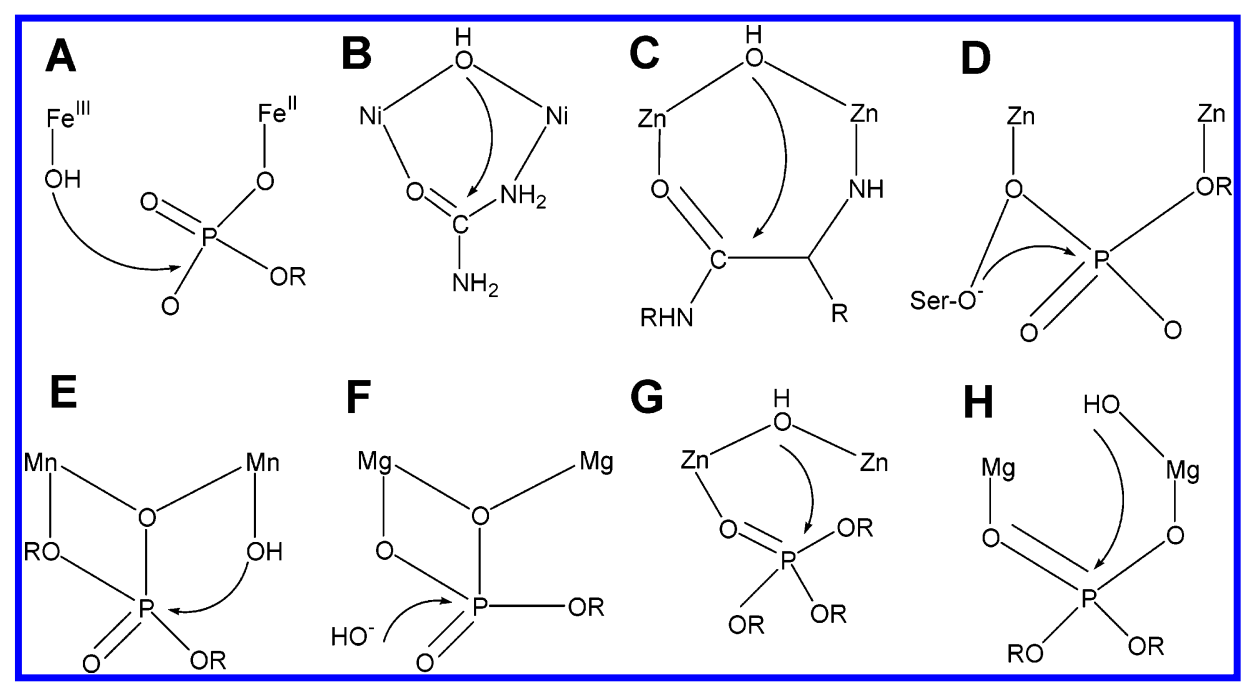

Figure 1. Diversity of proposed mechanisms for binuclear metallohydrolases. (A) Purple acid phosphatase, (B) urease, (C) leucine aminopeptidase, (D) alkaline phosphatase, (E) 3'-5' exonuclease, (F) inositol monophosphatase, (G) phosphotriesterase, and (H) EcoRV endonuclease.

\subsection{Structural Characterization}

Over the past decade crystal structures of PAPs from red kidney bean, ${ }^{62,63}$ sweet potato, ${ }^{64}$ pig, ${ }^{65}$ rat,${ }^{66,67}$ and human ${ }^{68}$ have been reported. To date, only structures of the inactive oxidized state have been determined for mammalian PAPs. The two subunits in the plant PAPs are linked via a disulfide bridge. Each subunit has an N-terminal domain of unknown function and a C-terminal domain that contains the catalytically active site (Figure 2). ${ }^{62-64}$ In contrast, the animal enzymes have a single domain, which is structurally related to the C-terminal domain of plant PAPs (Figure 2) ${ }^{65-68}$ The active site is formed by loops at the ends of $\beta$-strands in the middle of a $\alpha-\beta-\beta-\alpha$ cluster in both plant and mammalian PAPs. Despite the low overall sequence homology between PAPs from these two kingdoms, the seven metal-ligating amino acids in their active sites are invariant (Figure 3). ${ }^{8,21}$ The equivalence of their active site structures has also been demonstrated by metal ion replacement studies which have shown that the $\mathrm{Zn}$ (II)-derivatives of pig, bovine, rat, and human PAPs are kinetically indistinguishable from the native di-iron forms ${ }^{28,53,54,69-72}$ while the di-iron derivative of red kidney bean PAP has properties very similar to those of the native $\mathrm{Fe}(\mathrm{III})-\mathrm{Zn}$ (II) form. ${ }^{73,74}$ Furthermore, spectroscopic and magnetochemical measurements also support similar active site geometries and properties. The di-iron derivative of red kidney bean PAP is redox-active and has an antiferromagnetically coupled binuclear center with an exchange coupling constant $\left(2|J| \sim 10-20 \mathrm{~cm}^{-1}\right)$ similar to that determined for the animal enzymes. ${ }^{29,75}$ Also, ${ }^{1} \mathrm{H}$ NMR studies of the di-iron derivative of the red kidney bean enzyme and native mammalian enzymes provided strong evidence that the coordination environment of the chromophoric Fe(III) centers is very similar in both systems, an observation also supported by comparable charge-transfer 


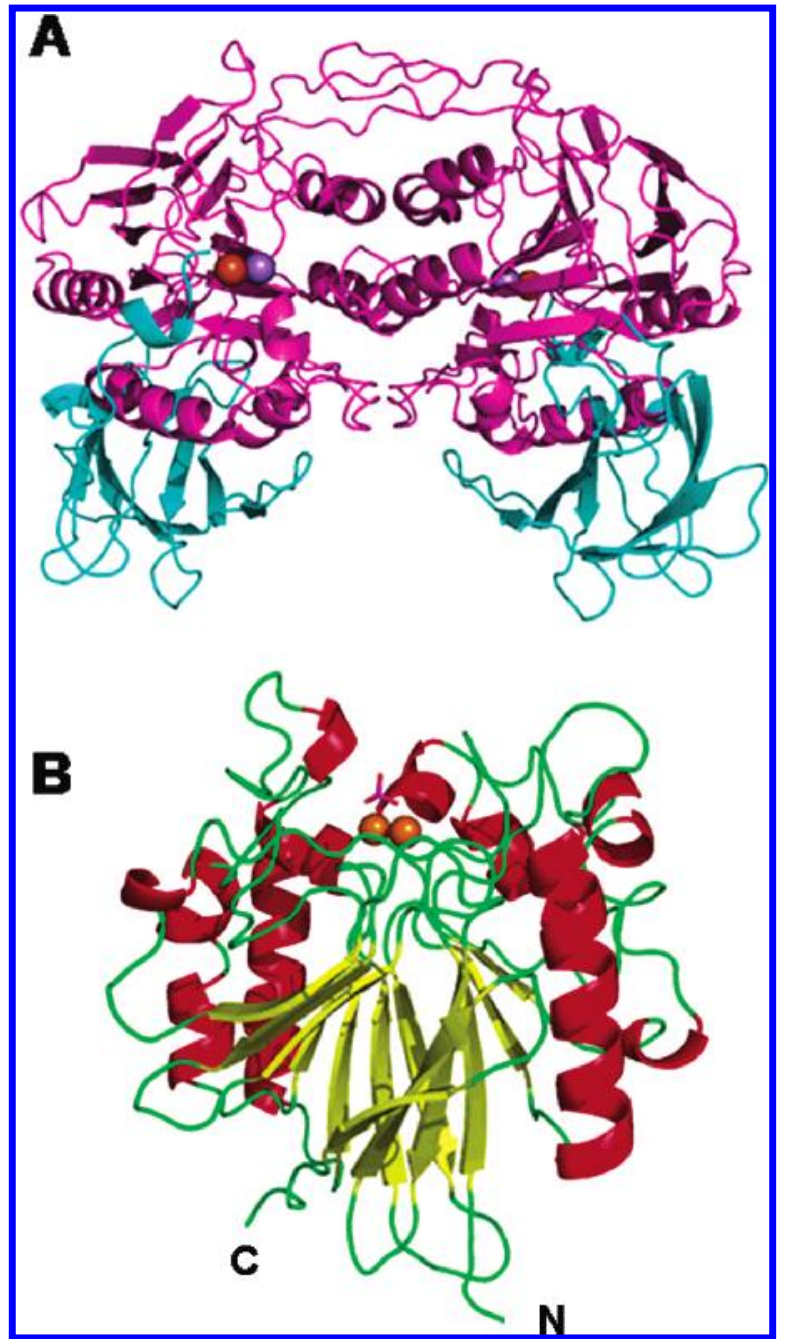

Figure 2. Ribbon representation of the overall structure of PAPs from (A) sweet potato (PDB code 1XZW), and (B) pig (PDB code 1UTE). Sweet potato PAP is homodimeric; each subunit contains two domains, an N-terminal domain (in blue) of unknown function and a catalytic C-terminal domain (in magenta). The structure was solved complexed with phosphate (not shown). The metal ions are colored orange for Fe(III) and blue for Mn(II). Mammalian PAPs are monomeric and contain only one domain. In panel B, the two Fe ions are shown as orange spheres and the bound phosphate is shown as a stick model.

transitions in the visible region. ${ }^{76}$ The Fe(III) site in PAPs is coordinated to the oxygen of a deprotonated tyrosine, the nitrogen atom of a histidine, and the oxygen atoms of two aspartate residues, one of which bridges the two metal sites (Figure 4). Although no binding constants have been reported, metal ion replacement studies indicate that Fe(III) is tightly bound. ${ }^{28,53,54,70,72,73,77-80}$ The divalent metal site ( $\mathrm{Zn}(\mathrm{II}), \mathrm{Fe}(\mathrm{II}), \mathrm{Mn}(\mathrm{II})$ ) is coordinated to the oxygen atom of the bridging aspartate, the nitrogen atoms of two histidine residues, and an asparagine oxygen atom. Its binding affinity is reduced compared to $\mathrm{Fe}(\mathrm{III})$, enabling the generation of mononuclear, inactive $\mathrm{Fe}(\mathrm{III})$ half-apoenzymes. ${ }^{28,73,79} \mathrm{~A}$ property observed among many binuclear metalloenzymes is the presence of a high- and low-affinity binding site for the metal ions (see also below). For comparative purposes, the high-affinity site is labeled M1, while the low-affinity site is M2 (Figure 4). The crystallographic metal-metal distances are in the range $3.1-3.3 \AA$ for red kidney bean PAP (Fe(III)-Zn(II)), $3.3 \AA$ for the Fe(III)-Mn(II) center in the sweet potato PAP, and 3.1-3.5 $\AA$ for mammalian
PAPs, in agreement with extended X-ray absorption fine structure (EXAFS) studies, which determined metal-metal distances for the $\mathrm{Zn}(\mathrm{II})$ derivatives of pig PAP in the range $3.2-3.3 \AA .^{81,82}$

The presence or absence of terminal and bridging aqua/ hydroxo ligands and the protonation state of the bridging water molecule have been points of some conjecture. The initial structure of red kidney bean PAP revealed no evidence of water molecules in the first coordination sphere of the two metal ions due to the limited resolution of the crystallographic data. ${ }^{62,63}$ To account for spectroscopic, kinetic, and magnetochemical data ${ }^{29,83-85}$ the coordination environments of the $\mathrm{Fe}(\mathrm{III})$ and $\mathrm{Zn}$ (II) were completed by modeling a hydroxide ligand bound to the $\mathrm{Fe}(\mathrm{III})$, a $\mathrm{H}_{2} \mathrm{O}$ ligand to $\mathrm{Zn}$ (II), and a bridging hydroxide (Figure 4). ${ }^{62,63}$ The presence of a bridging oxygen atom was subsequently observed in the electron density maps for pig and rat PAP, which were interpreted in terms of a hydroxide group. ${ }^{65,67}$ The pig PAP structure also contains a phosphate ion bridging the two metal sites, ${ }^{65}$ while in the rat PAP structure, a sulfate anion is bound monodentately to the redox-active iron. ${ }^{67}$ Pulsed electronnuclear double resonance (ENDOR) and EXAFS studies of the $\mathrm{Fe}(\mathrm{III})-\mathrm{Fe}$ (II) and $\mathrm{Fe}$ (III) $-\mathrm{Zn}$ (II) forms of pig PAP have since confirmed the presence of the bridging hydroxide ligand in the resting state. ${ }^{81,86}$ In addition, ENDOR measurements have also supported the presence of a water ligand, coordinated terminally to the redox-active divalent metal ion. However, in the same study, no evidence for a terminal, $\mathrm{Fe}(\mathrm{III})$-bound water molecule was found for the resting enzyme, suggesting that the trivalent metal ion is fivecoordinate. ${ }^{86}$ This observation contrasts with crystallographic data reported for rat PAP, where an area of electron density associated with the $\mathrm{Fe}(\mathrm{III})$ site has been assigned to a terminal solvent $\left(\mathrm{H}_{2} \mathrm{O} / \mathrm{OH}\right)$ molecule. ${ }^{67}$ However, the sulfate ion bound at the $\mathrm{Fe}(\mathrm{II})$ site in this structure may be partially responsible for recruiting this solvent molecule.

The $\mathrm{p} K_{\mathrm{a}}$ for the protonation equilibrium of the bridging water ligand depends on the metal ion composition. Magnetization and electron paramagnetic resonance (EPR) measurements have indicated that the $\mathrm{Fe}(\mathrm{III})-\mathrm{Fe}$ (II) center in pig PAP is weakly antiferromagnetically coupled at $\mathrm{pH} 4.9$, while the $\mathrm{Fe}(\mathrm{III})-\mathrm{Mn}$ (II) center in the sweet potato enzyme is strongly coupled at this $\mathrm{pH} .{ }^{29,36}$ These observations have been interpreted in terms of the presence of a $\mu$-hydroxo bridge in the mammalian PAPs and a $\mu$-oxo bridge in the sweet potato enzyme at that $\mathrm{pH} .{ }^{36,64}$

To date, most crystal structures of PAPs have been determined in the presence of the tetraoxoanions, phosphate, ${ }^{63-66,68}$ tungstate, ${ }^{63}$ or sulfate,${ }^{67}$ bound to the active site. The structure of the phosphate complexes in red kidney bean, pig, rat, and human PAPs all show a $\mu-\eta^{1}-\eta^{1}-\mathrm{PO}_{4}{ }^{3-}$ coordination mode ${ }^{87}$ with the phosphorus approximately equidistant from the two Fe sites, although limited resolution precluded the establishment of the proper orientation of the phosphate in the structure of the rat enzyme ${ }^{66}$ In these structures, the phosphate ion is invariably involved in an extensive network of hydrogen bonds and is assumed to be coordinated in the protonated $\mathrm{H}_{2} \mathrm{PO}_{4}{ }^{-}$state, reflecting the $\mathrm{pH}$ conditions under which the proteins were crystallized ( $\mathrm{pH} 4.5,5,6.4$, and 6-6.5 for the red kidney bean, pig, rat, and human enzymes, respectively). The structure of pig PAP, resolved to $1.55 \AA{ }^{65}$ shows that the uncoordinated oxygen atoms of the phosphate group form hydrogen bonds with His195(296) (2.76 ̊) and His92(202) (2.68 $)$ ), while the 


\begin{tabular}{|c|c|c|c|c|c|c|c|c|c|c|c|}
\hline & Source & Motif 1 & & Motif 2 & & Motif 3 & & Motif 4 & & Motif 5 & Length \\
\hline \multirow[t]{3}{*}{ Plants } & Red kidney beans & GDLG & 25 & GDLSY & 32 & GNHE & 79 & VLMH & 35 & GHVH & 459 \\
\hline & Sweet potato & GDIG & 25 & GDLSY & 32 & GNHE & 79 & VLVH & 35 & GHVH & 473 \\
\hline & Sweet potato ${ }^{a}$ & GDWG & 29 & GDNSY & 33 & GNHD & 89 & VIGH & 33 & GHDH & 313 \\
\hline \multirow{3}{*}{ Animals } & Human & GDWG & 34 & GDNSY & 34 & GNHD & 87 & VAGH & 33 & GHDH & 325 \\
\hline & Rat & GDWG & 34 & GDNSY & 34 & GNHD & 89 & VAGH & 33 & GHDH & 327 \\
\hline & Pig & GDWG & 34 & GDNSY & 34 & GNHD & 89 & VAGH & 33 & GHDH & 338 \\
\hline Fungi & A. ficuum & NDMG & 25 & GDLSY & 84 & GNHE & 151 & VMSH & 33 & GHIH & 614 \\
\hline Bacteria & M.tuberculosis & GDQG & 40 & GDLCY & 31 & GNHE & 89 & $\mathrm{VCMH}$ & 35 & GHEH & 529 \\
\hline \multicolumn{2}{|c|}{ Metal binding site ${ }^{b}$} & 1 & & $\mathrm{X}$ & & 2 & & 2 & & 21 & \\
\hline
\end{tabular}

Figure 3. Partial sequence alignment of PAPs from different kingdoms and sources. Only the five conserved motifs containing the seven metal ion-coordinating residues (in bold) are shown. ${ }^{21}$ The number of amino acid residues separating the motifs and the total sequence lengths are indicated.

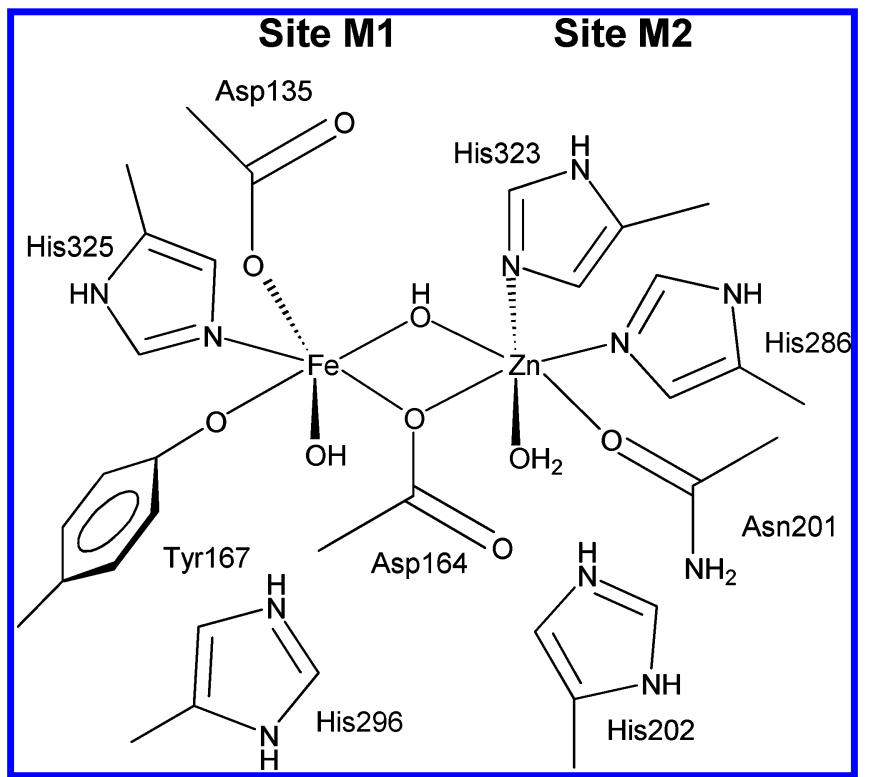

Figure 4. Active site of red kidney bean PAP. Fe(III) binds to the high-affinity metal site M1, and $\mathrm{Zn}(\mathrm{II})$ is bound to the low-affinity site M2. The seven metal ion-coordinating residues and the two histidines (His202 and His296) are highly conserved among PAPs from different sources. Tyr167 forms a charge-transfer complex with $\mathrm{Fe}(\mathrm{III})$.

two coordinated oxygen atoms interact with His92(202) (3.17 $\AA$ ), Asp52(164) (3.04 $\AA$ ), and His223(325) (3.13 $\AA$ ) as well as with the $\mu$-hydroxy bridge (the residue numbers in parentheses refer to the sequence of red kidney bean PAP). In red kidney bean PAP, tungstate coordinates to the metal centers in a mode similar to that of phosphate $\left(\mu-\eta^{1}-\eta^{1}\right.$ $\mathrm{WO}_{4}{ }^{2-}$ ) with a series of hydrogen bond contacts to the four residues, His323(221), His296(195), His202(92), and Asn201(91) (the numbers in parentheses refer to the sequence of pig PAP).$^{63}$ No large conformational changes are observed in the active site of red kidney bean PAP upon binding of phosphate and tungstate; superposition of the active sites of the resting and both the phosphate- and tungstate-bound forms reveal minor orientation differences for His 295 and His296 (only the latter residue is conserved throughout PAPs). ${ }^{63}$

The observed $\mu-\eta^{2}-\eta^{2}-\mathrm{H}_{2} \mathrm{PO}_{4}{ }^{-}$coordination mode in sweet potato PAP is unique among PAP structures.$^{64}$ One oxygen atom of the bound phosphate anion (O2) acts as a bridge between the $\mathrm{Fe}(\mathrm{III})$ and $\mathrm{Mn}(\mathrm{II})$ ions; $\mathrm{O} 1$ and $\mathrm{O} 3$ complete the coordination environment of the two six-coordinate metal ions. The protonation state of phosphate $\left(\mathrm{H}_{2} \mathrm{PO}_{4}{ }^{-}\right)$is defined by the hydrogen bonds which are distributed differently in two subunits of the molecule. In one subunit, $\mathrm{O} 3$ and $\mathrm{O} 4$ (uncoordinated oxygen atom) are protonated, while in the other, $\mathrm{O} 1$ and $\mathrm{O} 3$ are protonated, demonstrating structural flexibility. ${ }^{64}$ A similar $\mu-\eta^{2}-\eta^{2}-\mathrm{H}_{2} \mathrm{PO}_{4}{ }^{-}$mode of coordination has only been observed in the phosphate complex of the di$\mathrm{Ni}(\mathrm{II})$ urease from Bacillus pasteurii. ${ }^{88}$ Related coordination modes have been reported for $\mu-\eta^{2}-\eta^{2}-\mathrm{CO}_{3}{ }^{2-}$ complexes of iron, cobalt, nickel, copper, and zinc, ${ }^{87,89-91}$ as well as for the $\mu-\eta^{2}-\eta^{2}-\mathrm{SO}_{4}{ }^{2-}$ complex of the $\mathrm{Mn}(\mathrm{II})-\mathrm{Mn}$ (II) bacteriophage $\lambda$ protein phosphatase $(\lambda \mathrm{PP}) .^{92}$

The structure of rat PAP has also been determined in the presence of sulfate, ${ }^{67}$ which coordinates monodentately to the redox-active iron and forms hydrogen bonds with Asn91 and His92. Both metal ions in the active site have six ligands, with one $\mathrm{Fe}$ (III)-bound and one bridging water ligand completing their first coordination spheres. The location of the sulfate group relative to the binuclear metal center is further stabilized through interactions with an adventitiously bound $\mathrm{Zn}$ (II) (present in the crystallization solution). Red kidney bean PAP was crystallized recently in the presence of sulfate but absence of $\mathrm{Zn}(\mathrm{II})$ in the buffer (Guddat, L. W., and Schenk, G., unpublished results); interestingly, sulfate does not coordinate to the binuclear center but forms a number of strong hydrogen bonds in the second coordination sphere, including one to the bridging water molecule.

Depending on the source and/or tissue type from which mammalian PAPs are extracted, they are either monomers of $\sim 35 \mathrm{kDa}$ (isoform 5a) or heterodimers with disulfidelinked $\sim 20$ and $\sim 16 \mathrm{kDa}$ fragments (isoform $5 \mathrm{~b}$; vide supra). The crystal structures of intact pig and rat PAP, ${ }^{65,67}$ in combination with $\mathrm{N}$-terminal amino acid sequencing and mass spectrometry, have identified an exposed loop that is susceptible to proteolytic cleavage..$^{52,54,56,57}$ Several proteases (trypsin, papain, cathepsins $\mathrm{K}$ and L) have been shown to cleave within this loop; generally, the nicked enzyme has significantly increased reactivity, but this increase appears to be protease-dependent. ${ }^{52,57}$ Substrate specificity and the $\mathrm{pH}$ dependence of kinetic parameters are also altered upon proteolysis. ${ }^{52,54,56}$ Site-directed mutagenesis studies have identified loop residues Ser145 and Asp146 in rat PAP as important contributors to the regulation of enzyme activity. ${ }^{53,57}$ A similar role for these residues has also been proposed for the human enzyme. ${ }^{54}$ In addition, the observa- 
tion that the mode of fluoride inhibition is uncompetitive at $\mathrm{pH} 4.9$ or above but noncompetitive at lower $\mathrm{pH}$ values has been interpreted in terms of a regulatory role for a second aspartate residue in the loop (Asp158), at least in human PAP. ${ }^{56}$ Because of its role in the regulation of enzyme activity, the exposed loop is commonly referred to as "repression" loop. Its structural flexibility has recently been demonstrated by a comparison of two structures of intact (uncleaved) human PAP. ${ }^{68}$ The recombinant enzyme expressed in Pichia pastoris has an overall and active site structure similar to that of other PAPs, with the two metal ions linked via both a phosphate and a $\mu$-hydroxo bridge. In contrast, human PAP expressed in Escherichia coli crystallizes in a distinctly different manner. Here, Asp145 (corresponding to Asp147 in rat PAP) bidentately coordinates to the metal ions in the active site, occupying a position equivalent to that of the phosphate group in pig PAP and the human enzyme expressed in P. pastoris. ${ }^{65,68}$ Furthermore, Asn89 (Asn91 and 201 in pig and red kidney bean PAPs, respectively; Figure 4) is prevented from coordinating to the redox-active iron due to steric interactions with the loop residue Asn143; an additional water molecule completes the first coordination sphere instead. ${ }^{68}$ There is no space for substrate binding in this closed conformation of the active site, and thus, the enzyme is expected to be catalytically inactive. Thus, the two structures of human PAP are believed to represent an active, open and an inactive, closed form of the intact enzyme.$^{68}$ Upon proteolytic cleavage, the equilibrium between the two forms might be altered in favor of the active, open form, explaining the observed activation by proteolysis. The presence of the equilibrium between open and closed forms is supported by the observation that the $\mathrm{Fe}(\mathrm{III})-\mathrm{Zn}$ (II) derivative of human PAP is insensitive toward proteolysis; the enzyme is always in the active state, ${ }^{72}$ which indicates that metal ion substitution shifts the equilibrium toward the open conformation, possibly due to the inability of Asp145 to form a $\mu$-carboxylate complex. However, further studies (e.g., using site-directed mutagenesis) are necessary to assess the physiological relevance of the inhibitory, closed form of animal PAPs.

\subsection{Catalytic Mechanism}

The observation of both an apparent lack of a burst of product formation and the absence of enzyme-catalyzed transphosphorylation, ${ }^{93}$ and the measurements of kinetic and solvent isotope effects, ${ }^{94}$ supported by isotope labeling ${ }^{95}$ and site-directed mutagenesis studies, ${ }^{96}$ have led to the emergence of a mechanistic model for PAPs and PPs that invokes a direct transfer of the phosphoryl group of the substrate to a metal-coordinated, nucleophilic solvent molecule.

In the initial step of the catalytic cycle (Figure 5), substrate binds to the divalent metal ion (site M2; Figure 4), facilitated by the rapid exchange of the bound water ligand. ${ }^{79,85}$ It is uncertain if the substrate binds in a mono- or bidentate manner to the active site prior to hydrolysis. For the Fe(III)$\mathrm{Zn}$ (II) derivative of bovine PAP, it was shown that the addition of the reaction product (and inhibitor) phosphate does not affect the spectroscopic properties of the trivalent metal ion greatly at the $\mathrm{pH}$ of optimal activity $(\mathrm{pH} 6.5)$, suggesting monodentate binding to the divalent metal ion. ${ }^{70}$ In contrast, at lower $\mathrm{pH}$ phosphate perturbs the Fe(III) site, consistent with the formation of a $\mu$-phosphate complex. ${ }^{70}$ A similar observation has been reported for a proteolytically cleaved human PAP ( $\mathrm{pH}$ optimum at $\sim 6.3$ ), whereas in the

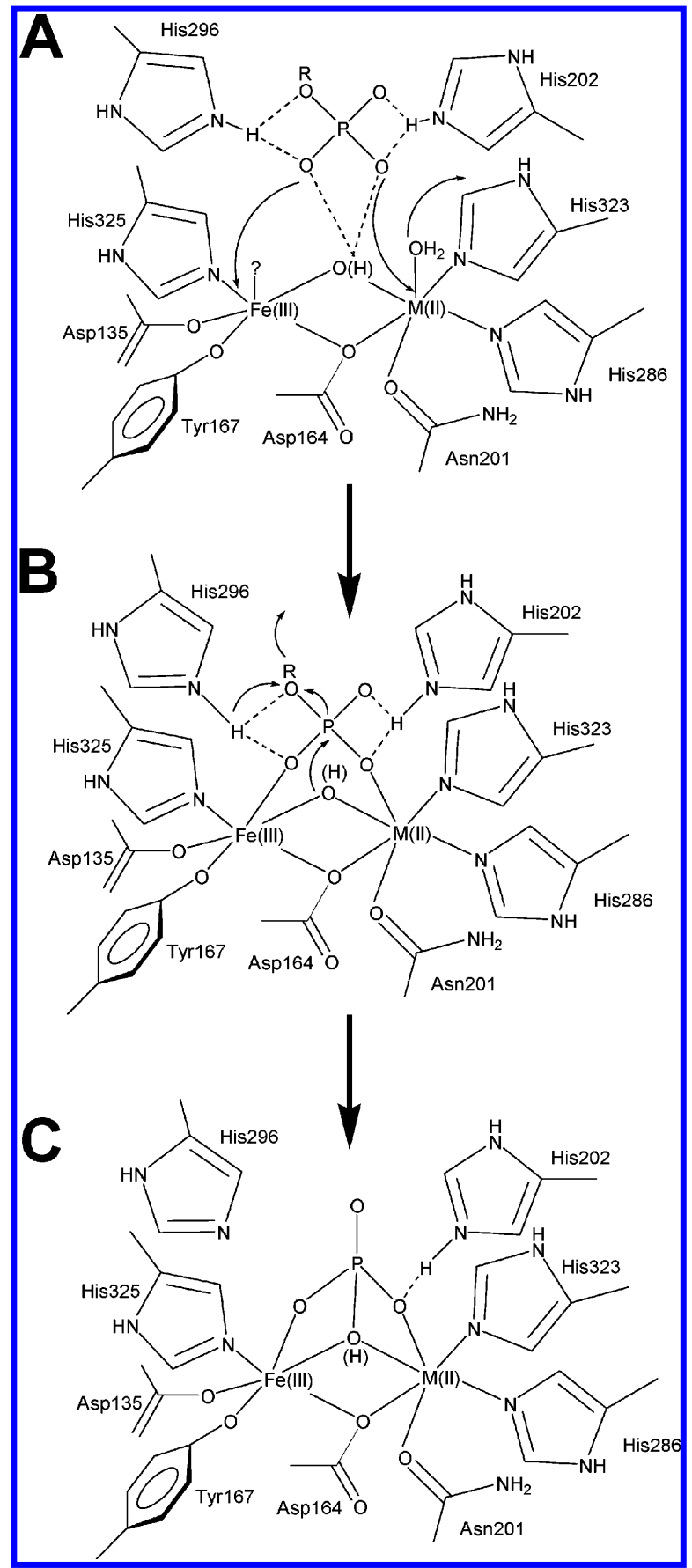

Figure 5. Proposed mechanism of hydrolysis by PAPs. (A) Substrate binding; (B) nucleophilic attack and release of leaving group; (C) regeneration of the active site; phosphate is replaced by two or three water molecules (see text for details).

intact enzyme, phosphate may not directly coordinate to the metal center, possibly because the majority of active sites is in the closed conformation. ${ }^{97}$ In contrast, pig PAP has a more acidic $\mathrm{pH}$ optimum $(\mathrm{pH} \sim 5),{ }^{47,85}$ and based on a combination of EPR, EXAFS, and resonance Raman spectroscopic data, it has been proposed that in this enzyme phosphate adopts a bidentate coordination geometry at that $\mathrm{pH} .{ }^{81,82,98,99}$ Thus, it is possible that the precise substrate coordination may be pH-dependent.

Another point of conjecture is the identity of the reactioninitiating nucleophile (Figure 5). Metal ion replacement studies demonstrated that the nucleophile is bound to the trivalent metal ion. ${ }^{77,78}$ Initially, for both pig and red kidney bean PAPs, it was suggested that the hydroxide terminally 


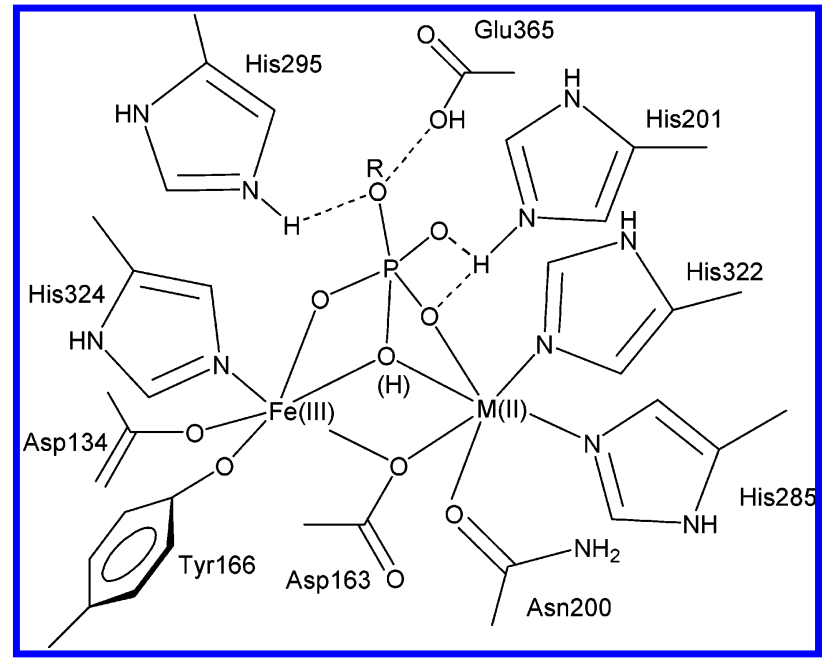

Figure 6. Proposed transition state in sweet potato PAP. An associative mechanism is promoted via transition state stabilization by His 295 and Glu365. ${ }^{64}$

bound to $\mathrm{Fe}(\mathrm{III})$ attacks the substrate, leading to the release of the product alcohol and the formation of a $\mu$-phosphate complex in the active site. ${ }^{9,79}$ However, the observation (by ENDOR) that no terminal Fe(III)-bound hydroxide group may be present in the resting state of pig PAP argues against this (although the possibility that substrate binding may promote the binding of a water molecule to $\mathrm{Fe}(\mathrm{III})$ cannot be ruled out at present). ${ }^{86}$ It could also be shown that fluoride can replace the bridging hydroxide group in pig PAP. ${ }^{99}$ Upon the further addition of phosphate, a ternary $\mathrm{PAP} \cdot \mathrm{F} \cdot \mathrm{PO}_{4}$ complex was formed, where phosphate binds to both metal ions, as observed in the crystal structure of pig PAP. ${ }^{65}$ Thus, in this instance, fluoride has been proposed to replace the bridging nucleophile. ${ }^{71,99}$ This hypothesis is in agreement with the crystal structure of the manganese-containing sweet potato PAP, where the bridging water molecule has been replaced by an oxygen atom of the bound phosphate group ${ }^{64}$ and recent fluoride inhibition studies of human PAP. ${ }^{56,97,100}$

The precise nature of the transition state of PAP-catalyzed reactions may vary between enzymes from different sources, or different isoforms from the same source. Both pig and red kidney bean PAPs display a similar Brønsted correlation with $\beta_{\mathrm{lg}} \approx-0.4 .^{64}$ The maximum value of $\beta_{\mathrm{lg}}$ for the hydrolysis of a dianionic monoester is $\sim-1.3,{ }^{101}$ indicative of a dissociative mechanism. While the small $\beta_{\lg }$ of -0.4 in pig and red kidney bean PAPs is not unambiguously consistent with such a mechanism, it is in contrast to the absence of a Brønsted correlation in sweet potato PAP, which has been interpreted in terms of an associative mechanism (i.e., bond formation between the nucleophile and the phosphorus atom occurs prior to hydrolysis; Figure 6). ${ }^{64}$ Interestingly, neither intact nor cleaved human PAP displays a significant Brønsted correlation, suggesting a transition state similar to that of the sweet potato enzyme. ${ }^{56}$ In addition, the observation that both intact and cleaved human PAPs appear to have similar transition states supports the regulatory model described above, whereby the intact enzyme exists in equilibrium between inactive, closed and active, open conformations. ${ }^{6}$

Since the electron-withdrawing potential of the leaving group affects the reactivities measured for both pig and red kidney bean PAPs, the rate-determining step in catalysis is likely to be associated with hydrolysis. ${ }^{64,93}$ At first glance, the lack of a Brønsted correlation in the sweet potato and human enzymes may indicate that the rate-limiting step occurs after hydrolysis. However, an analysis of the structure of sweet potato PAP has revealed that an associative transition state is likely to be stabilized by the tripodal coordination of the oxyphosphorane, which leads to effective charge neutralization. ${ }^{64}$ Furthermore, leaving group protonation by residue Glu365 may also contribute to the relative insensitivity of the sweet potato enzyme toward the leaving group $\mathrm{p} K_{\mathrm{a}}{ }^{64}$ The fact that Glu365 is not conserved among PAPs explains observed mechanistic variations. However, in human PAP, similar to the sweet potato enzyme, the associative transition state may be stabilized via residue Asp158, located in the flexible repression loop. ${ }^{56}$ Notably, both sweet potato and proteolytically cleaved human PAPs have considerably higher substrate turnover rates than other PAPs, especially at lower $\mathrm{pH}$. This has been interpreted in terms of Glu365 and Asp158 acting as proton donors for the leaving groups, at least at low $\mathrm{pH} .{ }^{56,64}$ At higher $\mathrm{pH}$, a conserved histidine residue (His195, His195, His296, and His295 in pig, human, red kidney bean, and sweet potato PAPs, respectively (Figure 4)), is the likely proton donor (Figure 5). ${ }^{63-65,67,80}$ The significance of this histidine residue has been demonstrated by site-directed mutagenesis studies of rat PAP where its replacement by alanine and glutamine leads to a drastic drop in reactivity. ${ }^{41} \mathrm{~A}$ second histidine residue in the active site (His92 or 202 in pig and red kidney bean PAPs, respectively; Figure 4) is not likely to act as proton donor, but mutations of this residue to alanine, asparagine, or arginine in rat and red kidney bean PAPs support a model where it plays an important part in the optimal orientation of both the nucleophile and the substrate during catalysis. ${ }^{80,102}$

In the final step of the catalytic cycle (Figure 5), the bound phosphate group is displaced, and at least two water molecules from the solvent are required to regenerate the active site for another catalytic cycle. ${ }^{64,103}$

\subsection{Biomimetics of PAPs}

In recent years, considerable attention has been devoted toward the synthesis, X-ray structures, and physicochemical characterization of binuclear $\mathrm{Fe}(\mathrm{III})-\mathrm{M}$ (II) complexes to mimic the active site of purple acid phosphatase. ${ }^{104}$ Studies on these synthetic analogues are a convenient strategy to gain insight into structural and spectroscopic properties and the catalytic mechanism of the corresponding metalloenzymes. Construction of accurate synthetic unsymmetrical models is not a simple matter, since considerable attention must be given to ligand design in order to achieve a coordination environment which is similar to that imposed by the unique topology of the protein. Often, synthetic models are binuclear complexes containing symmetrical ligands, since the preparation of the ligands is greatly simplified. ${ }^{105-107}$ However, unsymmetrical ligands presenting two potentially different coordination environments allow the generation of heterobinuclear $\mathrm{Fe}(\mathrm{III})-\mathrm{M}(\mathrm{II})$ complexes. ${ }^{108,109}$ Such systems include a single terminal $\mathrm{Fe}-\mathrm{O}_{\text {phenolate }}$ bond which is crucial in mimicking structural, spectroscopic, electrochemical, and catalytic properties of PAPs.

The $\mathrm{H}_{2} \mathrm{~L}$ ligand (where $\mathrm{L}=2$-bis[ $\{(2$-pyridyl-methyl)aminomethyl $\}-6$ - $\{(2$-hydroxy-benzyl)-(2-pyridyl-methyl) $\}$ aminomethyl]-4-methyl-phenol; Figure 7) is able to selectively generate homo- and heterobinuclear $\left[\mathrm{Fe}(\mathrm{III})(\mu \text {-OAc })_{2}(\mu\right.$ phenoxide $) \mathrm{M}(\mathrm{II})]^{+}$complexes when the reactions are carried out with stoichiometric amounts of $\mathrm{H}_{2} \mathrm{~L}, \mathrm{Fe}\left(\mathrm{ClO}_{4}\right)_{3} \cdot 9 \mathrm{H}_{2} \mathrm{O}$, 


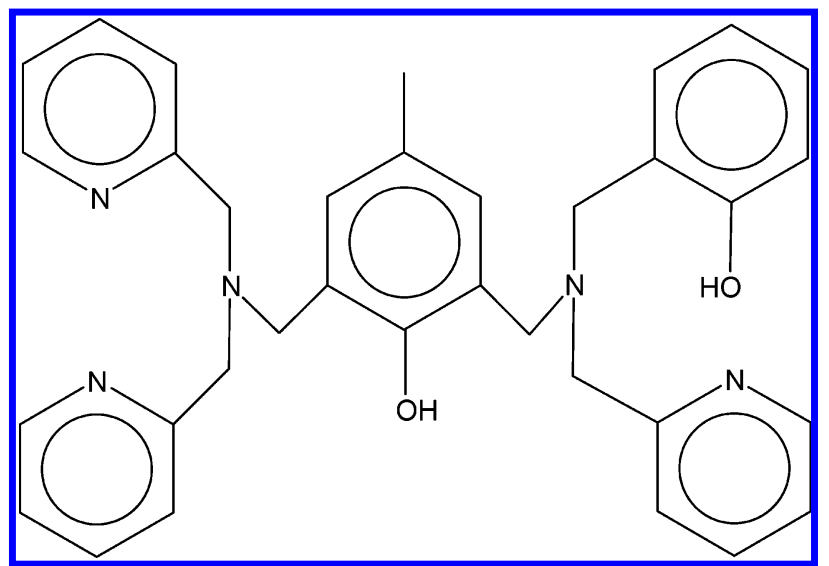

Figure 7. Schematic illustration of the $\mathrm{H}_{2} \mathrm{~L}$ ligand. $\mathrm{L}=2$-bis-

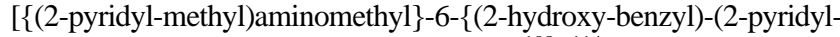
methyl)\}aminomethyl]-4-methyl-phenol. ${ }^{108-114}$

and $\mathrm{M}\left(\mathrm{ClO}_{4}\right)_{2} \cdot 6 \mathrm{H}_{2} \mathrm{O}$ in $\mathrm{CH}_{3} \mathrm{OH}$ in the presence of sodium acetate. ${ }^{108-114}$

The crystal structures of the mixed-valence Fe(III)-M(II) complexes show that the $\mathrm{Fe}(\mathrm{III})$ ion is coordinated by the tridentate hard site of $\mathrm{L}^{2-}$ which contains the terminal phenolate, while the $\mathrm{M}(\mathrm{II})$ ion lies in the other tridentate compartment containing the soft pyridyl groups (Figure 7). In all of the structures, the metals are in distorted octahedral environments, separated by $\sim 3.5 \AA$ and are bridged by two exogeneous carboxylate groups and the central phenolate ligand (Figure 7). As an illustration, the crystal structure of $\left[\mathrm{LFe}(\mathrm{III})(\mu-\mathrm{OAc})_{2} \mathrm{Cu}(\mathrm{II})\right]^{+}$is shown in Figure $8 .{ }^{112}$

The principal physicochemical properties including electronic spectra and electrochemical data and protonation constants for the $\left[\mathrm{LFe}(\mathrm{III})(\mu-\mathrm{OAc})_{2} \mathrm{M}(\mathrm{II})\right]^{+}$complexes are listed in Table 2. The electronic spectra of all complexes in $\mathrm{CH}_{3} \mathrm{CN}$ solution show absorption maxima in the range 522$555 \mathrm{~nm}$ attributed to the terminal phenolate-to-Fe(III) chargetransfer transition. Molecular mechanics calculations and an analysis of molecular orbitals indicate that the contribution of the bridging oxygen phenolate to the charge-transfer transition is negligible. ${ }^{114}$ The antiferromagnetic coupling constant of $-7.4 \mathrm{~cm}^{-1}$ for the Fe(III) $-\mathrm{Fe}$ (II) complex ( $H=$ $-J S_{1} S_{2} ; S_{1}=2$ and $S_{2}=5 / 2$ ) and the Mössbauer data (which show isomer shift and quadrupolar splitting values typical of coupled $\mathrm{Fe}$ (III) and Fe(II) ions) confirm the mixed-valence character of the binuclear iron complex, ${ }^{108}$ and these

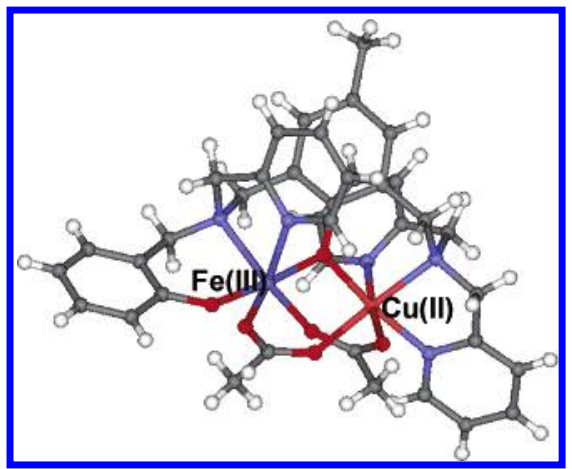

Figure 8. Crystal structure of the $\left[\mathrm{LFe}(\mathrm{III})(\mu-\mathrm{OAc})_{2} \mathrm{Cu}(\mathrm{II})\right]^{+}$ complex, showing the coordination environments of both $\mathrm{Fe}$ (III) and $\mathrm{Cu}(\mathrm{II})$ metal ions. ${ }^{112}$ The following color scheme applies: red for $\mathrm{O}$, blue for $\mathrm{N}$, gray for $\mathrm{C}$, and white for $\mathrm{H}$.

parameters compare very well with those observed for reduced uteroferrin. ${ }^{27,29,75,115}$ The half-wave potential of 0.38 $\mathrm{V}$ versus NHE observed in the cyclic voltammogram of this complex is ascribed to the $\mathrm{Fe}(\mathrm{III}) \mathrm{Fe}(\mathrm{II}) / \mathrm{Fe}$ (III)Fe(III) couple and closely resembles the corresponding redox potential of uteroferrin $\left(0.344 \mathrm{~V}\right.$ vs $\left.\mathrm{NHE}^{26}\right)$ indicating that both species have similar Fe(II) Lewis acidities. Therefore, the binuclear iron complex can be considered as a good synthetic analogue for the redox properties of the metalloenzyme.

Potentiometric titrations of the complexes listed in Table 2 in water/ethanol (30:70) have revealed three protonation equilibria in the $\mathrm{pH}$ range $4-10 .{ }^{108-113}$ It has been proposed that upon dissolving the complexes the dissociation of the first carboxylate leads to a species described as $\left[(\mathrm{OH}) \mathrm{Fe}(\mathrm{III})(\mu-\mathrm{OAc}) \mathrm{M}(\mathrm{II})\left(\mathrm{OH}_{2}\right)\right]$, where the $\mathrm{p} K_{\mathrm{a} 1}$ value is consistent with the dissociation of the $\mathrm{Fe}(\mathrm{III})$-bound terminal water molecule. Dissociation of the second carboxylate bridge results in the formation of a species in which a second water molecule is bound to the $\mathrm{Fe}$ (III) center and, upon its deprotonation $\left(\mathrm{p} K_{\mathrm{a} 2}\right)$, an $\mathrm{Fe}(\mathrm{III})(\mu-\mathrm{OH}) \mathrm{M}(\mathrm{II})$ species is formed. Finally, deprotonation of the M(II)-bound terminal water molecule bond $\left(\mathrm{p} K_{\mathrm{a} 3}\right)$ leads to the $[(\mathrm{OH}) \mathrm{Fe}(\mathrm{III})(\mu$ $\mathrm{OH}) \mathrm{M}(\mathrm{II})(\mathrm{OH})]$ species. The distinct $\mathrm{p} K_{\mathrm{a} 3}$ values observed for the complexes (Table 2) are in agreement with the trend observed for the first deprotonation of the $\left[\mathrm{M}(\mathrm{II})\left(\mathrm{H}_{2} \mathrm{O}\right)_{6}\right]^{2+}$ complexes. Moreover, it is important to note that the $\mathrm{p} K_{\mathrm{a} 1}$ values related to the deprotonation of the $\mathrm{Fe}(\mathrm{III})-\mathrm{OH}_{2}$ bond are comparable to the $\mathrm{p} K_{\mathrm{a}}$ values determined from the acidic limbs of the $\mathrm{pH}$ dependence parameters for PAPs. ${ }^{47,56,79,85}$

Table 2. Physicochemical Properties of PAP Mimetics ${ }^{a}$

\begin{tabular}{|c|c|c|c|c|c|c|c|}
\hline$[\mathrm{Fe}(\mathrm{III}) \mathrm{M}(\mathrm{II})]$ & $\lambda_{\max }(\mathrm{nm})$ & $\epsilon\left(\mathrm{M}^{-1} \mathrm{~cm}^{-1}\right)$ & $E_{1 / 2}^{1}(\mathrm{~V})^{i}$ & $E_{1 / 2}^{2}(\mathrm{~V})^{i}$ & $\mathrm{p} K_{\mathrm{a} 1}$ & $\mathrm{p} K_{\mathrm{a} 2}$ & $\mathrm{p} K_{\mathrm{a} 3}$ \\
\hline $\mathrm{M}(\mathrm{II})=\mathrm{Fe}^{b}$ & 555 & 4560 & -0.49 & 0.38 & & & \\
\hline$=\mathrm{Mn}^{c}$ & 544 & 2680 & -0.47 & 0.84 & 5.80 & & 7.76 \\
\hline$=\mathrm{Zn}^{d}$ & 540 & 3700 & -0.51 & & 4.84 & 5.99 & 7.97 \\
\hline$=\mathrm{Cu}^{e}$ & 546 & 3400 & -0.60 & -0.90 & 5.25 & 6.20 & 7.82 \\
\hline$=\mathrm{Ni}^{f}$ & 522 & 2600 & -0.54 & 0.76 & 5.30 & 6.80 & 8.61 \\
\hline \multicolumn{8}{|l|}{ Pig PAP } \\
\hline $\mathrm{Fe}(\mathrm{III})-\mathrm{Fe}(\mathrm{II})^{g}$ & 515 & 4000 & & $0.35^{j}$ & & & \\
\hline $\mathrm{Fe}(\mathrm{III})-\mathrm{Cu}(\mathrm{II})^{g}$ & 545 & 3400 & & & & & \\
\hline Red Kidney Bean PAP & & & & & & & \\
\hline $\mathrm{Fe}(\mathrm{III})-\mathrm{Zn}(\mathrm{II})^{h}$ & 544 & 3200 & & & & & \\
\hline $\begin{array}{l}\text { Sweet Potato PAP } \\
\mathrm{Fe}(\mathrm{III})-\mathrm{Mn}(\mathrm{II})^{h}\end{array}$ & 560 & 3200 & & & & & \\
\hline
\end{tabular}

${ }^{a}$ All models have been generated using the ligand 2-bis[\{(2-pyridylmethyl)aminomethyl\}-6-\{(2-hydroxybenzyl)(2-pyridylmethyl)\}aminomethyl]4-methylphenol). For comparative purposes, corresponding data for PAPs are included. ${ }^{b}$ From Neves et al. ${ }^{108}{ }^{c}$ From Karsten et al. ${ }^{109}{ }^{d}$ From Lanznaster et al. ${ }^{113}{ }^{e}$ From Lanznaster et al. ${ }^{12}{ }^{f}$ From Batista et al. ${ }^{111}{ }^{g}$ From Twitchett et al. ${ }^{79}{ }^{h}$ From Schenk et al. ${ }^{35}{ }^{i}$ Potentials measured vs NHE. ${ }^{j}$ From Bernhardt et al. ${ }^{26}$ 
Table 3. Kinetic Parameters for the Hydrolysis of BDNPP by PAP Mimetics ${ }^{a}$

\begin{tabular}{ccccc}
\hline$[\mathrm{Fe}(\mathrm{III}) \mathrm{M}(\mathrm{II})]$ & $\begin{array}{c}K_{\mathrm{m}} \\
(\mathrm{M})\end{array}$ & $\begin{array}{c}k_{\text {cat }} \\
\left(\mathrm{s}^{-1}\right)\end{array}$ & $\begin{array}{c}k_{\text {cat }} / K_{\mathrm{m}} \\
\left(\mathrm{s}^{-1} \mathrm{M}^{-1}\right)\end{array}$ & $k_{\text {cat }} / k_{\text {uncat }}$ \\
\hline $\mathrm{M}(\mathrm{II})=\mathrm{Mn}^{b}$ & $2.1 \times 10^{-3}$ & $7.1 \times 10^{-4}$ & $3.3 \times 10^{-1}$ & $3.9 \times 10^{3}$ \\
$=\mathrm{Zn}^{c}$ & $8.1 \times 10^{-3}$ & $1.1 \times 10^{-3}$ & $1.3 \times 10^{-1}$ & $6.1 \times 10^{3}$ \\
$=\mathrm{Cu}^{d}$ & $1.1 \times 10^{-2}$ & $1.8 \times 10^{-3}$ & $1.6 \times 10^{-1}$ & $1.0 \times 10^{4}$ \\
$=\mathrm{Ni}^{e}$ & $3.8 \times 10^{-3}$ & $4.4 \times 10^{-4}$ & $1.2 \times 10^{-1}$ & $2.4 \times 10^{3}$
\end{tabular}

${ }^{a}$ All models have been generated using the ligand 2-bis[\{(2pyridylmethyl)aminomethyl\}-6-\{(2-hydroxybenzyl)(2-pyridylmethyl)\}aminomethyl]-4-methylphenol). ${ }^{b}$ From Karsten et al. ${ }^{109}{ }^{c}$ From Lanznaster et al. ${ }^{113}{ }^{d}$ From Lanznaster et al. ${ }^{112}{ }^{e}$ From Batista et al., ${ }^{111}$ $k_{\text {uncat }}=$ uncatalyzed turnover number.

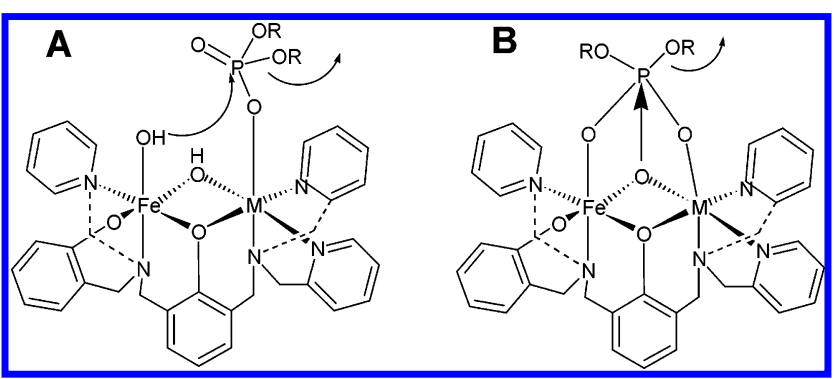

Figure 9. Proposed reaction mechanisms for the hydrolysis of BDNPP by $\mathrm{Fe}-\mathrm{Zn}$ and $\mathrm{Fe}-\mathrm{Cu}$ complexes, respectively. In the $\mathrm{Fe}-$ $\mathrm{Zn}$ complex, the proposed nucleophile is terminally coordinated to $\mathrm{Fe}(\mathrm{III}),{ }^{113}$ while in the $\mathrm{Fe}-\mathrm{Cu}$ complex, the nucleophile is proposed to be the metal ion bridging oxygen. ${ }^{12}$

Catalytic activities of the $\mathrm{Fe}-\mathrm{Mn}, \mathrm{Fe}-\mathrm{Zn}, \mathrm{Fe}-\mathrm{Cu}$, and $\mathrm{Fe}-\mathrm{Ni}$ complexes have been measured with the activated substrate 2,4-bis(dinitrophenyl) phosphate (BDNPP). Kinetic parameters are summarized in Table 3 . These reactions are strongly dependent on $\mathrm{pH}$, giving rise to bell-shaped $\mathrm{pH}$ versus rate profiles and $\mathrm{pH}$ optima in the range 6.07.0. ${ }^{109-113}$ In each case, the two protonation equilibria associated with catalytic activity are in good agreement with the $\mathrm{p} K_{\mathrm{a} 1}$ and $\mathrm{p} K_{\mathrm{a} 3}$ determined by potentiometric titrations (Table 2). Thus, the catalytically active species is of the type $\left[(\mathrm{OH}) \mathrm{Fe}(\mathrm{III})(\mu-\mathrm{OH}) \mathrm{M}(\mathrm{II})\left(\mathrm{OH}_{2}\right)\right]$. For the $\mathrm{Fe}-\mathrm{Zn}$ complex, it has been postulated that diester hydrolysis is likely to occur via a mechanism similar to that proposed for red kidney bean PAP, where substrate (bound as monodentate ligand) is activated by the divalent metal ion, followed by intramolecular nucleophilic attack of the terminally Fe(III)-bound $\mathrm{OH}^{-}$group on the phosphorus atom (Figure 9A). ${ }^{63,113}$ In contrast, a combination of mass spectrometry and EXAFS data collected for the $\mathrm{Fe}-\mathrm{Cu}$ complex has indicated that the ferric site in the resting state of this complex may be fivecoordinate, lacking the terminal water/hydroxide ligand. ${ }^{112}$ A similar observation has been reported for the resting state of pig PAP (see above). ${ }^{86}$ Thus, similar to pig and sweet potato PAPs, the $\mathrm{Fe}-\mathrm{Cu}$ complex is likely to employ the bridging hydroxo/oxo group as the initiating nucleophile (Figure 9B). ${ }^{36,64,86,99}$

\section{Ser/Thr Protein Phosphatases}

\subsection{Biochemical Characterization and Function}

The reversible phosphorylation/dephosphorylation of serine, threonine, and tyrosine residues in proteins is a key intracellular control mechanism in eukaryotes and prokaryotes and is regulated by protein kinases and phosphatases, respectively. Among the phosphatases are the Ser/Thr protein phosphatases (PPs; E.C. 3.1.3.16), a large group of enzymes that catalyze the dephosphorylation of serine and threonine residues. Approximately 30 different PPs have been identified in the human genome, while in the A. thaliana genome, more than 90 have been observed. ${ }^{116,117}$ Multiple copies have also been identified in both bacteria and archaea. ${ }^{118,119}$

There are two distinct gene families of PPs, labeled PPP and PPM. ${ }^{6}$ Although both gene families employ a similar catalytic strategy via a binuclear metal center, they have different protein folds and are not evolutionarily related. It is therefore likely that the two families have emerged as a result of convergent evolution to produce enzymes with similar catalytic mechanisms. ${ }^{120}$ Advances in our understanding of Ser/Thr protein phosphatases-catalyzed reactions have been greatly aided by recent investigations of the structures and functions of two PPPs (human PP5 and bacteriophage $\lambda \mathrm{PP}$ ) and two PPMs (human PP2C and PstP/Ppp from Mycobacterium tuberculosis). PP5 is widely expressed in mammalian tissues and was shown (i) to convert breast cancer cells from estrogen-dependent to estrogen-independent phenotypes, and (ii) to inactivate an apoptosis signal regulating kinase. ${ }^{121,122}$ The precise biological role of $\lambda \mathrm{PP}$ is unknown, while PP2C has been implicated in a number of cellular stress response processes. ${ }^{123,124}$ There are numerous proteins that contain PP2C-like domains. These include yeast adenyl cyclase, SpoIIE phosphatase from Bacillus subtilis, and mammalian mitochondrial pyruvate dehydrogenase. ${ }^{125}$ PstP/Ppp is a broad-specificity PPM domain encoded in the M. tuberculosis genome. The role of PstP/Ppp is to dephosphorylate the targets of $11 \mathrm{Ser} / \mathrm{Thr}$ protein kinases which mediate essential developmental and metabolic signals. ${ }^{126}$ In this review, the main focus is on structural and mechanistic studies of these four PPs.

All PPPs characterized to date share extensive sequence and structural homology in their catalytic cores. The metal ion coordinating amino acid side chains and most of the catalytically relevant residues are conserved. ${ }^{6}$ Furthermore, the six amino acid ligands of PPPs are also conserved in other binuclear metallohydrolases including PAPs and 5'NTs (which have an additional tyrosine and glutamine ligand, respectively). ${ }^{11}$ However, variations between different metallohydrolases, and specifically between different PPPs, exist with respect to their metal ion compositions. For comparison, PAPs in their active state are heterovalent (Fe(III)-M(II), $\mathrm{M}=\mathrm{Fe}, \mathrm{Zn}$, or $\mathrm{Mn}$ (see section 2)), and while the biologically relevant metal ion composition in $5^{\prime}$-NTs is at present unknown, enzymatic activity is generally highest for $\mathrm{Co}(\mathrm{II})-\mathrm{Co}$ (II) derivatives (see section 5). For PPPs, the identity of the physiologically relevant metal ions are also uncertain. For PP2B (also known as calcineurin) and $\lambda \mathrm{PP}$, heterobinuclear $\mathrm{Fe}-\mathrm{Zn}$ centers have been identified or generated in vitro. ${ }^{96,127-129}$ Initial studies using a combination of experimental techniques including EPR and reversible reduction and oxidation by dithionite and hydrogen peroxide, respectively, led to the suggestion that $\mathrm{PP} 2 \mathrm{~B}$ from bovine brain may be active in the heterovalent $\mathrm{Fe}$ (III)- $\mathrm{Zn}$ (II) state. ${ }^{129}$ A similar conclusion was reported for $\lambda \mathrm{PP} .{ }^{130}$ More recently, catalytically active $\mathrm{PP} 2 \mathrm{~B}$ was extracted under reducing conditions, indicating that the $\mathrm{Fe}(\mathrm{II})-\mathrm{Zn}$ (II) state is the active species. ${ }^{131,132}$ Also, the observation that the recombinant expression of $\lambda \mathrm{PP}$ in $E$. coli leads to a dramatic increase in intracellular manganese concentrations has been interpreted in terms of manganese being the most likely in vivo metal ion for this enzyme. ${ }^{133}$ Gradual addition of $\mathrm{Mn}$ (II) to $\lambda \mathrm{PP}$, monitored by EPR, has demonstrated that the active 
site has a homobinuclear Mn(II)-Mn(II) center. ${ }^{134,135}$ Similar to PAPs, the two metal binding sites are distinguished by considerable differences in their affinities for the metal ions, with $K_{\mathrm{D}}$ values of $\sim 2$ and $\sim 160 \mu \mathrm{M}$, respectively. ${ }^{134} \mathrm{~A}$ recent redox titration study of the $\mathrm{Fe}-\mathrm{Zn}$ derivative of $\lambda \mathrm{PP}$ has determined the redox potential for the $\mathrm{Fe}(\mathrm{III}) / \mathrm{Fe}$ (II) couple to be $\sim 120 \mathrm{mV}$. ${ }^{136}$ Although it is not known if PPPs are able to conduct hydrolytic reactions in the oxidized form, the possibility exists that these enzymes may be regulated in vivo by reversible oxidation/reduction, as has been speculated for the PAPs. ${ }^{136}$ Also, it has been proposed that, as an alternative mechanism to reconstitute enzyme activity, only one metal ion may be present in the resting state rendering the enzyme inactive. The second metal ion may enter the active site upon substrate binding, thus, reconstituting a fully active enzyme. ${ }^{135} \mathrm{~A}$ similar mechanism has also been proposed for the proofreading activity of DNA polymerases (see section 4).

Apart from $\mathrm{Mn}$ (II), $\lambda$ PP can also be activated by Ni(II), ${ }^{137}$ while activity in other PPPs such as PP1 and PP2A can be reconstituted with $\mathrm{Mn}$ (II), $\mathrm{Fe}(\mathrm{II})$, and $\mathrm{Co}(\mathrm{II}) .{ }^{133}$ It appears thus that within the group of catalytically active PPPs, divalent metal centers are the rule, but various combinations may occur. For instance, X-ray fluorescence and anomalous dispersion data indicate the presence of three different metal ions, $\mathrm{Mn}(\mathrm{II}), \mathrm{Fe}(\mathrm{II})$, and $\mathrm{Zn}(\mathrm{II})$, in the ratio 1:0.35:0.15 in the active site of PP5. ${ }^{138}$

Less is known about the metal ion requirements of PPMs. The biologically relevant metal ions are unclear, but human PP2C is activated most efficiently by both $\mathrm{Fe}(\mathrm{II})$ and $\mathrm{Mn}$ (II) and to some extent by $\mathrm{Mg}$ (II), while $\mathrm{Cu}(\mathrm{II}), \mathrm{Ni}$ (II), and $\mathrm{Zn}$ (II) tend to inhibit enzyme activity. ${ }^{139}$ For the recently detected Pst/Ppp from M. tuberculosis, metal ion analysis detected only the presence of manganese; no significant quantities of iron or zinc were found. ${ }^{117}$ Furthermore, in assays, $\mathrm{Mg}(\mathrm{II})$, $\mathrm{Ca}(\mathrm{II}), \mathrm{Ba}(\mathrm{II}), \mathrm{Zn}(\mathrm{II})$, and $\mathrm{Li}(\mathrm{I})$ were not able to substitute $\mathrm{Mn}(\mathrm{II})$ in vitro, even at concentrations as high as $4 \mathrm{mM} .{ }^{140}$

The $\mathrm{pH}$ optima of PPPs are at neutral to moderately alkaline $\mathrm{pH}^{6,141} \mathrm{An}$ analysis of the $\mathrm{pH}$ dependence of the $k_{\text {cat }}$ for the hydrolysis of $p$ NPP by $\lambda$ PP has indicated the presence of at least two protonation equilibria relevant to catalysis $\left(\mathrm{p} K_{\mathrm{a} 1} \sim 7.7, \mathrm{p} K_{\mathrm{a} 2} \sim 8.6\right) .{ }^{141}$ The more acidic equilibrium is likely to describe the deprotonation of a divalent metal ion-bound water molecule, the proposed nucleophile, while the basic limb may be associated with a residue involved in substrate binding. ${ }^{141}$ Similar to PAPs, PPPs display a decreasing affinity toward substrates at increasing $\mathrm{pH}$ values.

For the best characterized member of the PPM family, human PP2C, a pH dependence of $k_{\text {cat }}$ similar to that of the PPPs has been reported, with $\mathrm{p} K_{\mathrm{a} 1} \sim 7$ and $\mathrm{p} K_{\mathrm{a} 2} \sim 9 .{ }^{142,143}$ The $\mathrm{p} K_{\mathrm{a} 1}$ is also proposed to be associated with the deprotonation of a metal ion-bound water molecule, while a site-directed mutagenesis study has identified a histidine residue (His62) as the likely group that needs to be protonated for catalysis, possibly in order to act as a proton donor for the leaving group. ${ }^{143}$

PPPs are inhibited by a number of tetraoxo anions to an extent similar to that of PAPs. ${ }^{137,144}$ For instance, at their respective optimal $\mathrm{pH}$, both groups of enzymes are moderately and competitively inhibited by orthophosphate $\left(K_{\mathrm{i}} \sim\right.$ $1 \mathrm{mM}){ }^{64,144}$ Both are also strongly inhibited by orthovanadate. ${ }^{144,145}$ Since phosphate and vanadate are believed to be substrate and transition state analogues, respectively, these observations highlight the similarity of the mechanisms of PAP- and PPP-catalyzed reactions, a correlation which can be expanded to include members of the PPM family, since PP2C is also inhibited by phosphate in a manner similar to PPPs and PAPs. ${ }^{142}$

\subsection{Structural Characterization}

Crystal structures of several PPPs have been determined over the past decade, including those for rabbit muscle PP1 ${ }^{146,147}$ and both bovine and human PP2B (calcineurin). ${ }^{148,149}$ More recently, structures for $\lambda \mathrm{PP}^{92}$ and PP5 ${ }^{138}$ have been reported. In general, the catalytic domains are structurally conserved with a sequence homology ranging from 35\% to $45 \% .{ }^{150}$ For instance, the catalytic domain of PP5 has been determined to $1.65 \AA$ resolution and shows a similar overall fold to that of PP1 and PP2B, with root-mean-square deviations (rmsd) of $\sim 2 \AA$ for $270 \mathrm{C} \alpha$ atoms. ${ }^{138}$ Similar to other PPPs, PP5 has an N-terminal domain, but it is extended to include what is known as a tetratricopeptide repeat domain (Figure 10). Interestingly, proteolytic cleavage in this domain leads to the removal of the three repeat motifs and a concomitant significant increase in catalytic activity, 151,152 suggesting a regulatory mechanism similar to that of mammalian PAPs (see section 2).

While $\lambda \mathrm{PP}$ is considerably smaller than its eukaryotic counterparts (221 amino acid residues as compared to 330 residues for PP1 and 524 for PP2B), its three-dimensional fold in the catalytic core is very similar to that of other PPPs, ${ }^{92}$ with the active site located on the surface of the protein in a shallow groove. The structure of $\lambda \mathrm{PP}$ has been determined to $2.15 \AA$ resolution in the presence of both $\mathrm{Mn}$ (II) and sulfate. ${ }^{92}$ The metal-coordinating residues in all PPPs characterized to date are identical, and their relative geometries are well-conserved. The active sites of PPPs are thus exemplified here by the structure of $\lambda \mathrm{PP}$ (Figure 11).

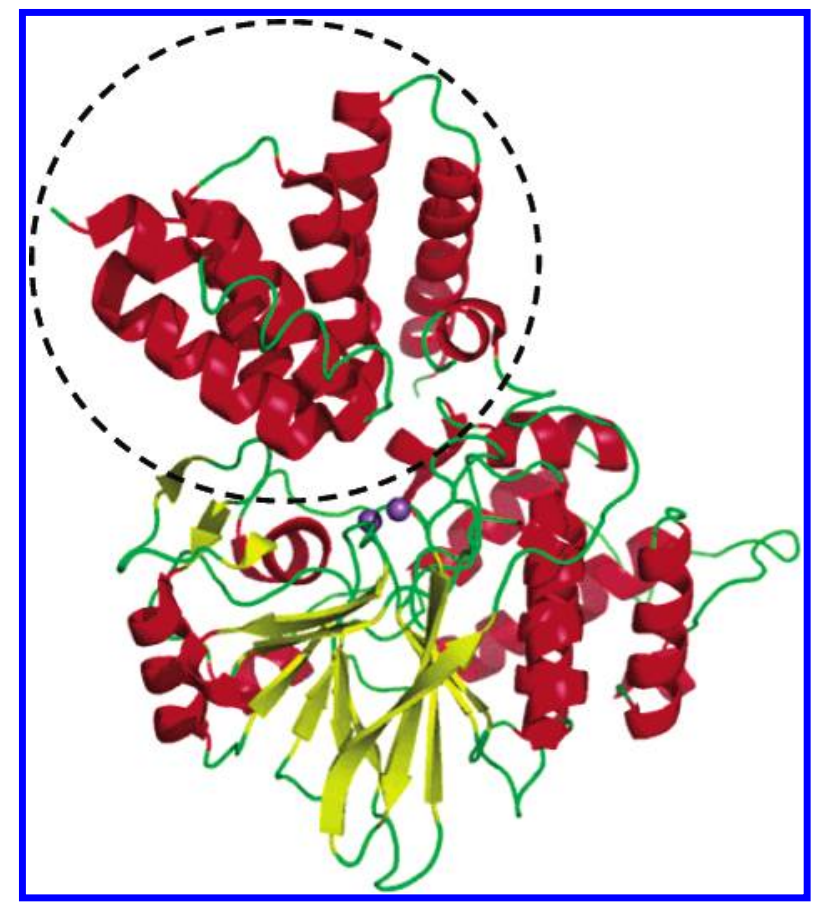

Figure 10. Ribbon diagram depicting the overall fold of PP5 (PDB code $1 \mathrm{WAO}$ ). The N-terminal tetratricopeptide repeat is circled. Proteolytic cleavage within the repeat segment leads to significant increase in reactivity. ${ }^{151,152}$ The two metal ions are shown as purple spheres. 


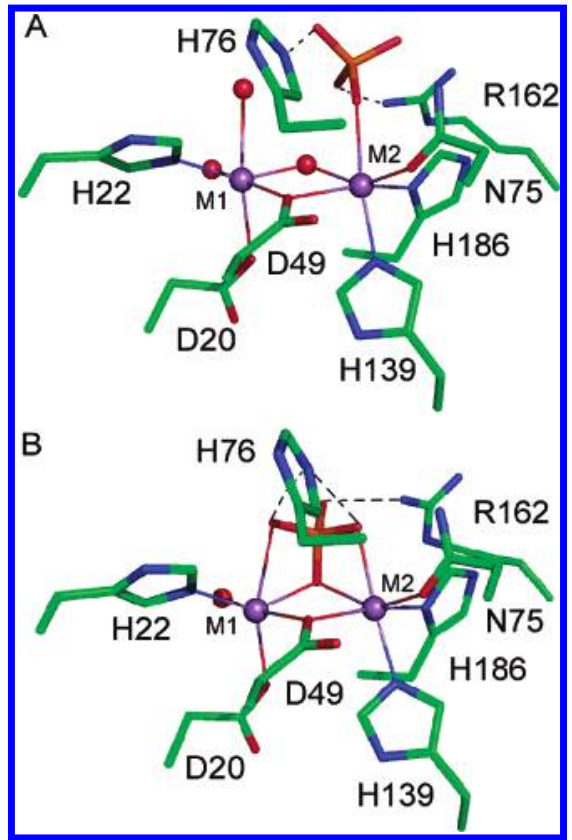

Figure 11. The active site of $\lambda \mathrm{PP}$ complexed with sulfate (PDB code $1 \mathrm{G} 5 \mathrm{~B})$. Sulfate binds in two different modes to the active site, (A) monodentately to the metal ion in site M2 and (B) tridentately, with two of its oxygen atoms forming a $\mu-1,3$ bridge and one coordinating in $\mu-1,1$ mode. ${ }^{92}$ A similar coordination mode has been observed for phosphate in the active site of sweet potato PAP. ${ }^{64}$

The two metal ions are separated by $3.5 \AA$ and, similar to PAPs, are bridged monodentately by an oxygen atom of a conserved aspartate (Asp49). Additional ligands to the metal ion in site M1 are His22, Asp20, and three water molecules (or one water molecule and a bidentately bound sulfate ligand; Figure 11). The Mn2 site is coordinated by nitrogen atoms from His 139 and His186, and three oxygen atoms, one of which is donated by Asn75. The remaining two oxygens are either from a bridging water molecule and a monodentate sulfate, or from a bidentate sulfate (Figure 11; note that the asymmetric unit contains three enzyme molecules, in two of which sulfate binds terminally to M2 and in one it binds in a bidentate mode). Similar to PAPs, the two metal centers can be distinguished with respect to their metal ion affinities. ${ }^{135}$ However, in contrast to PAPs, $\lambda$ PP displays a higher affinity in site $\mathrm{M} 2\left(K_{\mathrm{D}}(\mathrm{MnII}) \sim 2 \mu \mathrm{M}\right)$.

The active site geometry of PP5 is in essence equivalent to that of $\lambda \mathrm{PP},{ }^{138}$ although it is, at present, not known if the two metal centers have different binding affinities. The structure was solved in the presence of phosphate, which binds in a bridging, bidentate mode to the metal ions. Overall, the geometric arrangement in the active site of PP5 in the presence of phosphate is very similar to that observed for pig and red kidney bean PAPs. ${ }^{63,65}$

Structures of the resting states of $\lambda$ PP and PP5 have not yet been solved, but crystallization of $\lambda \mathrm{PP}$ in the presence of sulfate results in two distinct active site conformations. ${ }^{92}$ In one conformation, sulfate is monodentately bound to the site M2 metal center and a bridging water molecule ensures six-coordinate, distorted octahedral geometries for both metal ions (Figure 11A). This arrangement is equivalent to the sulfate-bound structure of rat PAP (see section 2). ${ }^{67}$ Alternatively, sulfate is also found to bind to both metal ions in an unusual tripodal arrangement (Figure 11B), where three of the ligand oxygen atoms coordinate to the metal ions. This arrangement is rare but has been observed in the phosphate-

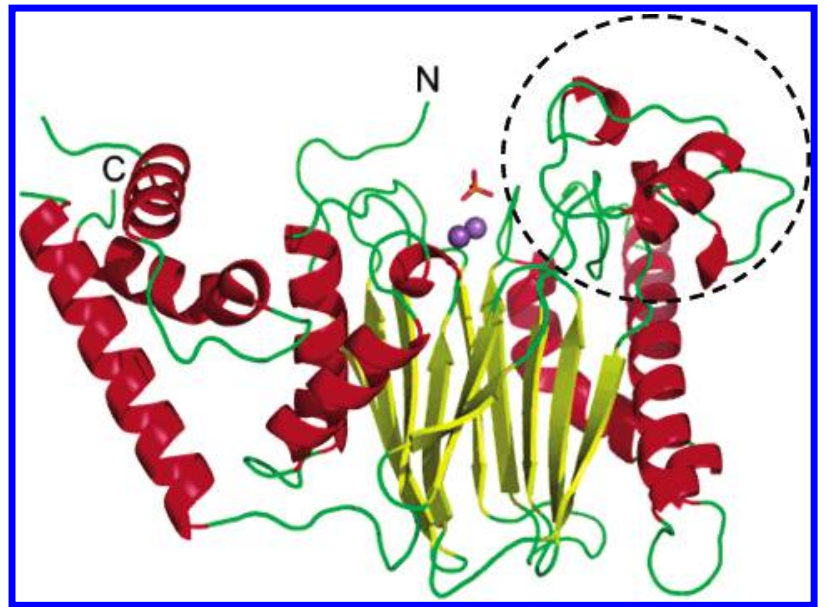

Figure 12. Ribbon diagram depicting the overall fold of PP2C (PDB code 1A6Q). The orientation and structure of the circled region (flap region) varies between different PPM structures. It is hypothesized that the location of this region relative to the binuclear center may play an important role in the regulation of enzyme activity. ${ }^{117}$ The two metal ions are shown as purple spheres, and the bound phosphate is shown as a stick model.

bound structures of sweet potato PAP and the di-Ni(II) urease from $B$. pasteurii. ${ }^{64,88}$ In summary, structural similarities in the active site of PAPs and PPPs support the hypothesis that both systems employ a similar catalytic mechanism.

PPMs are unrelated to PPPs (and PAPs) in terms of overall structure and sequence. ${ }^{6}$ Crystals of human PP2C were obtained in the presence of $\mathrm{Mn}(\mathrm{II})$ and phosphate. The protein consists of two domains, an N-terminal catalytic domain of 290 amino acid residues, and a smaller 90 residue $\mathrm{C}$-terminal domain (Figure 12). The N-terminal domain has a central pair of $\beta$-sheets that are flanked on either side by a pair of $\alpha$-helices. The binuclear metal center is held in place by the loops at the ends of the $\beta$-strands. ${ }^{125}$ PPPs contain two sandwiched $\beta \alpha \beta \alpha \beta$ motifs with parallel $\beta$-strands in the catalytic core. Loops at the C-terminal ends of these parallel strands contain the ligands to the metal ions in the active site. A similar arrangement is also observed in PPMs; however, the two sandwiched $\beta$-sheets have an antiparallel orientation. Recently, the crystal structure of another member of the PPM family, the catalytic domain of resting $M$. tuberculosis PstP/Ppp, has been determined to $1.95 \AA .{ }^{117}$ Despite low overall sequence homology $(\sim 17 \%)$, the structural fold of the bacterial enzyme resembles that of human PP2C, with an rmsd of $2.2 \AA$ for all $\mathrm{C} \alpha$ atoms within the bulk of the catalytic domain. Furthermore, the residues and solvent ligands in the immediate vicinity of the metal centers are strictly conserved. There are, however, two striking differences. First, the presence of an additional C-terminal domain in human PPC2, and second, a small subdomain, or flap, associated with the catalytic domain, has different orientations in the two enzymes (Figure 12). Associated with this subdomain is a third metal ion in PstP/Ppp that is not present in PP2C. ${ }^{117}$ The specific role of the third metal ion is unclear, but it may fulfill a regulatory function by modulating the location of the flap relative to the binuclear active site. The flap region may thus play a role similar to that of the mobile loop in mammalian PAPs (see section 2).

In the active sites of resting PPMs, the metal ions are separated by $\sim 4 \AA$ and bridged by a water molecule (Figure 13). In addition, the increased metal-metal distance in these enzymes in comparison to PAPs and PPPs is consistent with a bridging aspartate residue coordinated in $\mu-1,3$ rather than 


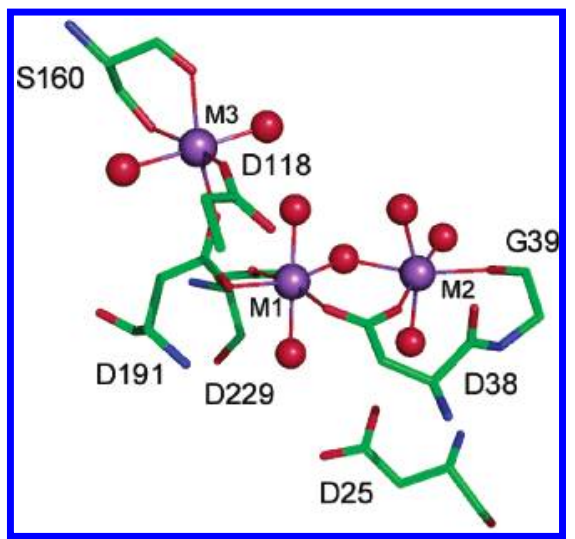

Figure 13. The active site of PstP/Ppp (PDB code 1TXO). Two $\mathrm{Mn}(\mathrm{II})$ ions are present in the active site (M1 and M2). A third manganese (M3) is observed in the flap region. The bridging aspartate ligand coordinates in $\mu-1,3$ mode contrasting the $\mu-1,1$ mode observed in PAPs and PPPs.

$\mu-1,1$ mode. Site M1 is further coordinated by four oxygen atoms, two from conserved aspartate residues (Asp191 and Asp229 in PstP/Ppp) and two water molecules, while site M2 is also coordinated by a backbone carbonyl oxygen (Gly39) and three water molecules. It is not known if the two sites differ with respect to their metal ion affinity. Interestingly, in PP2C, none of the oxygen atoms of bound phosphate directly coordinate to the metal ions. ${ }^{125}$ Instead, two oxygens form hydrogen bonds with three water ligands, two of which are terminally bound to the metal ions and one is bridging. Two additional hydrogen bonds between phosphate oxygen atoms and the conserved Arg20 further stabilize the ligand. ${ }^{117,125}$

\subsection{Catalytic Mechanism}

The previous discussion has illustrated that different PPPs are likely to employ the same mechanistic strategy to catalyze hydrolysis of phosphate ester bonds. Furthermore, the reaction mechanism of PPPs is closely related to that of PAPs.

In the initial step (Figure 14), substrate binds to the active site. On the basis of steric considerations, it has been proposed that the likely binding mode involves the formation of a $\mu$-phosphate bridge, since this would be the least rearrangement required to accommodate the leaving group. ${ }^{138}$ Interactions between the noncoordinating oxygen atoms of the substrate and the positively charged, conserved residues Arg53, Arg162, and His76 stabilize this conformation in the enzyme-substrate complex (unless mentioned otherwise, residue numbers are corresponding to the $\lambda \mathrm{PP}$ sequence).

In the next phase of catalysis, a nucleophilic attack on the phosphorus atom induces hydrolysis (Figure 14). Kinetic isotope effects and the apparent lack of phosphoenzyme intermediates have indicated that a water molecule (hydroxide) coordinated to the binuclear metal center is the only likely nucleophile. ${ }^{6,94,153}$ In the enzyme-substrate complex described above, the only water molecule present in the active site is the one bridging the two metal ions (Figure 14). This is in an ideal position for an in-line attack on the phosphorus with an $\mathrm{O}(\mathrm{N})-\mathrm{P}-\mathrm{O}(\mathrm{R})$ angle of $\sim 180^{\circ}(\mathrm{O}(\mathrm{N})$ and $\mathrm{O}(\mathrm{R})$ are the oxygen atoms of the nucleophile and leaving group, respectively). ${ }^{138}$ The assignment of the bridging water molecule as the nucleophile is further supported by the observation that its orientation relative to the substrate is stabilized via a strong hydrogen bond to the

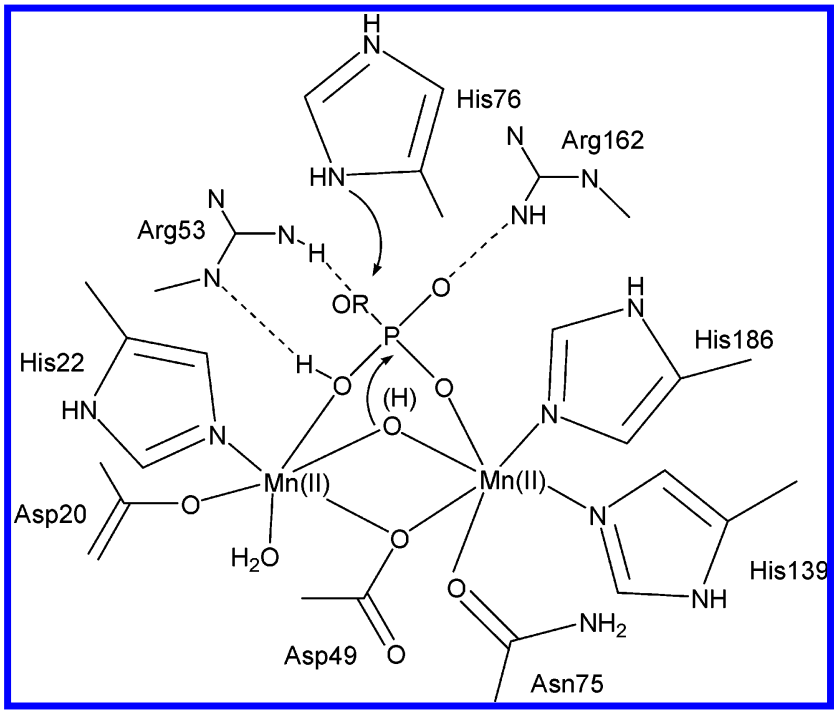

Figure 14. Proposed mechanism of hydrolysis by PPPs. The bridging water molecule between the two metal ions is in an ideal position for a direct in-line nucleophilic attack on the phosphorus atom of the substrate.

backbone carbonyl oxygen atom of His186, whose side chain coordinates to the metal ion in site M2 (Figure 11). Notably, the same hydrogen bonding interaction is also conserved in PAPs. ${ }^{64,65}$ Another interesting correlation between PPPs and PAPs is the unusual tripodal coordination modes for sulfate and phosphate in the active sites of $\lambda \mathrm{PP}$ and sweet potato PAP, respectively (Figure 11B), an observation consistent with a role of the bridging water molecule as a nucleophile. ${ }^{64,92}$

Kinetic isotope studies with $\lambda \mathrm{PP}$ and PP2B have shown that as a consequence of the nucleophilic attack a highly dissociative transition state is formed. ${ }^{141,154,155}$ At least in $\lambda \mathrm{PP}$, the cleavage of the phosphoester bond is rate-limiting. ${ }^{141}$ Hengge and co-workers have shown that the equatorial $\mathrm{P}-\mathrm{O}$ bonds in the trigonal bipyramidal transition state are strongly polarized, a conformation that is stabilized by interactions with the two metal ions and the conserved active site residues Asn75, Arg53, Arg162, and His76. ${ }^{141}$ As the bond order between the phosphorus and the oxygen atom of the leaving group decreases, the development of negative charge on the latter will facilitate its protonation. The most likely candidate as a proton donor, supported by both structural and sitedirected mutagenesis studies, is His76. ${ }^{92,138,141}$

Following the decay of the transition state and the release of the leaving group, phosphate is anticipated to remain bound to the active site in a tripodal coordination mode, as observed in the structures of sulfate-bound $\lambda \mathrm{PP}$ (Figure 11) and phosphate-bound sweet potato PAP. ${ }^{64,92}$

In the final stage of catalysis, the active site has to be regenerated for the next cycle by expulsion of the phosphate group and the formation of a $\mu$-hydroxide bridge. His 76 needs to be protonated in the process, but the identity of the proton donor is currently unknown.

The mechanism employed by PPMs has received less attention than that of other binuclear metallohydrolases and is based mainly on research from Denu and coworkers. ${ }^{6,142,143}$ In the current model, substrate binds in a mode similar to that of phosphate in the active site (Figure 15); no direct coordination to the metal ions occurs, but the conserved residue Arg20 assists in enhancing substrate binding and orientation. ${ }^{143}$ In this conformation, the bridging water molecule is proposed to be the most plausible 


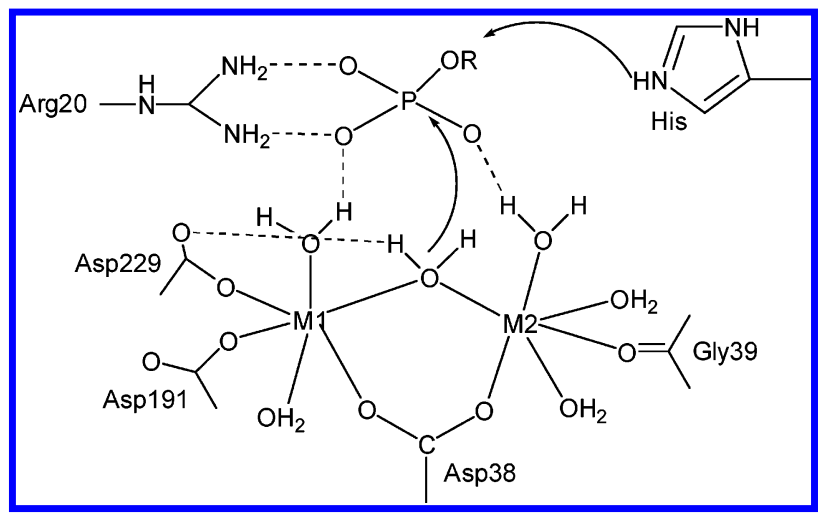

Figure 15. Proposed mechanism of hydrolysis by PPMs. The substrate does not coordinate directly to the metal ions. Instead, it is hydrogen-bonded to two terminal water ligands. Residue Arg20 plays a crucial role in substrate orientation. The bridging water molecule is proposed as nucleophile and is activated through hydrogen bonding with Asp229.

nucleophile, activated via hydrogen bonding interaction with an aspartate ligand to the metal ion in site M1 (Asp229 in PstP/Ppp; Figure 15). From an analysis of the $\mathrm{pH}$ dependence of kinetic parameters, a $\mathrm{p} K_{\mathrm{a}}$ of $\sim 7.5$ is associated with this nucleophile. ${ }^{142}$ A Brønsted correlation has shown that the transition state of PP2C develops a moderate charge buildup, similar to that reported for pig and red kidney bean PAPs. ${ }^{64,142}$ This observation is consistent with a partially dissociative mechanism. The breakage of the $\mathrm{P}-\mathrm{O}$ bond is not likely to be rate-limiting, since pre-steady-state kinetics measurements have detected an initial product burst, followed by a slower steady-state rate (instead, the release of phosphate is proposed as the slowest step in the catalytic cycle). ${ }^{6,142}$ The release of the leaving group necessitates its protonation. A recent site-directed mutagenesis study indicates that the likely proton donor in PP2C is a histidine residue (His62 in PP2C). ${ }^{143}$ Interestingly, although the overall structure of the active sites of PP2C and PstP/Ppp from M. tuberculosis are very similar, the latter does not have a histidine residue corresponding to His62 in PP2C. ${ }^{117}$ At present, no candidate as general acid has been identified for the reaction catalyzed by bacterial PPMs.

\section{3'-5' Exonucleases}

\subsection{Biochemical Characterization and Function}

3'-5' exonucleases (E.C. 2.7.7.7) are part of the DNA replication process and catalyze the hydrolysis of 3 '-terminal nucleotides from single-stranded DNA, although doublestranded DNA can also be a substrate. ${ }^{156-162}$ Their primary role is in proofreading during replication, where misincorporated nucleotides will be excised (via hydrolysis of the 3 '-terminal phosphodiester bond), thus, ensuring genome integrity. ${ }^{163-169}$

In general, $3^{\prime}-5^{\prime}$ exonucleases are a component of DNA polymerases, large multifunctional enzymes that also contain polymerase and $5^{\prime}-3^{\prime}$ exonuclease activities. ${ }^{170-173}$ In most systems studied to date, the three catalytic activities reside in different structural domains of the same polypeptide chain. Apart from their obvious role in DNA synthesis, DNA polymerases from thermophiles (e.g., Thermus aquaticus) have become a routine reagent in molecular biology, finding application in techniques such as the polymerase chain reaction (PCR). ${ }^{174,175}$ DNA polymerases are characterized by a remarkably low-error frequency during replication. The estimated mutation rate of $\sim 10^{-10}$ to $10^{-12}$ per replicated base pair is attributed to both high-fidelity polymerase activity and low-error frequency in the proofreading process. ${ }^{176-179}$

Six classes of DNA polymerases have been identified, distinguished by their amino acid sequences and structural characteristics. ${ }^{180}$ These classes are labeled as E. coli DNA polymerase I (Pol I), E. coli DNA polymerase II (Pol II, which also includes archaebacterial and eukaryotic DNA polymerases), E. coli DNA polymerase III (Pol III), DNA polymerase $\mathrm{D}$ (found in euryarchaea), as well as families $\mathrm{X}$ and $\mathrm{Y}$, which lack $3^{\prime}-5^{\prime}$ exonuclease activity. ${ }^{180,181}$

Pol III is different from other DNA polymerases, since it contains the DNA polymerase and 3'-5' exonuclease activites on separate subunits. ${ }^{156,182}$ Apart from the $\alpha$ subunit (130 $\mathrm{kDa}$ ), which contains the polymerase activity, and the $\epsilon$ subunit $(28 \mathrm{kDa})$, which contains the $3^{\prime}-5^{\prime}$ exonuclease activity, the catalytic core of Pol III has a third component, a small $9 \mathrm{kDa}$ protein labeled the $\theta$ subunit. ${ }^{156,183,184}$ Although its precise role is unknown at present, it has been shown that the $\theta$ component binds to the $\mathrm{N}$-terminal domain of the $\epsilon$ subunit. ${ }^{185,186}$ Consequently, the $3^{\prime}-5^{\prime}$ exonuclease activity is increased by a factor of 2 . A combination of NMR and electrospray ionization mass spectrometry has further indicated that the $\theta$ subunit does not directly interfere with the active site structure but may assist binding of substrate to the active site of the $3^{\prime}-5^{\prime}$ exonuclease ${ }^{187,188}$ Additionally, component $\theta$ also increases the thermostability of the $\epsilon$ subunit. ${ }^{189}$

Apart from E. coli, 3'-5' exonucleases have been identified in, and at least partially characterized from, various sources. Examples are the human 3 '-repair exonucleases 1 and 2 (TREX1 and TREX2); ${ }^{160,190}$ the human Werner syndrome protein; ${ }^{191-193}$ the exonuclease components of human, mouse, and rat p53; ${ }^{194}$ the $3^{\prime}-5^{\prime}$ exonuclease activity of the human metastasis suppressor NM23-H1; ${ }^{195}$ Choristoneura fumiferana nucleopolyhedroviral 3'-repair exonuclease (VTREX); ${ }^{196}$ the $3^{\prime}-5^{\prime}$ exonuclease activity associated with apurinic/apyrimidinic endonuclease (Ape1) found in human leukemia cells; ${ }^{197} E$. coli exonuclease IX; ${ }^{198}$ and the $3^{\prime}-5^{\prime}$ exonuclease activities of $E$. coli RNase $\mathrm{T}^{199}$ and the human DNA damage checkpoint protein hRad9. ${ }^{200}$ Their overall sequence homology is low, with $<20 \%$ identity. ${ }^{201}$ However, three conserved sequence motifs are recognized, termed Exo I, Exo II, and Exo III, that contain most of the metalcoordinating and catalytically relevant amino acid residues. ${ }^{158,192,202-207}$ Exo III generally displays greater sequence variability than the other two motifs.

$3^{\prime}-5^{\prime}$ exonuclease activity has a strict requirement for divalent metal ions, in particular $\mathrm{Mg}(\mathrm{II}), \mathrm{Mn}(\mathrm{II})$, and $\mathrm{Zn}(\mathrm{II}),{ }^{208-211}$ although it is not known which metal ion is preferred in vivo. For the $\epsilon$ subunit of Pol III, rates of hydrolysis are optimal in the presence of $\mathrm{Mn}$ (II) with a $k_{\text {cat }}$ of $334 \mathrm{~min}^{-1}$ compared to a $k_{\text {cat }}$ of $20 \mathrm{~min}^{-1}$ for an enzyme reconstituted with $\mathrm{Mg}(\mathrm{II}) .{ }^{189}$ For a catalytically competent enzyme, two metal ions are required in the active site. Mutations that affect metal ion binding generally lead to a significant loss in enzyme activity, as was shown by sitedirected mutagenesis experiments on various exonucleases. ${ }^{158,212-218}$ For example, a mutation of the second coordination sphere residue Asp424 to alanine in the $3^{\prime}-5^{\prime}$ exonuclease of $E$. coli Pol I resulted in complete loss of enzymatic activity, since only one metal ion was able to bind to the active site. ${ }^{219}$ 
Similar to PAPs, $3^{\prime}-5^{\prime}$ exonucleases have a high- and lowaffinity site for the metal ions (sites M1 and M2, respectively; see below). In the case of T4 DNA polymerase, $\mathrm{Mg}$ (II) binding studies utilizing fluorescence steady-state emission have shown a high-affinity metal binding site $\left(K_{\mathrm{D}}=5.1 \mu \mathrm{M}\right)$ and a low-affinity site $\left(K_{\mathrm{D}}=2.5 \mathrm{mM}\right){ }^{220}$ Lanthanide binding (Eu(III) and $\mathrm{Tb}(\mathrm{III})$ ) to $3^{\prime}-5^{\prime}$ exonuclease domains in $\mathrm{T} 4$ DNA polymerase and E. coli Pol I has been analyzed by luminescence spectroscopy. These studies have confirmed the presence of a high-affinity site in both systems with $K_{\mathrm{D}}$ values of 0.8 and $1.3 \mu \mathrm{M}$, respectively; binding affinities to a lower affinity site could not be determined accurately. ${ }^{221}$ EPR spectroscopy has shown, for the Pol I enzyme, that sites $\mathrm{M} 1$ and $\mathrm{M} 2$ have $\mathrm{Mn}$ (II) binding affinities corresponding to $K_{\mathrm{D}}$ values of $2.5 \mu \mathrm{M}$ (tight) and $600 \mu \mathrm{M}$ (weak), respectively. ${ }^{222}$ Interestingly, the addition of the reaction product deoxythymidine $5^{\prime}$-monophosphate (dTMP) increased the affinity of site $2 \sim 100$-fold, while site M1 was largely unaffected. ${ }^{222} \mathrm{~A}$ recent $\mathrm{Mn}$ (II) titration of the $\epsilon$ subunit of E. coli Pol III (monitored by EPR) has also demonstrated a significant variation in metal ion binding affinity for sites $\mathrm{M} 1$ and $\mathrm{M} 2$ in this enzyme $\left(K_{\mathrm{D}}=15\right.$ and $300 \mu \mathrm{M}$, respectively) (Mitić, N., and Schenk, G,, unpublished results). $\mathrm{Mn}$ (II) can only bind to site 2 in the presence of dTMP; in its absence, a mononuclear center is formed with $\mathrm{Mn}$ (II) bound to site $\mathrm{M} 1\left(K_{\mathrm{D}}=10 \mu \mathrm{M}\right)$. Thus, substrate/productinduced formation of a catalytically fully active binuclear center may be a regulatory mechanism to control proofreading activity in vivo, allowing for an optimal coordination between the processes of DNA synthesis and proofreading (e.g., a permanently active exonuclease may affect the selectivity of the editing process).

Most previous kinetic studies of $3^{\prime}-5^{\prime}$ exonucleases utilized radiolabeled single-stranded or primer-template DNA substrates, the latter with mismatched 3'-termini. ${ }^{158,186,223,224}$ Assays with single-stranded DNA have shown that the $\epsilon$ subunit is far more reactive than the $3^{\prime}-5^{\prime}$ exonuclease activity of E. coli Pol I, with $k_{\text {cat }}$ values of $\sim 200$ and $\sim 1 \mathrm{~s}^{-1}$, respectively. ${ }^{158}$ More recently, the para-nitrophenol ester of deoxythymidine $5^{\prime}$-monophosphate ( $p$ NP-dTMP) has been used as substrate to directly monitor spectrophotometrically the formation of the product of the hydrolytic reaction, paranitrophenol. ${ }^{189,225}$ In general, it has been found that the rates of hydrolysis of $p$ NP-TMP by various exonucleases are significantly lower than those determined for the hydrolysis of polynucleotide substrates. For example, $k_{\text {cat }}$ values reported for the hydrolysis of $p$ NP-TMP and single-stranded DNA by the $\epsilon$ subunit of DNA Pol III are $0.32 \mathrm{~s}^{-1}$ (at $25^{\circ} \mathrm{C}$ and $\mathrm{pH}=8.0)$ and $200 \mathrm{~s}^{-1}(\mathrm{pH}=8.0)$, respectively. ${ }^{189,224}$ Similar trends have been observed for the $3^{\prime}-5^{\prime}$ exonuclease domains of $E$. coli DNA Pol I and T7 DNA polymerase. ${ }^{225,226} \mathrm{~A}$ region (residues 144-157) in T7 DNA Polymerase has been identified as being crucial for DNA binding during catalysis. While the deletion of this region does not affect the $3^{\prime}-5^{\prime}$ exonuclease active site, it leads to a substantial decrease of the hydrolytic activity in the presence of DNA substrates, indicating that substrate binding may trigger conformational changes required for optimal catalytic efficiency. ${ }^{225}$

A majority of $3^{\prime}-5^{\prime}$ exonucleases have optimal activity in alkaline environments with $\mathrm{pH}$ optima ranging from 7.5 to 10.2. ${ }^{158,189,216}$ The $\mathrm{pH}$ dependence of the $K_{\mathrm{m}}$ values of the $\epsilon$ subunit of $E$. coli Pol III for the substrate $p \mathrm{~N}$-dTMP associates a basic amino acid with a $\mathrm{p} K_{\mathrm{a}}>8.5$ in substrate interactions (possibly Arg 159). ${ }^{189}$ Similarly, an analysis of the $\mathrm{pH}$ dependence of enzymatic activity $\left(k_{\text {cat }}\right)$ indicates a lower $\mathrm{p} K_{\mathrm{a}}$ value of $\sim 7.7$ (for the $\epsilon$ subunit of $E$. coli Pol III) and $\sim 9.8$ (for $3^{\prime}-5^{\prime}$ exonuclease of $E$. coli Pol I) that is associated with a mechanistically relevant protonation equilibrium. ${ }^{158,189}$ For the $\epsilon$ subunit, the catalytic rates for $p \mathrm{~N}$ dTMP hydrolysis are $\sim 1 \mathrm{~s}^{-1}$ at $\mathrm{pH}<6.5$ and $\sim 7 \mathrm{~s}^{-1}$ at $\mathrm{pH}$ $>9.0 .^{189}$ The observation that this $3^{\prime}-5^{\prime}$ exonuclease has substantial activity even at low $\mathrm{pH}$ values has led to the suggestion that, depending on the $\mathrm{pH}$, a different reaction mechanism may apply. ${ }^{189}$ Details of the mechanism of $3^{\prime}-5^{\prime}$ exonuclease-catalyzed reactions will be discussed below.

Interestingly, recent pre-steady-state kinetic studies with the $3^{\prime}-5^{\prime}$ exonuclease activities of RB69 and $\phi 29$ polymerase under single turnover conditions have provided no evidence for a $\mathrm{pH}$ dependence of the activity in the $\mathrm{pH}$ range 6.58.5. ${ }^{227}$ This difference has been interpreted in terms of a ratelimiting step preceding the excision of the $3^{\prime}$-terminal nucleotide.

\subsection{Structural Characterization}

The first $3^{\prime}-5^{\prime}$ exonuclease structure reported was for the proofreading activity from E. coli DNA Pol I. ${ }^{172}$ Over the past decade, several crystal structures of $3^{\prime}-5^{\prime}$ exonucleases have been determined. Among them are those from Bacillus stearothermophilus; $;^{228}$ bacteriophages $\mathrm{T} 7,{ }^{229,230} \mathrm{~T} 4,,^{231}$ and RB69;232 phage $\phi 29 ;{ }^{233}$ Desulfurococcus sp. Tok;234 Sulfolobus solfataricus; ${ }^{235}$ Pyrococcus kodakaraensis; ${ }^{236,237}$ T. aquaticus; $;^{238}$ Thermococcus sp. $9^{\circ} \mathrm{N}-7 ; 2^{239}$ and Thermococcus gorgonarius. ${ }^{240}$ Recently, crystal structures of the $\epsilon$ subunit of E. coli Pol III and of human TREX2 have been solved. ${ }^{201,241}$ A structural comparison reveals that despite low sequence homology (e.g., $\sim 17 \%$ sequence identity between the $\epsilon$ subunit of $E$. coli Pol III and 3'-5' exonuclease domain of T4 DNA polymerase), ${ }^{242}$ their overall structural fold is conserved with the characteristic five-stranded, antiparallel $\beta$-sheet structure in the center surrounded by several $\alpha$-helices (Figure 16).

The active sites of most $3^{\prime}-5^{\prime}$ exonucleases are very similar, with four conserved carboxylate groups and a histidine or tyrosine side chain (Figures 17 and 18), and are located in geometrically equivalent positions. In addition, their binuclear metal centers have very similar coordination environments. The exceptions are the recently isolated and characterized $3^{\prime}-5^{\prime}$ exonuclease activities associated with DNA polymerases of class D (see above) from Methanococcus jannaschii ${ }^{243,244}$ and Pyrococcus horikoshii. ${ }^{245}$ Unlike $3^{\prime}-5^{\prime}$ exonucleases from the Pol I-III classes, these enzymes contain predominantly histidine-rich active sites, similar to those of PPPs (Figure 11) and nucleases such as Mre11 from Pyrococcus furiosus. ${ }^{246}$

An initial analysis showed that in the absence of a substrate analogue or product the exonuclease active site of $3^{\prime}-5^{\prime}$ exonuclease from Pol I contains only one metal ion. This observation is in agreement with spectroscopic data, which have demonstrated that the addition of dTMP to the enzyme facilitates the formation of catalytically active binuclear centers (see above). The crystal structure of $3^{\prime}-5^{\prime}$ exonuclease from Pol I, crystallized in the presence of dTMP, shows two metal ions with different coordination geometries separated by $\sim 3.9 \AA$ (Figure 17B). ${ }^{172}$ Site M1 has five ligands and is coordinated by five oxygen atoms from Asp355, Asp501, and Glu357, the phosphate group from dTMP, and an hydroxide group. This site has a high affinity for the metal ion and is occupied by a metal ion even in the absence of 


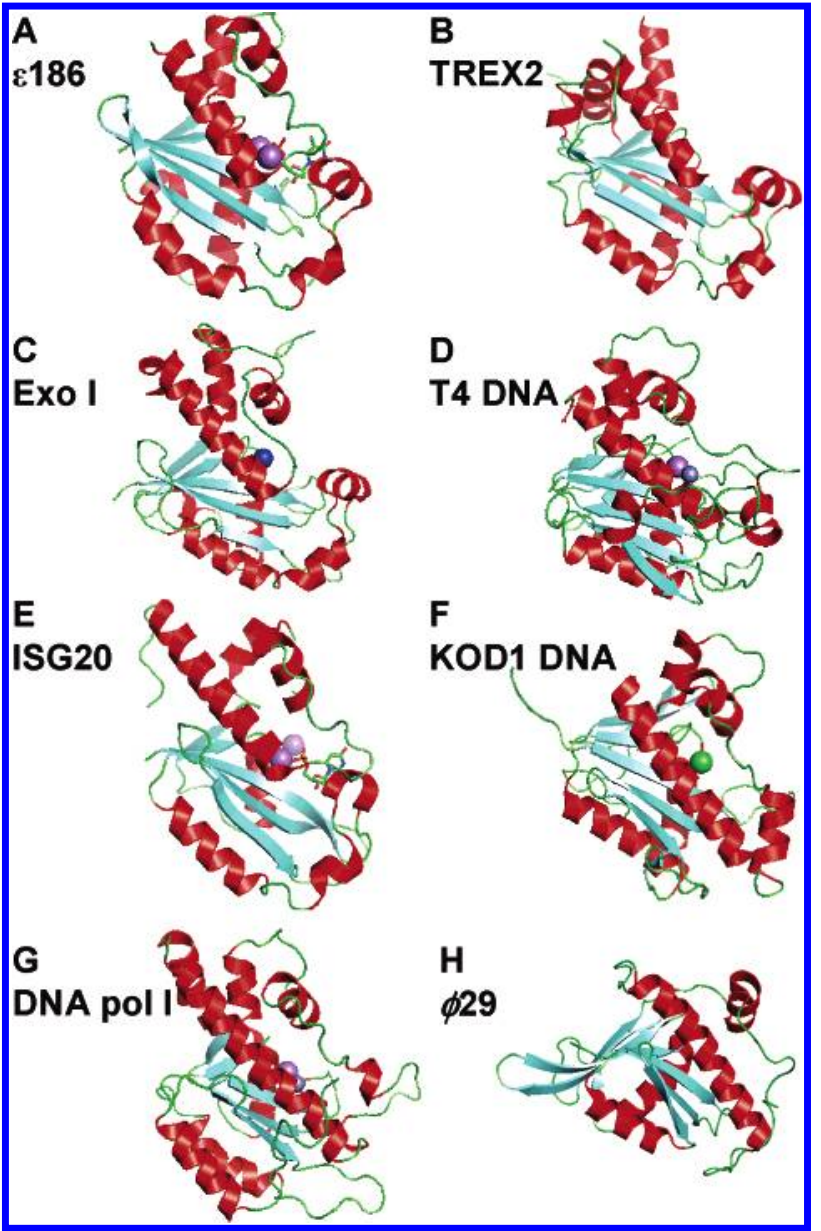

Figure 16. Comparison of overall structure and fold of the 3'5 'exonuclease domains from various DNA polymerases. (A) The $\epsilon$ subunit of bacterial DNA Pol III (PDB code 1J53); (B) human TREX2 (PDB code 1Y97); (C) E. coli exonuclease I (PDB code 1FXX); (D) exonuclease domain of bacteriophage T4 DNA polymerase (PDB code 1NOY); (E) human antiviral ribonuclease ISG20 (PDB code 1WLJ); (F) exonuclease from the hyperthermophilic archaeon $P$. kodakaraensis (PDB code $1 \mathrm{WN7}$ ); (G) exonuclease domain of DNA Pol I (PDB code 2KZM); and $(\mathrm{H})$ bacteriophage $\Phi 29$ DNA polymerase (PDB code $1 \mathrm{XHX}$ ). There is a significant structural similarity of the exonuclease domain in various DNA polymerases. The active site metal ion(s) are shown as spheres, and the products of the exonuclease reaction (TMP and UMP molecules) in the case of the $\epsilon$ subunit (A) and ISG20 (E) are shown as sticks.

dTMP (i.e., this site is equivalent to the chromophoric Fe(III)binding site in PAPs). Site M2 has six ligands, but only one is from the protein. The metal ion is coordinated to six oxygen atoms, one from the bridging Asp355, two from the bound phosphate group of dTMP, and three from water molecules. This site represents the low-affinity site (site M2; equivalent to the redox-active site in mammalian PAPs).

An interesting discovery has been reported for the crystal structure of the $\epsilon$ subunit of E. coli Pol III, determined in the presence of $\mathrm{Mn}(\mathrm{II})$ and dTMP at two different $\mathrm{pH}$ values (pH 5.8 and 8.5; Figure 18). ${ }^{241}$ With respect to the amino acid side chains in the active site, and the coordination geometry of the two $\mathrm{Mn}$ (II) ions, the two structures are very similar. The two metal ions are separated by $3.7 \AA$, and no bridging water molecules are present. The primary differences between the two structures are the bridging mode of dTMP and the coordination of terminal water molecules. In the low $\mathrm{pH}$ structure, the $\mathrm{Mn}$ (II) ion in the high-affinity site M1 has five ligands and is coordinated by five oxygen atoms,

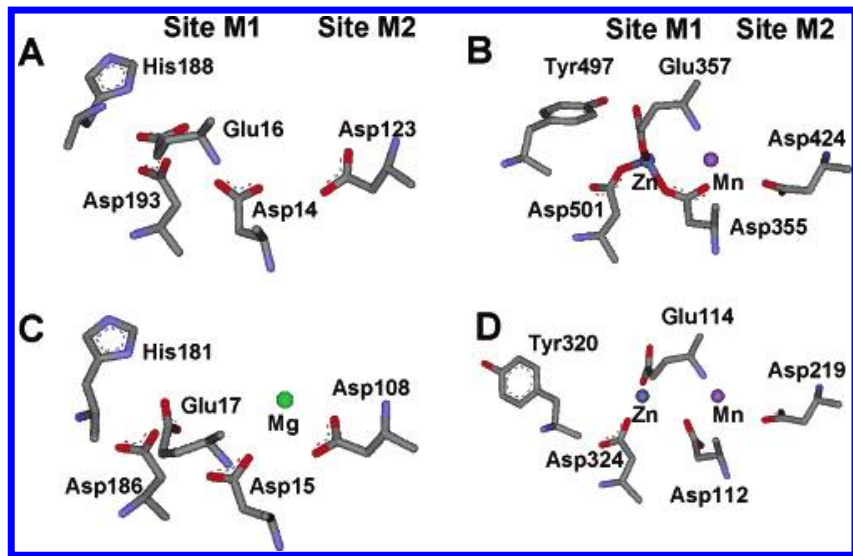

Figure 17. Active site structures of various $3^{\prime}-5^{\prime}$ exonuclease domains. (A) Human TREX2 (PDB code 1Y97); (B) DNA Pol I (PDB code 2KZM); (C) E. coli exonuclease I (PDB code 1FXX); and (D) exonuclease of bacteriophage T4 DNA polymerase (PDB code 1 NOY). Three aspartate residues and one glutamate are highly conserved among $3^{\prime}-5^{\prime}$ exonucleases and coordinate to the two divalent metal ions in the active site. Additionally, active sites generally contain a conserved tyrosine or histidine residue which does not act as a ligand but plays an important role in catalysis. Note that structure A has no metal ions present (enzyme was crystallized in the apo form ${ }^{201}$ ) and structure $\mathrm{C}$ has only one metal ion present as a result of crystallization conditions (the enzyme was crystallized in the absence of substrate/product, and under these conditions, only one metal ion binds). ${ }^{166}$

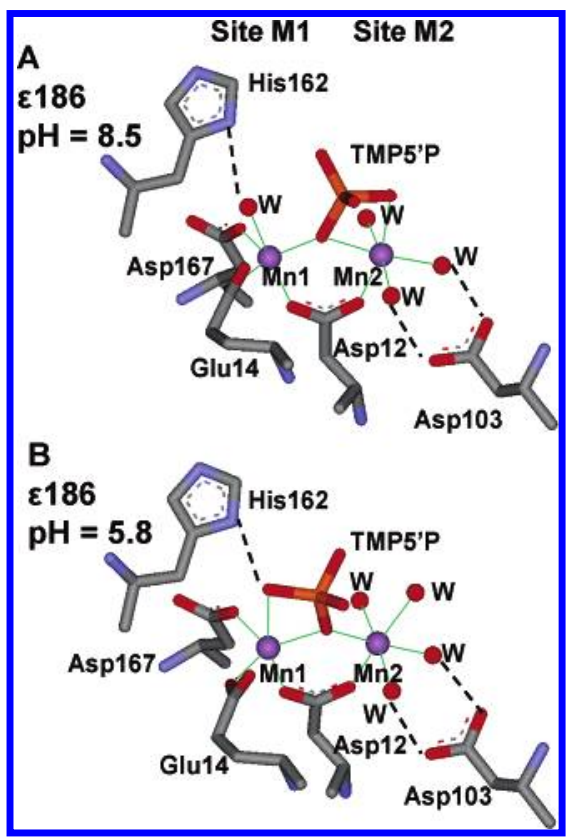

Figure 18. Active site structure of the $\epsilon$ subunit of $E$. coli DNA Pol III complexed with dTMP at (A) $\mathrm{pH}=8.5$ and (B) $\mathrm{pH}=5.8$. Only the phosphate moiety of dTMP is shown for clarity. The phosphate group bidentately coordinates $\mathrm{Mn}(\mathrm{II})$ in site M2 or M1 at high or low $\mathrm{pH}$, respectively. The two $\mathrm{Mn}$ (II) ions are shown as purple spheres.

three from Asp12, Asp167, and Glu14 and two from bound phosphate, one of which is bridging (Figure 18B). The coordination geometry is trigonal bipyramidal and very similar to that of site M1 in the $3^{\prime}-5^{\prime}$ exonuclease from $E$. coli Pol I (Figure 17B). The Mn(II) in the low-affinity site M2 has highly symmetric octahedral geometry with six oxygen ligands, only one from the protein (the bridging carboxylate of Asp12; Figure 18). The remaining ligands are provided from four terminal water molecules and from the bridging phosphate. Again, this site is very similar to the 
corresponding site in the $3^{\prime}-5^{\prime}$ exonuclease from $E$. coli $\mathrm{Pol}$ I (Figure 17B).

In the high $\mathrm{pH}$ structure (Figure 18A), the metal ion in site M1 is still five-coordinate; however, the phosphate group of dTMP only interacts with its bridging oxygen atom. The fifth ligand is a water molecule occupying nearly the same position as the terminal oxygen atom of the phosphate group of dTMP in the low $\mathrm{pH}$ structure. In contrast, a second oxygen atom from this phosphate group displaces one of the water ligands in site 2 in this high $\mathrm{pH}$ structure. Both at low and high $\mathrm{pH}$, the conserved residue His 162 plays an important mechanistic role. At low $\mathrm{pH}$, it is protonated and hydrogen-bonded to the terminal oxygen ligand from the bound phosphate group in site M1 (Figure 18B). At high $\mathrm{pH}$, it is deprotonated and within hydrogen bonding distance of the water ligand coordinated to site M1, which is expected to lower the $\mathrm{p} K_{\mathrm{a}}$ value of this ligand. The mechanistic implications of this observation will be discussed below. Similar interaction of substrate/product has been previously observed in other exonucleases.

Similar coordination geometries have been observed in other $3^{\prime}-5^{\prime}$ exonucleases, for example, in the proofreading activity of Pol I (Figure 17B) and the recently published structures of the human interferon-induced antiviral ribonuclease ISG20 247 and human TREX2. ${ }^{201}$ The observed structural similarities in $3^{\prime}-5^{\prime}$ exonucleases suggest that these enzymes employ a common catalytic mechanism, outlined in the next section.

\subsection{Catalytic Mechanism}

The hydrolysis of nucleic acid diester bonds by $3^{\prime}-5^{\prime}$ exonucleases results in the formation of a deoxynucleoside $5^{\prime}$-monophosphate and a free $3^{\prime}$-hydroxide group at the shortened DNA substrate. The following discussion on the mechanism of $3^{\prime}-5^{\prime}$ exonucleases is mainly based on recent insights gained from the crystal structures and kinetic studies for the $\epsilon$ subunit of $E$. coli Pol III, but since the active site residues and geometry are conserved, it is likely that the mechanism shown in Figure 19 is generally valid for this group of enzymes. ${ }^{189,210,219}$

In the initial stage of catalysis, a nucleic acid substrate binds to the active site of the enzyme. Pre-steady-state kinetic measurements with the $\epsilon$ subunit have shown that the enzyme-DNA complex is formed rapidly, with $k_{\mathrm{f}}=280$ $\mathrm{s}^{-1} .224$ Although DNA binding itself is thus not likely to be the rate-limiting step in the reaction, the structure of the DNA duplex has a significant effect on the catalytic efficiency of $3^{\prime}-5^{\prime}$ exonuclease. ${ }^{224}$ The preferred substrate is singlestranded DNA; it has been shown that in a series of duplex DNA oligonucleotides with increasing numbers of mismatched base pairs at the $3^{\prime}$-terminus the rate of hydrolysis increases. ${ }^{224}$ To accommodate observed catalytic rates, a model has been proposed that invokes a mechanism, whereby DNA binds rapidly to the active site in a form that is not susceptible to hydrolysis. ${ }^{224}$ Structural rearrangements (DNA "melting") lead to activated DNA, termed DNA*, that is the preferred substrate for $3^{\prime}-5^{\prime}$ exonuclease. The rate constant for hydrolysis derived from this model is in good agreement with rate constants determined for the hydrolysis of singlestranded DNA substrates. ${ }^{224}$ The observation that duplex DNA binds rapidly to the enzyme, but hydrolysis is delayed, has led to the suggestion that DNA "melting" may be the rate-limiting step in the proofreading reaction. ${ }^{224} \mathrm{~A}$ similar conclusion has been drawn for the $3^{\prime}-5^{\prime}$ exonuclease activity

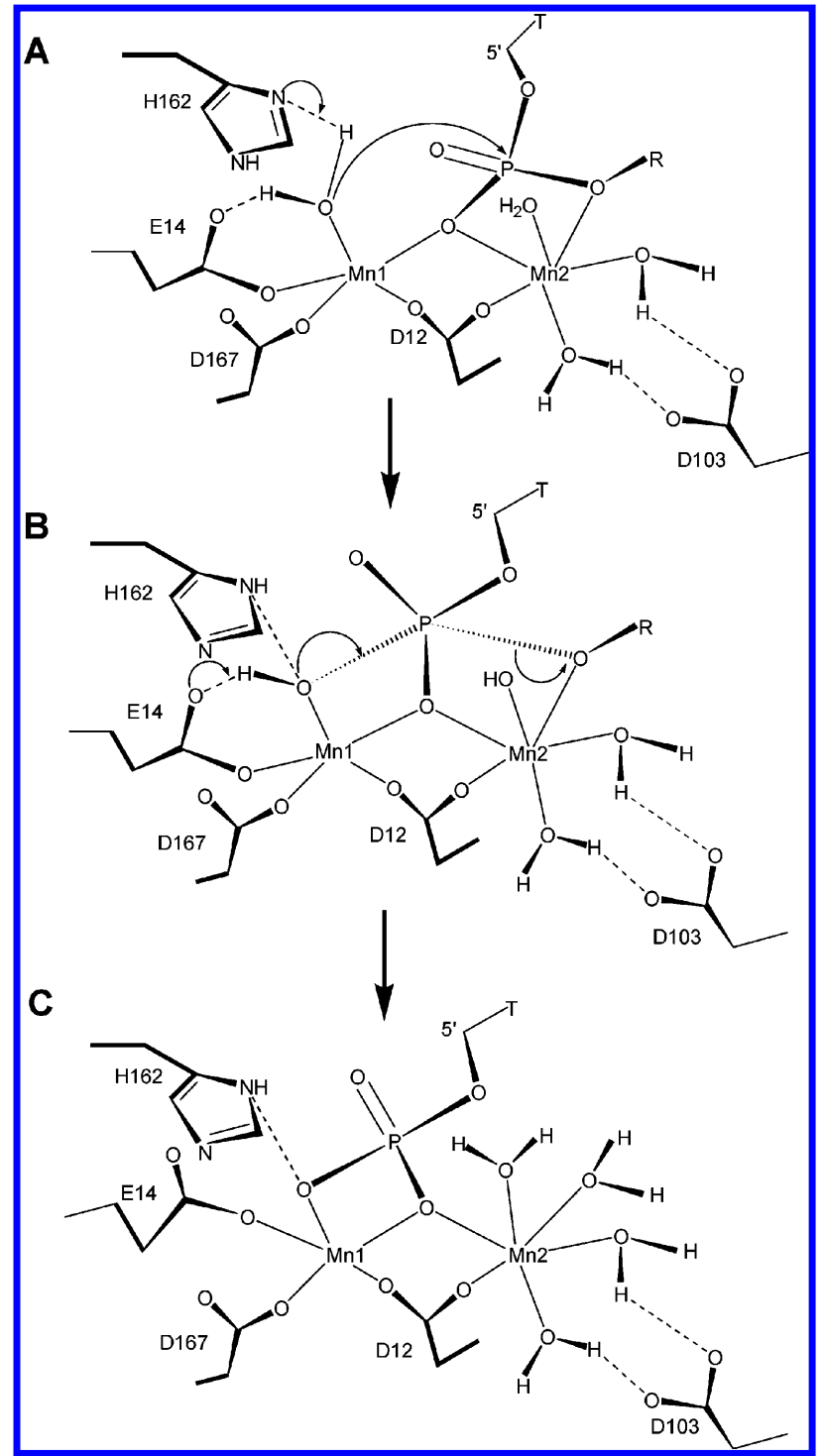

Figure 19. Proposed mechanism of hydrolysis by the $\epsilon$ subunit of E. coli DNA Pol III at high pH. (A) Substrate binding; (B) nucleophilic attack and release of leaving group; (C) regeneration of the active site; the product-bound state resembles that of the $\epsilon-$ dTMP complex at low pH (Figure 18B). Adapted with permission from ref 189. Copyright 2002 American Chemical Society.

from T4 DNA polymerase based on the pre-steady-state kinetic studies with matched and mismatched 3'-termini of the primer-DNA duplex. Different rate constants for matched $\left(1 \mathrm{~s}^{-1}\right)$ and mismatched $3^{\prime}$-termini of the primers $\left(5 \mathrm{~s}^{-1}\right)$ implicated "melting" of DNA duplex as the necessary activation step, that is, the rate-limiting step prior to the fast exonucleolytic cleavage $\left(100 \mathrm{~s}^{-1}\right) .^{248}$

The precise coordination of the substrate in the active site is, at least in the $\epsilon$ subunit of $E$. coli Pol III, pH-dependent (see above). ${ }^{241}$ In the structure of the subunit $\epsilon-$ dTMP complex, determined at $\mathrm{pH} 8.5$, the phosphate group of dTMP binds with two oxygen atoms to the metal ions: one bridges the metal ions, and one is terminally bound to the site 2 metal ion (Figures 18 and 19). ${ }^{241}$ Importantly, the site 1-coordinated water molecule forms strong hydrogen bonds with the deprotonated His 162 and Glu14 side chain, which leads to the generation of the reaction-initiating hydroxo nucleophile (Figure 19A). The significance of His162 is illustrated by a comparison to $3^{\prime}-5^{\prime}$ exonuclease from $E$. coli Pol I. Instead of a histidine residue, this enzyme has a 
tyrosine ligand in the equivalent position. ${ }^{158}$ The higher basicity of the histidine side chain in the $\epsilon$ subunit of $E$. coli Pol III is likely to promote formation of a more potent nucleophile, a proposal that is consistent with the observed increased reactivity of this enzyme relative to the Pol I $3^{\prime}-5^{\prime}$ exonuclease. ${ }^{241}$ Attack by this nucleophile on the phosphorus leads to the formation of a trigonal-bipyramidal transition state (Figure 19B). At present, it is not known if bond formation precedes bond breakage in this mechanism. However, from the crystal structure of the $\epsilon-\mathrm{dTMP}$ complex, it has been inferred that following the abstraction of a proton by Glu14 the transition state collapses to form product molecules. ${ }^{189,241}$ It is postulated that a site 2-bound water molecule acts as proton donor for the leaving alcohol group (Figure 19B). ${ }^{241}$ The phosphate group of the deoxynucleoside $5^{\prime}$-monophosphate remains coordinated with two oxygen atoms to the metal ions. However, while one oxygen is still bridging, the other one is now terminally bound to the site M1 center (Figure 19C), in a mode similar to that observed in the low $\mathrm{pH}$ structure of the $\epsilon$ subunit complexed with dTMP (Figure 18B). Hence, the low pH structure appears to be a good model for the product-bound state of $3^{\prime}-5^{\prime}$ exonuclease. ${ }^{241}$

It has been speculated that the role of metal ion M2 (lower affinity site) is to stabilize the negative charge on the oxygen atom of the leaving group. Kinetic studies of the $3^{\prime}-5^{\prime}$ exonuclease domain of $E$. coli Pol I employing DNA substrate analogues (deoxyribo-3'-S-phosphorothiolates, where a sulfur atom replaces the oxygen at the $3^{\prime}$ leaving position) were carried out in order to probe the reaction mechanism. ${ }^{249,250}$ These studies have shown that in the presence of $\mathrm{Mg}(\mathrm{II})$ the rate of exonucleolytic cleavage of S-containing substrates decreased 60000 -fold relative to that of $\mathrm{O}$ containing substrates, whereas in the presence of $\mathrm{Mn}(\mathrm{II})$, the decrease was only 600-fold. These data represent the first direct evidence that the low-affinity metal binding site interacts with the leaving group by stabilizing its negative charge. ${ }^{250}$ In addition, crystal structures of the $3^{\prime}-5^{\prime}$ exonuclease domain of $E$. coli Pol I complexed with singlestranded DNA (deoxyribo-3'-S-phosphorothiolates) and $\mathrm{Mn}(\mathrm{II})$ or $\mathrm{Zn}(\mathrm{II})$ were consistent with the proposal that the sulfur atom in the $3^{\prime}$ position of the substrate does affect the binding of the metal ion in the low-affinity site. ${ }^{251}$

In the structures of the subunit $\epsilon$-dTMP complex, determined at high and low $\mathrm{pH}$ (Figure 18), the phosphate group of dTMP binds with two oxygen atoms to the metal ions. One oxygen bridges the metal ions, and one is terminally bound to one of the two metal ions, site 2 or site M1, respectively (Figures 18 and 19). ${ }^{241}$ Thus, at low $\mathrm{pH}$, substrate binding may displace the proposed nucleophile at site M1 (see above). Instead, a site M2-bound water molecule, activated via a hydrogen bonding interaction with Asp103, has been proposed to act as the nucleophile (Figure 18). ${ }^{189}$ Thus, in the proposed mechanisms at low and high $\mathrm{pH}$, crucial roles for residues Asp103 and His162 are invoked for the activation of proposed nucleophiles, a hypothesis which awaits further substantiation via site-directed mutagenesis studies. The proposed $\mathrm{pH}$ dependence of the catalytic mechanism of the $\epsilon$ subunit of E. coli Pol III is reminiscent of $\mathrm{pH}$-mediated changes in the reaction cycle of some PAPs. For both sweet potato and proteolytically cleaved (activated) human PAPs, evidence has accumulated that supports a model where the identity of the proton donor for the leaving group depends on $\mathrm{pH}$ (see above). ${ }^{56,64}$

\section{5'-Nucleotidases}

\subsection{Biochemical Characterization and Function}

$5^{\prime}$-NT (E.C. 3.1.3.5) is a member of the calcineurin superfamily (see section 3) of binuclear metallophosphatases ${ }^{252,253}$ and catalyzes the dephosphorylation of ribo- and deoxyribonucleoside 5'-monophosphates to the corresponding nucleosides, thus, forming the catabolic arm responsible for maintaining balanced nucleotide pools. ${ }^{254}$

$5^{\prime}$-NTs have been isolated from numerous sources, including multiple mammalian species, ${ }^{254-258}$ birds, ${ }^{259}$ arthropods, ${ }^{260}$ reptiles, ${ }^{261}$ plants, ${ }^{262,263}$ and bacteria. ${ }^{264-266}$ In animals, two types of $5^{\prime}$-NTs are present, but of these, only one form, labeled ecto- $5^{\prime}$-NTs, has a binuclear center. ${ }^{254,255}$ Ecto- $5^{\prime}$ NTs are typically bound to the outer surface of the plasma membrane with their C-terminus anchored via a glycosylphosphatidylinositol (GPI) group, but have also been isolated in soluble form. ${ }^{267,268}$ The amino acid sequences of mammalian ecto- $5^{\prime}$-NTs are highly conserved, with an identity of greater than $85 \% .{ }^{268}$ In bacteria, different forms of $5^{\prime}$-NT have also been identified. ${ }^{264-266,269}$ A majority of these enzymes seem to be binuclear systems, ${ }^{264,266}$ and although the overall sequence homology between homodimeric mammalian ecto- $5^{\prime}$-NT and the monomeric bacterial enzymes is low, their active site and substrate binding residues are conserved. ${ }^{255,270}$

The best-characterized $5^{\prime}$-NT to date is the E. coli enzyme. ${ }^{65} \mathrm{Zn}$ enrichment of the growth medium indicated that $E$. coli $5^{\prime}$-NT contains at least one tightly bound zinc atom. ${ }^{271}$ Similarly, metal ion analyses of $5^{\prime}$-NT purified from bull seminal plasma, chicken gizzard, and snake venom have shown these enzymes to contain at least one zinc atom per active site. ${ }^{261}$ Interestingly, the $\mathrm{Co}$ (II) derivative of the enzyme is most active. ${ }^{264,272}$ Other divalent metals, including manganese and magnesium, also promote activity, 264,272,273 while an excess of zinc has an inhibitory effect. ${ }^{264}$ Similar to PAPs, the metal ion composition does affect not only reactivity, but also the $\mathrm{pH}$ dependence of kinetic parameters. ${ }^{254,264,273}$ For E. coli $5^{\prime}$-NT with AMP as the substrate, the optimal $\mathrm{pH}$ varies from 8.0 with manganese to 6.0 with a mixture of cobalt and calcium. ${ }^{264,273}$ The $\mathrm{pH}$ dependence is also governed to some extent by the nature of the substrate. ${ }^{273}$ For di- and triphosphates, the optimum $\mathrm{pH}$ range is broad, ranging between $\mathrm{pH} 5.5$ and 8.5. The ecto- $5^{\prime}-\mathrm{NTs}$ derived from chicken gizzard and rat liver exhibit a $\mathrm{pH}$ optimum of $7.5,{ }^{259,274}$ while other enzymes exhibit broader pH optima: $\mathrm{pH} 6.8-8.0$ for the rat renal enzyme ${ }^{275}$ and $\mathrm{pH}$ 8.0-9.0 for guinea pig skeletal muscle enzyme. ${ }^{254,276}$

E. coli 5'-NT hydrolyzes all 5'-ribo- and 5'-deoxyribonucleotides (including di- and triphosphates), with a preference for AMP. ${ }^{252,264,273}$ The enzyme also hydrolyzes uridine diphosphate sugars ${ }^{260,272}$ and the synthetic substrates bis- $p$ nitrophenyl phosphate and $p$-nitrophenyl phosphate ( $p$-NPP), which are widely used to assay enzyme activities in metallohydrolases. ${ }^{253,258,260}$ The animal ecto- $5^{\prime}$-NTs are more specific. AMP is purported to be the major physiological substrate, and ADP and ATP are competitive inhibitors of AMP hydrolysis. ${ }^{255,276}$ Additionally, ecto-5'-NTs do not hydrolyze $p$-NPP. ${ }^{258}$ Inhibitors of the $5^{\prime}$-NTs include adenosine $5^{\prime}-[\alpha, \beta$-methylene $]$ diphosphate $(\mathrm{AMPCP})^{254,277,278}$ and concanavalin $\mathrm{A},{ }^{254,276}$ but phosphate has no inhibitory effect. $^{268}$ The selective inhibition by ATP and ADP of dibut not monoesterase activity in $E$. coli $5^{\prime}$-NT has been interpreted in terms of two substrate binding sites, a catalytic 
site with high affinity and an inhibitory site with low affinity for substrate. ${ }^{279}$ The presence of two distinct substrate binding sites may also account for the observed deviation of $E$. coli $5^{\prime}$-NT from common Michaelis-Menten behavior, suggesting uncompetitive substrate inhibition. ${ }^{253,264,273,279,280}$ This deviation is not observed in enzymes from other sources. ${ }^{275,277,281}$

The precise biological role(s) of $5^{\prime}$-NTs is still obscure. In bacteria, these enzymes are believed to play a role in the hydrolysis of extracellular nucleoside diphosphate sugars to nucleosides and nonphosphorylated sugar products which are readily transported into the cell, thus, providing a carbon source for the cell. ${ }^{258}$ The activity of $5^{\prime}$-NTs within E. coli cells is repressed by a protein inhibitor, possibly to prevent the disruption of nucleic acid metabolism. ${ }^{252,269,272,282}$

Ecto-5'-NTs are present in most animal tissues, ${ }^{258}$ and have been proposed to play a key role in nucleotide salvage by dephosphorylating oxy- and deoxynucleotides. The abundance of extracellular adenine nucleotides and the high affinity of ecto-5'-NTs for AMP suggest that adenosine is the major nucleoside produced by ecto-5'-NTs. However, other extracellular nucleotides are also dephosphorylated by this enzyme, albeit with decreased efficiency. ${ }^{254}$

Additionally, ecto-5'-NTs have been ascribed a role in the inactivation of ATP, and the formation of adenosine, ${ }^{254}$ which may be of particular importance in controlling the function of ATP as an intercellular messenger. ${ }^{258}$ In the final step of ATP inactivation, ecto-5'-NTs catalyzes the dephosphorylation of AMP to adenosine, which can interact with specific receptors to induce an array of physiological functions including vasodilation, lipolysis, a decrease in glomerular filtration rate, the inhibition of renin release, and the inhibition of both neurotransmitter release and immune/ inflammatory response. ${ }^{258,283}$ Although ecto-5'-NT may not be the only enzyme that is involved in the generation of extracellular adenosine, there is evidence that its expression and activity is functionally associated with adenosine receptor activation. ${ }^{284-286}$ Its preference for AMP implicates ecto-5' NT in a wide range of physiological functions, ${ }^{258}$ suggesting a possible role as a drug target.

\subsection{Structural Characterization}

The crystal structure of E. coli 5'-NT has been determined. ${ }^{287,288}$ It is a monomeric protein consisting of an $\mathrm{N}$-terminal domain linked via an $\alpha$-helix to a smaller C-terminal domain (Figure 20). There are relatively few interactions between the two domains, and they are separated by a layer of water molecules. ${ }^{288}$ The substrate binding pocket is located on the C-terminal domain, while the binuclear active site is situated on the $\mathrm{N}$-terminal domain, close to the domain interface within a cleft approximately $20 \AA$ deep and $15-17 \AA$ wide. ${ }^{253,287}$

The active site contains two $\mathrm{Zn}$ (II) ions and has a positive electrostatic potential, attracting negatively charged phosphoester substrates to the active site. ${ }^{287}$ The zinc ions are $3.3 \AA$ apart and, similar to PAPs, bridged monodentately by Asp84 and by either a water molecule or an adventitious bicarbonate or acetate ion (Figure 21). ${ }^{287}$ The zinc ions are fivecoordinate, with trigonal bipyramidal geometry. ${ }^{287}$ Site M1 (Figure 21) has $\mathrm{Zn}$ also coordinated by two oxygen atoms from Asp41 and Gln254 and one nitrogen atom from His43 and represents the site with high affinity for the metal ion (i.e., this site is equivalent to the chromophoric Fe(III)-

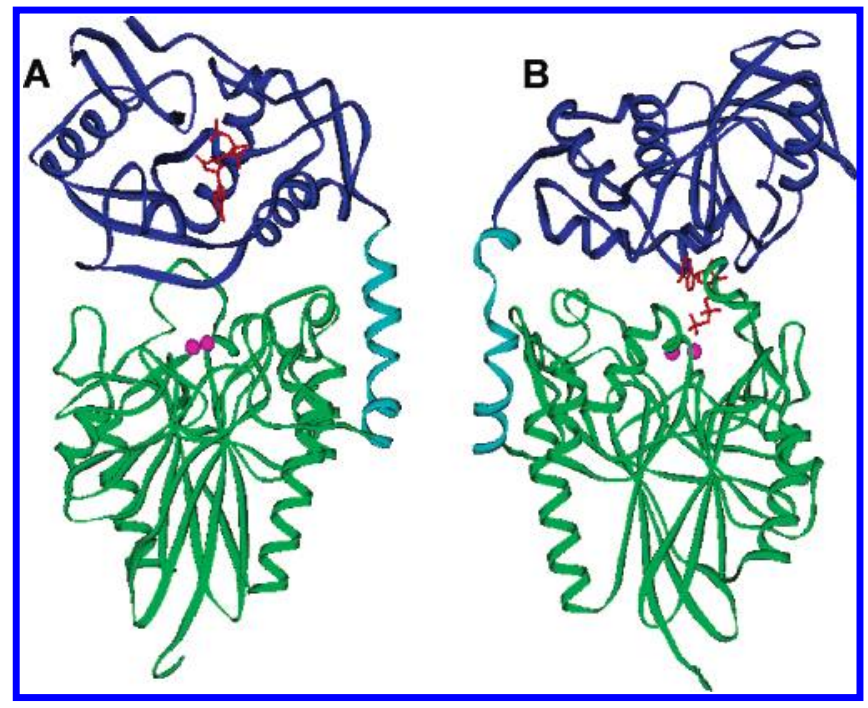

Figure 20. Ribbon diagram depicting the overall fold of $E$. coli $5^{\prime}$-NT in complex with (A) ATP and (B) AMPCP (PDB codes 1HP1 and 1HPU, respectively). The N-terminal domain is green, the C-terminal domain is blue, the domain-linking helix is blue, and the metal ions are silver. Adapted with permission from ref 288 . Copyright 2001 Elsevier Publishing.

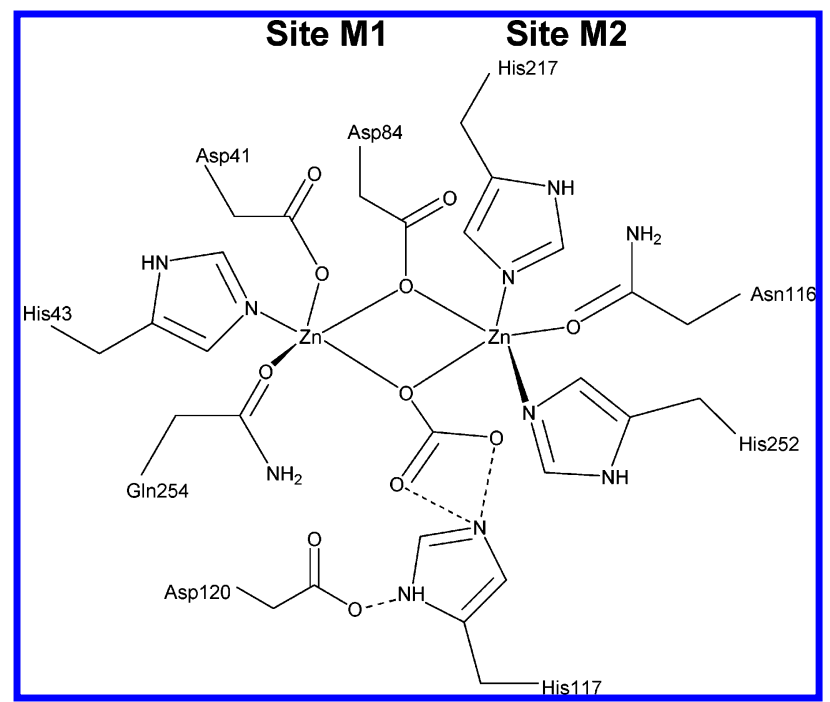

Figure 21. The active site of E. coli $5^{\prime}$-NT. In the absence of substrate analogues or products, the two metal centers are fivecoordinate. Adventitious carbonate (or acetate) is present as a consequence of the crystallization conditions. ${ }^{287}$

binding site in PAPs). ${ }^{280}$ Site M2 (Figure 21) is coordinated to the nitrogen atoms of two histidine residues (His217 and His252) and an asparagine oxygen atom (Asn116). The metal-ligating residues and the catalytic histidine are highly conserved both between $5^{\prime}$-NTs from different sources and in a number of other phosphoesterases, including PAPs and PPPs. ${ }^{11,21,287}$ Also shown in Figure 21 is the catalytic His117-Asp120 dyad. Site-directed mutagenesis studies have also invoked a catalytic role for the second coordination sphere residue Glu118 (the Glu118Gln mutant is only $\sim 6 \%$ as active as the wild-type), although its precise function in the active site remains to be determined. ${ }^{280}$

The structure of E. coli $5^{\prime}$-NT has also been determined in the presence of the bound ADP analogue AMPCP, ATP, and the reaction products adenosine and phosphate. In the presence of AMPCP, the active site contains two Mn(II) ions due to inclusion of manganese in the crystallization solution. ${ }^{270}$ The metal ions are six-coordinate in an octahedral 
environment, bound to the seven amino acid ligands shown in Figure 21, in addition to two water molecules and one of the phosphate oxygen atoms (coordinated to $\mathrm{Mn} 2$, which corresponds to $\mathrm{Zn} 2$ in Figure 21). One of the water/hydroxide molecules bridges the two metal ions, while the other is terminally bound to $\mathrm{Mn} 1$ (corresponding to $\mathrm{Zn} 1$ ). Thus, the active site geometry is similar to that observed for rat PAP in the presence of bound sulfate (see section 2). ${ }^{67}$ The structure of the substrate analogue/inhibitor-protein complexes indicate that the substrate binding pocket for nucleotides is mainly formed by residues in the C-terminal domain, while $\mathrm{N}$-terminal amino acids provide most of the catalytic residues. ${ }^{270}$ Substrate binding is facilitated predominantly by a hydrophobic stacking interaction between the ADP analogue and the aromatic residues of Phe 429 and Phe491. ${ }^{270}$

The comparison between $5^{\prime}$-NT structures with bound AMPCP and ATP identified two distinct structural conformations. ${ }^{288}$ In the open form (ATP-bound structure; Figure $20 \mathrm{~A}$ ), the substrate binding pocket is $\sim 25 \AA$ distant from the catalytically active site. In the closed form, both the substrate binding pocket and the active site are situated in close proximity at the domain interface (AMPCP-bound structure; Figure 20B). The domain-connecting $\alpha$-helix acts as a hinge region facilitating the $96^{\circ}$ rotation required to toggle between open and closed conformations. ${ }^{288}$ The significance of domain rotation for catalysis has been demonstrated in two variants of $E$. coli $5^{\prime}-\mathrm{NT}$ with fixed open $\left(5^{\prime}\right.$-NT-O) or closed (5'-NT-C) conformation. ${ }^{289}$ As expected, $5^{\prime}-\mathrm{NT}-\mathrm{O}$ is unable to hydrolyze AMP. In contrast, $5^{\prime}$-NT-C is approximately half as active as the wild-type enzyme. The residual activity has been ascribed to partial interdomain rotation $\left(43.2^{\circ}\right)$, presumably enabling substrate binding, but with decreased efficiency. ${ }^{253}$

\subsection{Catalytic Mechanism}

The bulk of mechanistic studies of $5^{\prime}$-NTs have been focused on the E. coli enzyme, but since all but one of the catalytically relevant residues are conserved, the general features of the reaction mechanism are anticipated to be similar in the nonbacterial $5^{\prime}$-NTs. ${ }^{252}$

In the initial step of the reaction cycle, the enzyme is in the open conformation allowing unhindered access for the substrate to the $\mathrm{C}$-terminal domain containing the substrate binding pocket. A structural comparison by circular dichroism between resting wild-type E. coli 5'-NT and the 5'-NT-O mutant strongly suggests an open conformation for the former in solution. ${ }^{253}$ Subsequently, substrate binding induces conformational change via domain rotation, thus, positioning the substrate in the interdomain region adjacent to the active site.

In the second step of catalysis, the phosphate group is proposed to bind monodentately to the low-affinity metal ion (site M2 in Figures 21 and 22). Hydrogen bonding interactions between the phosphate group and the side chains of His117 and Arg410 ensure optimal orientation of the substrate for attack by a nucleophile (Figure 22A). The precise identity of this nucleophile is subject to debate, with two metal-bound water molecules (one bridging the metal ions and one terminally bound to the metal ion in site M1; Figure 22B) proposed as likely candidates. ${ }^{270,288}$ In accord with the E. coli $5^{\prime}$-NT crystal structure with bound AMPCP (Figure 20B), the water molecule coordinated terminally to site M1 is $3.2 \AA$ distant from the phosphorus atom of the substrate and in an ideal position for an in-line nucleophilic

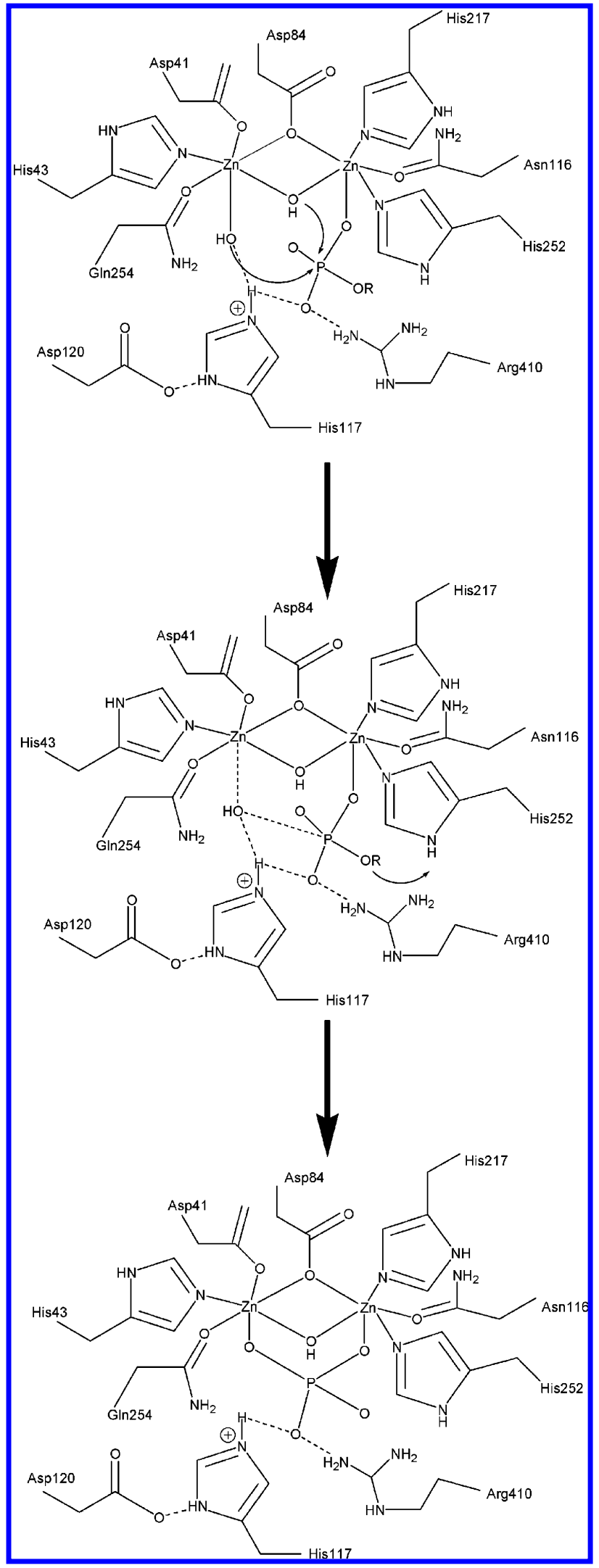

Figure 22. Proposed mechanism of hydrolysis by E. coli $5^{\prime}$-NT. (A) Substrate binding; (B) nucleophilic attack and release of leaving group; (C) regeneration of the active site (see text for details).

attack with an $\mathrm{O}(\mathrm{N})-\mathrm{P}-\mathrm{O}(\mathrm{R})$ angle of $155^{\circ}(\mathrm{O}(\mathrm{N})$ and $\mathrm{O}(\mathrm{R})$ represent oxygen atoms of the nucleophile and the leaving group, respectively). ${ }^{252,270}$ The $\mathrm{p} K_{\mathrm{a}}$ values reported for $\mathrm{Zn}$ (II)bound water molecules in a range of model complexes 
depend strongly on the coordination environment and range from 7.3 to $10.8 .^{290-296}$ Since $E$. coli $5^{\prime}$-NT is an efficient catalyst even at $\mathrm{pH} 6$, it seems likely that the $\mathrm{p} K_{\mathrm{a}}$ of the terminal water molecule is lowered through hydrogen bonding interactions with His117 (Figure 22A). The pH dependence of kinetic parameters for $5^{\prime}$-NT-catalyzed reactions has not yet been analyzed in detail, but based on $\mathrm{pH}$ optima ranging from 5.5 to 9 for different enzymes, it appears that in some $5^{\prime}$-NTs the likely candidate for the role of a nucleophile is the bridging water ligand, which is expected to have a lower $\mathrm{p} K_{\mathrm{a}}$ value. ${ }^{292,297}$

Similar to the other binuclear metallohydrolases, the transition state is proposed to be a pentacoordinated phosphoryl species stabilized by hydrogen bonding interactions with the side chains of Asn116, His 117, and Arg410. ${ }^{270}$ Since no general acid is positioned appropriately for protonation of the leaving group, a role for a solvent water molecule as the proton donor has been invoked. ${ }^{270}$ After hydrolysis, the tetrahedral phosphate ion remains bound to the active site in a bidentate fashion (Figure 22C), as observed in the crystal structures of pig and red kidney bean purple acid phosphatases. ${ }^{63,65}$ The release of the leaving group is presumably assisted by a structural rearrangement, which returns the protein to its open conformation. This latter step offers an explanation for the observed substrate inhibition, since substrate molecules bound to a low-affinity, inhibitory site may prevent domain rotation and thus the release of reaction products. $^{253}$

In the final step of the catalytic cycle, phosphate is removed and the catalytic site is regenerated for the next cycle. The crystal structure of $E$. coli $5^{\prime}$-NT complexed with phosphate and adenosine indicates that phosphate may change its coordination from bi- to monodentate prior to being released. ${ }^{270}$ In the crystal structure of the dizinc enzyme in the resting state, both metals are five-coordinate and no terminal water ligand is present, ${ }^{287}$ and at present, it is uncertain when the terminally bound water ligand enters the active site.

\section{Conclusions}

The family of binuclear metallohydrolases contains several members which have been recognized as potential targets for the development of chemotherapeutics and promising candidates in bioremediation (Table 1). Understanding the factors that contribute to the observed mechanistic versatility of these systems is not only essential in understanding how these enzymes catalyze reactions, but is also critical in the design and development of potent and selective pharmaceuticals. This article has focused on four specific binuclear metallohydrolases, PAPs, PPs, 3'-5' exonucleases, and 5'NTs, which are experimentally well-developed systems showing the geometric and electronic structures of active sites and transition states for these binuclear metal centers.

Other enzymes, which we have not alluded to, but which have comparable binuclear metal centers, include the Ni(II)dependent ureases, ${ }^{88,298-301}$ phosphotriesterases, ${ }^{302,303}$ and aminopeptidases ${ }^{304-308}$ and nucleases such as the DNA double-strand break repair enzyme Mre11246,309 and the UDPgalactose: $\beta$-galactoside- $\alpha$-1,3-galactosyltransferase. ${ }^{310}$ In addition, global efforts into the sequencing and annotation of genomes are continually revealing other novel binuclear metalloenzymes. Examples are a recently characterized phosphodiesterase from $M$. jannaschii ${ }^{311}$ and a vacuolar protein sorting protein from human. ${ }^{312}$
Another group of binuclear metalloenzymes with great pharmacological potential is the metallo- $\beta$-lactamase family. $\beta$-Lactamases are of profound importance due to their ability to hydrolyze, and thus inactivate, $\beta$-lactam antibiotics. Of these, the metallo- $\beta$-lactamases are a major concern, since they hydrolyze virtually all known $\beta$-lactams and because there are no efficient inhibitors known to date. ${ }^{313,314}$ Crystal structures of several members of the metallo- $\beta$-lactamase superfamily have been solved recently. ${ }^{315-319}$ The structure of the zinc-dependent $\beta$-lactamase from Fluoribacter gormanii (FEZ-1) shows that the aspartate residue coordinated terminally to one of the zinc ions in the active site (Asp120) forms a hydrogen bond with the bridging water molecule, thus, activating the latter for its role as a nucleophile. ${ }^{317,319}$ Site-directed mutagenesis studies in the related metallo- $\beta$ lactamase L1 from Stenotrophomonas maltophiliac have further lent support to the catalytic role of this aspartate residue; specifically, it has been suggested that it positions the bridging nucleophile suitably for catalysis. ${ }^{314}$ This hydrogen bond interaction between a terminal aspartate ligand and a bridging water molecule is a common feature among the structurally characterized metallo- $\beta$ lactamases,${ }^{315-319}$ which is also observed in PPMs. A similar hydrogen bonding interaction is established via a backbone carbonyl oxygen atom from a histidine ligand for PAPs and PPPs (see sections 2 and 3). Also of interest is the observation that FEZ-1, unlike most binuclear metallohydrolases, does not have a metal ion-bridging amino acid ligand, while one member of the metallo- $\beta$-lactamase family (rubredoxin:oxygen oxidoreductase (ROO) from Desulfovibrio gigas $^{316}$ ) has a bridging aspartate ligand in the $\mu-1,3$ coordination mode like PPMs and $3^{\prime}-5^{\prime}$ exonuleases, and three others (human gloxylase II (GOX), RNase Z from $B$. subtilis, and the phosphorylcholine esterase (Pce) domain of the virulence factor choline-binding protein $\mathrm{E}^{315,318,319}$ ) have an aspartate residue in a $\mu-1,1$ coordination mode, as observed in PAPs, PPPs, and 5'-NTs. Furthermore, in RNase $\mathrm{Z}$ and Pce, the active sites in the presence of phosphate are very similar to those of pig and red kidney bean PAPs with a $\mu-1,3$ coordination of phosphate. Little is currently known about the specific metal ion requirements of metallo- $\beta$ lactamases, but ROO requires iron to catalyze its redox reactions, ${ }^{316}$ while GOX appears to be more flexible with iron, manganese, and zinc present in the active site. ${ }^{320,321}$ Ultimately, it will be interesting to investigate the detailed catalytic mechanisms of metallo- $\beta$-lactamases and compare them with those of the enzymes reviewed here.

The binuclear metallohydrolases discussed in this review illustrate both mechanistic similarities, and functional variations. The latter is a reflection of the evolutionary adaptation for a specific task. In particular, active sites have optimized geometries to accommodate specific substrates. Mechanistic similarities include that each enzyme requires two metal ions and a metal ion-bound water molecule (hydroxide or oxide) for activity. Correspondingly, catalysis is accompanied by an inversion of the stereochemistry of the phosphate group. This observation is the main feature that distinguishes these enzymes from alkaline phosphatases (Table 1), which utilize a serine ligand as nucleophile and thus form phospho-enzyme reaction intermediates. $6,322,323$

In summary, key features of the mechanism of metallohydrolase-catalyzed reactions include the mode of binding of the substrate, the identity of the nucleophile, the release of the leaving group, and the regeneration of the active site. 
Recent structures incorporating substrate analogues or inhibitors such as sulfate, tungstate, and phosphate have provided snapshots of distinct catalytic steps, particularly for PAPs. While still the subject of conjecture, it appears that in some metallohydrolases, including PAPs and PPs, the substrate may form a $\mu-1,3$ precatalytic complex, while in others (e.g., $5^{\prime}$-NTs), the phosphate group of the substrate binds only to one metal ion prior to the nucleophilic attack.

The precise identity of the nucleophile also remains conjectural, although recent spectroscopic and crystallographic data favor a bridging hydroxide/oxo group for PAPs. Similar conclusions were drawn for PPs (both PPPs and PPMs), while proposed models for the mechanism of $3^{\prime}-5^{\prime}$ exonucleases and $5^{\prime}$-NTs tend to prefer a terminally bound water molecule as nucleophile (alkaline phosphatases utilize a serine residue as nucleophile 322,323$)$.

For pig and red kidney bean PAPs, as well as PPPs and alkaline phosphatases, a (partial) dissociative mechanism is likely to operate, while sweet potato and activated human PAPs appear to follow an associative mechanism. For $3^{\prime}-5^{\prime}$ exonucleases, 5'-NTs, and several other metallohydrolases listed above, the formation of a pentacoordinated phosphoryl transition state has been proposed, but at present, it is not known if bond formation precedes bond breakage.

The final stage of the mechanism involves regeneration of the active site for the next cycle by displacement of the bound phosphate group, replacement of aqua ligands (bridging or terminal), and, in some instances, protonation of proposed proton donors. Especially for PPMs, this last step in catalysis has been proposed to be rate-limiting.

In conclusion, the broad features of catalysis are conserved across the four different enzymes systems, but there are significant differences which emerge when each is probed by various physicochemical techniques currently available. Furthermore, this review has illustrated gaps in our current understanding of the mechanisms of binuclear metallohydrolase-catalyzed reactions. It is hoped that the interested reader may find this article stimulating to address these issues.

\section{Abbreviations}

AMPCP adenosine $5^{\prime}$-[ $\alpha, \beta$-methylene $]$ diphosphate

Ape apurinic/apyrimidinic endonuclease

BDNPP 2,4-bis(dinitrophenyl) phosphate

dTMP deoxythymidine 5'-monophosphate

ENDOR electron-nuclear double resonance

EPR electron paramagnetic resonance

EXAFS X-ray absorption fine structure

GPI glycosylphosphatidylinositol

NHE normal hydrogen electrode

5'-NT 5'-nucleotidase

PAP purple acid phosphatase

$p$ NPP para-nitrophenyl phosphate

$\mathrm{PP} \quad \mathrm{Ser} / \mathrm{Thr}$ protein phosphatase

rmsd root-mean-square deviation

ROS reactive oxygen species

TREX 3'-repair exonuclease

V-TREX viral 3'-repair exonuclease

\section{Acknowledgments}

The authors thank the Australian Research Council for funding (DP0558652). A. Neves thanks CNPq for financial support. The assistance of Ms. Eleanor Leung, Mr. Paul Herrald, Mr. Tristan Elliott, and Ms. Ah Young Park in the preparation of this manuscript is gratefully appreciated.

\section{References}

(1) Wilcox, D. E. Chem. Rev. 1996, 96, 2435.

(2) Sträter, N.; Lipscomb, W. N.; Klabunde, T.; Krebs, B. Angew. Chem. Int. Ed. Engl. 1996, 35, 2024.

(3) Dismukes, G. C. Chem. Rev. 1996, 96, 2909.

(4) Barford, D.; Das, A. K.; Egloff, M.-P. Annu. Rev. Biophvs. Biomol. Struct. 1998, 27, 133.

(5) Rusnak, F.; Mertz, P. Phvsiol. Rev. 2000, 80, 1483.

(6) Jackson, M. D.; Denu, J. M. Chem. Rev. 2001, 101, 2313.

(7) Lowther, W. T.; Matthews, B. W. Biochim. Biophvs. Acta 2000, 1477, 157.

(8) Klabunde, T.; Krebs, B. Struct. Bonding 1997, 89, 177.

(9) Twitchett, M. B.; Sykes, A. G. Eur. J. Inorg. Chem. 1999, 2105.

(10) Oddie, G. W.; Schenk, G.; Angel, N. Z.; Walsh, N.; Guddat, L. W.; de Jersey, J.; Cassady, A. I.; Hamilton, S. E.; Hume, D. A. Bone 2000, 27, 575.

(11) Koonin, E. V. Protein Sci. 1994, 3, 356.

(12) Antanaitis, B. C.; Aisen, P. J. Biol. Chem. 1982, 257, 5330.

(13) Doi, K.; Bradley, C.; Aisen, P. Struct. Bonding 1988, 70, 1.

(14) Chen, T. T.; Bazer, F. W.; Cetorelli, J. J.; Pollard, W. E.; Roberts, R. M. J. Biol. Chem. 1973, 248, 8560.

(15) Campbell, H. D.; Zerner, B. Biochem. Biophvs. Res. Commun. 1973 $54,1493$.

(16) Campbell, H. D.; Dionysius, D. A.; Keough, D. T.; Wilson, B. E.; de Jersey, J.; Zerner, B. Biochem. Biophys. Res. Commun. 1978, 82, 615.

(17) Robinson, D. B.; Glew, R. H. J. Biol. Chem. 1980, 255, 5864

(18) Hayman, A. R.; Warburton, M. J.; Pringle, J. A.; Coles, B.; Chambers, T. J. Biochem. J. 1989, 261, 601.

(19) Allen, S. H.; Nuttleman, P. R.; Ketcham, C. M.; Roberts, R. M. $\underline{J}$ Bone Miner. Res. 1989, 4, 47.

(20) Janckila, A. J.; Woodford, T. A.; Lam, K. W.; Li, C. Y.; Yam, L. T. Leukemia 1992, 6, 199.

(21) Schenk, G.; Guddat, L. W.; Ge, Y.; Carrington, L. E.; Hume, D. A.; Hamilton, S.; de Jersey, J. Gene 2000, 250, 117.

(22) Antanaitis, B. C.; Aisen, P.; Lilienthal, H. R. J. Biol. Chem. 1983, $258,3166$.

(23) Averill, B. A.; Davis, J. C.; Burman, S.; Zirino, T.; Sanders-Loehr, J.; Loehr, T. M.; Sage, J. T.; Debrunner, P. G. J. Am. Chem. Soc. 1987, 109, 3760 .

(24) Yang, Y.-S.; McCormick, J. M.; Solomon, E. I. J. Am. Chem. Soc 1997, 119, 11832

(25) Wang, D. L.; Holz, R. C.; David, S. S.; Que, L.; Stankovich, M. T. Biochemistry 1991, 30, 8187.

(26) Bernhardt, P. V.; Schenk, G.; Wilson, G. J. Biochemistry 2004, 43, 10387.

(27) Debrunner, P. G.; Hendrich, M. P.; de Jersey, J.; Keough, D. T.; Sage, J. T.; Zerner, B. Biochim. Biophvs. Acta 1983, 745, 103.

(28) Beck, J. L.; Keough, D. T.; de Jersey, J.; Zerner, B. Biochim. Biophys. Acta 1984, 791, 357

(29) Day, E.; David, S.; Peterson, J.; Dunham, W.; Bonvoisin, J.; Sands, R.; Que, L., Jr. J. Biol. Chem. 1988, 263, 15561.

(30) Beck, J. L.; McConachie, L. A.; Summors, A. C.; Arnold, W. N.; de Jersey, J.; Zerner, B. Biochim. Biophys. Acta 1986, 869, 61.

(31) Nakazato, H.; Okamoto, T.; Nishikoori, M.; Washio, K.; Morita, N.; Haraguchi, K.; Thompson, G. A., Jr.; Okuyama, H. Plant Physiol. 1998, 118, 1015 .

(32) Durmus, A.; Eicken, C.; Sift, B. H.; Kratel, A.; Kappi, R.; Hütterman, J.; Krebs, B. Eur. J. Biochem. 1999, 260, 709.

(33) Bozzo, G. G.; Raghothama, K. G.; Plaxton, W. C. Biochem. J. 2004, 377,419

(34) Bozzo, G. G.; Raghothama, K. G.; Plaxton, W. C. Eur. J. Biochem. 2002, 269, 6278

(35) Schenk, G.; Ge, Y.; Carrington, L. E.; Wynne, C. J.; Searle, I. R.; Carroll, B. J.; Hamilton, S.; de Jersey, J. Arch. Biochem. Biophvs. 1999, $370,183$.

(36) Schenk, G.; Boutchard, C. L.; Carrington, L. E.; Noble, C. J.; Moubaraki, B.; Murray, K. S.; de Jersey, J.; Hanson, G. R.; Hamilton, S. J. Biol. Chem. 2001, 276, 19084

(37) Ullah, A. H. J.; Cummins, B. J. Prep. Biochem. 1988, 18, 37.

(38) Schenk, G.; Korsinczky, M. L. J.; Hume, D. A.; Hamilton, S.; de Jersey, J. Gene 2000, 255, 419.

(39) Nuttleman, P. R.; Roberts, R. M. J. Biol. Chem. 1990, 265, 12192.

(40) Sibille, J. C.; Doi, K.; Aisen, P. J. Biol. Chem. 1987, 262 , 59.

(41) Kaija, H.; Alatalo, S. L.; Halleen, J. M.; Lindqvist, Y.; Schneider, G.; Väänänen, H. K.; Vihko, P. Biochem. Biophvs. Res. Commun 2002, 292, 128

(42) Räisänen, S. R.; Alatalo, S. L.; Ylipahkala, H.; Halleen, J. M.; Cassady, A. I.; Hume, D. A.; Väänänen, H. K. Biochem. Biophvs. Res. Commun. 2005, 331, 120. 
(43) Moss, D. W.; Raymond, F. D.; Wile, D. B. Crit. Rev. Clin. Lab. Sci. 1995, 32, 431 .

(44) Angel, N. Z.; Walsh, N.; Forwood, M. R.; Ostrowski, M. C.; Cassady, A. I.; Hume, D. A. J. Bone Miner. Res. 2000, 15, 103

(45) Hayman, A. R.; Jones, S. J.; Boyde, A.; Foster, D.; Colledge, W. H.; Carlton, M. B.; Evans, M. J.; Cox, T. M. Development 1996, 122,3151 .

(46) Ek-Rylander, B.; Flores, M.; Wendel, M.; Heinegard, D.; Andersson, G. J. Biol. Chem. 1994, 269, 14853.

(47) Valizadeh, M.; Schenk, G.; Nash, K.; Oddie, G. W.; Guddat, L. W.; Hume, D. A.; de Jersey, J.; Burke, T. R., Jr.; Hamilton, S. Arch. Biochem. Biophys. 2004, 424, 154

(48) Lau, K.-H. W.; Stefan, J. J.; Aera, Y.; Mohan, S.; Baylink, D. J. Int. J. Biochem. 1991, 23, 1237.

(49) Hayman, A. R.; Dryden, A. J.; Chambers, T. J.; Warburton, M. Biochem. J. 1991, 277, 631.

(50) Lam, K.-W.; Lee, P.; Li, C.-Y.; Yam, L. T. Clin. Chem. 1980, 26, 420.

(51) Janckila, A. J.; Parthasarathy, R. N.; Parthasarathy, L. K.; Seelan, R. S.; Yam, L. T. Clin. Chim. Acta 2002, 326, 113.

(52) Ljusberg, J.; Ek-Rylander, B.; Andersson, G. Biochem. J. 1999, 343, 63 .

(53) Funhoff, E. G.; Ljusberg, J.; Wang, Y.; Andersson, G.; Averill, B. A. Biochemistry 2001, 40, 11614.

(54) Funhoff, E. G.; Klaassen, C. H. W.; Samyn, B.; Van Beeumen, J.; Averill, B. A. ChemBioChem 2001, 2, 355.

(55) Lång, P.; Andersson, G. Cell. Mol. Life Sci. 2005, 62, 905.

(56) Mitić, N.; Valizadeh, M.; Leung, E. W. W.; de Jersey, J.; Hamilton, S.; Hume, D. A.; Cassady, A. I.; Schenk, G. Arch. Biochem. Biophvs. 2005, 154

(57) Ljusberg, J.; Wang, Y.; Lång, P.; Norgård, M.; Dodds, R.; Hultenby, K.; Ek-Rylander, B.; Andersson, G. J. Biol. Chem. 2005, 280, 28370.

(58) Cashikar, A. G.; Kumaresan, R.; Rao, N. M. Plant Phvsiol. 1997, 114, 907.

(59) Li, D.; Zhu, H.; Liu, K.; Liu, X.; Leggewie, G.; Udvardi, M.; Wang, D. J. Biol. Chem. 2002, 277, 27772.

(60) Liao, H.; Wong, F.-L.; Phang, T.-H.; Cheung, M.-Y.; Li, W.-Y. F.; Shao, G.; Yan, X.; Lam, H.-M. Gene 2003, 318, 103.

(61) Zimmermann, P.; Regierer, B.; Kossmann, J.; Frossard, E.; Amrhein, N.; Bucher, M. Plant Biol. 2004, 6, 519.

(62) Sträter, N.; Klabunde, T.; Tucker, P.; Witzel, H.; Krebs, B. Science 1995, 268, 1489

(63) Klabunde, T.; Sträter, N.; Fröhlich, R.; Witzel, H.; Krebs, B. J.Mol. Biol. 1996, 259, 737.

(64) Schenk, G.; Gahan, L. R.; Carrington, L. E.; Mitić, N.; Valizadeh, M.; Hamilton, S. E.; de Jersey, J.; Guddat, L. W. Proc. Natl. Acad. Sci. U.S.A. 2005, 102, 273

(65) Guddat, L. W.; McAlpine, A. S.; Hume, D.; Hamilton, S.; de Jersey, J.; Martin, J. L. Structure 1999, 7, 757.

(66) Uppenberg, J.; Lindqvist, F.; Svensson, C.; Ek-Rylander, B.; Andersson, G. J. Mol. Biol. 1999, 290, 201.

(67) Lindqvist, Y.; Johansson, E.; Kaija, H.; Vihko, P.; Schneider, G. $\underline{J}$. Mol. Biol. 1999, 291, 135.

(68) Sträter, N.; Jasper, B.; Scholte, M.; Krebs, B.; Duff, A. P.; Langley, D. B.; Han, R.; Averill, B. A.; Freeman, H. C.; Guss, J. M. J. Mol. Biol. 2005, 351, 233.

(69) Merkx, M.; Averill, B. A. Biochemistry 1998, 37, 11223.

(70) Merkx, M.; Pinkse, M. W. H.; Averill, B. A. Biochemistry 1999, 38, 9914.

(71) Pinkse, M. W. H.; Merkx, M.; Averill, B. A. Biochemistry 1999, 38, 9926.

(72) Funhoff, E. G.; Bollen, M.; Averill, B. A. J. Inorg. Biochem. 2005, 99, 521.

(73) Beck, J. L.; McArthur, M. J.; de Jersey, J.; Zerner, B. Inorg. Chim. Acta 1988, 153, 39.

(74) Beck, J. L.; de Jersey, J.; Zerner, B. J. Am. Chem. Soc. 1988, 110, 3317.

(75) Gehring, S.; Fleischhauer, P.; Behlendorf, M.; Huber, M.; Lorösch, J.; Haase, W.; Dietrich, M.; Witzel, H.; Locke, R.; Krebs, B. Inorg. Chim. Acta 1996, 252, 13.

(76) Battistuzzi, G.; Dietrich, M.; Locke, R.; Witzel, H. Biochem. J. 1997, 593

(77) Merkx, M.; Averill, B. A. J. Am. Chem. Soc. 1999, 121, 6683.

(78) Merkx, M.; Averill, B. A. Biochemistry 1998, 37, 8490.

(79) Twitchett, M. B.; Schenk, G.; Aquino, M. A. S.; Yiu, D. T. Y.; Lau, T.-C.; Sykes, A. G. Inorg. Chem. 2002, 41, 5787.

(80) Funhoff, E. G.; Wang, Y.; Andersson, G.; Averill, B. A. FEBS J. 2005, 272, 2968.

(81) Wang, X.; Que, L. Biochemistry 1998, 37, 7813.

(82) Wang, X.; Randall, C. R.; True, A. E.; Que, L. Biochemistry 1996, $35,13946$.

(83) Dietrich, M.; Muenstermann, D.; Suerbaum, H.; Witzel, H. Eur. J. Biochem. 1991, 199, 105.
(84) Suerbaum, H.; Koerner, M.; Witzel, H.; Althaus, E.; Mosel, B. D.; Mueller-Warmuth, W. Eur. J. Biochem. 1993, 214, 313.

(85) Aquino, M. A. S.; Lim, J. S.; Sykes, A. G. J. Chem. Soc., Dalton Trans. 1994, 429.

(86) Smoukov, S. K.; Quaroni, L.; Wang, X.; Doan, P. E.; Hoffman, B. M.; Que, L., Jr. J. Am. Chem. Soc. 2002, 124, 2595.

(87) Youngme, S.; Chaichit, N.; Kongsaeree, P.; van Albada, G. A.; Reedijk, J. Inorg. Chim. Acta 2001, 324, 232.

(88) Benini, S.; Rypniewski, W. R.; Wilson, K. S.; Ciurli, S.; Mangani, S. J. Biol. Inorg. Chem. 2001, 6, 778

(89) Mao, Z.-W.; Heinemann, F. W.; Liehr, G.; van Eldik, R. J. Chem. Soc., Dalton Trans. 2001, 3652.

(90) Adams, H.; Bradshaw, D.; Fenton, D. E. J. Chem. Soc., Dalton Trans. 2001, 3407.

(91) Kitajima, N.; Hikichi, S.; Tanaka, M.; Morooka, Y. J. Am. Chem. Soc. 1993, 115, 5496.

(92) Voegtli, W. C.; White, D. J.; Reiter, N. J.; Rusnak, F.; Rosenzweig, A. C. Biochemistry 2000, 39, 15365.

(93) Wynne, C. J.; Hamilton, S. E.; Dionysius, D. A.; Beck, J. L.; de Jersey, J. Arch. Biochem. Biophys. 1995, 319, 133.

(94) Martin, B. L.; Graves, D. J. Biochim. Biophys. Acta 1994, 1206, 136.

(95) Mueller, E. G.; Crowder, M. W.; Averill, B. A.; Knowles, J. R. J. Am. Chem. Soc. 1993, 115, 2974.

(96) Mertz, P.; Yu, L.; Sikkink, R.; Rusnak, F. J. Biol. Chem. 1997, 272, 21296.

(97) Funhoff, E.; de Jongh, T.; Averill, B. J. Biol. Inorg. Chem. 2005 10,550 .

(98) True, A. E.; Scarrow, R. C.; Randall, C. R.; Holz, R. C.; Que, L., Jr. J. Am. Chem. Soc. 1993, 115, 4246

(99) Wang, X.; Ho, R. Y. N.; Whiting, A. K.; Que, L., Jr. J. Am. Chem. Soc. 1999, 121, 9235.

(100) Dikiy, A.; Funhoff, E. G.; Averill, B. A.; Ciuril, S. $\underline{\text { J. Am. Chem. }}$ Soc. 2002, 124, 13974

(101) Williams, A. Adv. Phvs. Org. Chem. 1992, 27, 1.

(102) Truong, N. T.; Naseri, J. I.; Vogel, A.; Rompel, A.; Krebs, B. Arch. Biochem. Biophys. 2005, 440, 38 .

(103) Kimura, E. Curr. Opin. Chem. Biol. 2000, 4, 207.

(104) Gavrilova, A. L.; Bosnich, B. Chem. Rev. 2004, 104, 349.

(105) Belle, C.; Gautier-Luneau, I.; Pierre, J.-L.; Scheer, C.; Saint-Aman, E. Inorg. Chem. 1996, 35, 3706.

(106) Belle, C.; Gautier-Luneau, I.; Karmazin, L.; Pierre, J.-L.; Albedyhl, S.; Krebs, B.; Bonin, M. Eur. J. Inorg. Chem. 2002, 2002, 3087.

(107) Lambert, E.; Chabut, B.; Chardon-Noblat, S.; Deronzier, A.; Chottard, G.; Bousseksou, A.; Tuchagues, J.-P.; Laugier, J.; Bardet, M.; Latour, J.-M. J. Am. Chem. Soc. 1997, 119, 9424.

(108) Neves, A.; de Brito, M. A.; Drago, V.; Griesar, K.; Haase, W. Inorg. Chim. Acta 1995, 237, 131.

(109) Karsten, P.; Neves, A.; Bortoluzzi, A. J.; Lanznaster, M.; Drago, V. Inorg. Chem. 2002, 41, 4624.

(110) Karsten, P.; Neves, A.; Bortoluzzi, A. J.; Strahle, J.; MaichleMossmer, C. Inorg. Chem. Commun. 2002, 5, 434.

(111) Batista, S. C.; Neves, A.; Bortoluzzi, A. J.; Vencato, I.; Peralta, R. A.; Szpoganicz, B.; Aires, V. V. E.; Terenzi, H.; Severino, P. C. Inorg. Chem. Commun. 2003, 6, 1161.

(112) Lanznaster, M.; Neves, A.; Bortoluzzi, A. J.; Aires, V. V. E.; Szpoganicz, B.; Terenzi, H.; Severino, P. C.; Fuller, J. M.; Drew, S. C.; Gahan, L. R.; Hanson, G. R.; Riley, M. J.; Schenk, G. J. Biol. Inorg. Chem. 2005, 10, 319 .

(113) Lanznaster, M.; Neves, A.; Bortoluzzi, A. J.; Szpoganicz, B.; Schwingel, E. Inorg. Chem. 2002, 41, 5641.

(114) Paes, L. W.; Faria, R. B.; Machuca-Herrera, J. O.; Neves, A.; Machado, S. P. Can. J. Chem. 2004, 82, 1619.

(115) Sage, J. T.; Xia, Y. M.; Debrunner, P. G.; Keough, D. T.; de Jersey, J.; Zerner, B. J. Am. Chem. Soc. 1989, 111, 7239.

(116) Kerk, D.; Bulgrien, J.; Smith, D. W.; Barsam, B.; Veretnik, S.; Gribskov, M. Plant Phvsiol. 2002, 129, 908.

(117) Pullen, K. E.; Ng, H.-L.; Sung, P.-Y.; Good, M. C.; Smith, S. M.; Alber, T. Structure 2004, 12, 1947.

(118) Andreeva, A. V.; Kutuzov, M. A. BMC Evol. Biol. 2004, 4, 47.

(119) Eichler, J.; Adams, M. W. W. Microbiol. Mol. Biol. Rev. 2005, 69, 393.

(120) McCluskey, A.; Sim, A. T. R.; Sakoff, J. A. J. Med. Chem. 2002 45,1151

(121) Urban, G.; Golden, T.; Aragon, I. V.; Scammell, J. G.; Dean, N. M.; Honkanen, R. E. J. Biol. Chem. 2001, 276, 27638.

(122) Morita, K.; Saitoh, M.; Tobiume, K.; Matsuura, H.; Enomoto, S.; Nishitoh, H.; Ichijo, H. EMBO J. 2001, 20, 6028.

(123) Leung, J.; Bouvier-Durand, M.; Morris, P.-C.; Guerrier, D.; Chefdor, F.; Giraudat, J. Science 1994, 264, 1448.

(124) Meyer, K.; Leube, M. P.; Grill, E. Science 1994, 264, 1452.

(125) Das, A. K.; Helps, N. R.; Cohen, P. T. W.; Barford, D. EMBO J. 1996, $15,6798$.

(126) Av-Gay, Y.; Everett, M. Trends Microbiol. 2000, 8, 238. 
(127) King, M. M.; Huang, C. Y. J. Biol. Chem. 1984, 259, 8847.

(128) Yu, L.; Haddy, A.; Rusnak, F. J. Am. Chem. Soc. 1995, 117, 10147.

(129) Yu, L.; Golbeck, J.; Yao, J.; Rusnak, F. Biochemistry 1997, 36, 10727

(130) Mertz, P.; Yu, L.; Sikkink, R.; Rusnak, F. J. Biol. Chem. 1997, 272, 21296.

(131) Namgaladze, D.; Hofer, H. W.; Ullrich, V. J. Biol. Chem. 2002, 277 5962

(132) Ullrich, V.; Namgaladze, D.; Frein, D. Toxicol. Lett. 2003, 139, 107.

(133) Reiter, T. A.; Reiter, N. J.; Rusnak, F. Biochemistry 2002, 41, 15404

(134) Rusnak, F.; Yu, L.; Todorovic, S.; Mertz, P. Biochemistrv 1999, 38 6943.

(135) White, D. J.; Reiter, N. J.; Sikkink, R. A.; Yu, L.; Rusnak, F. Biochemistry 2001, 40, 8918.

(136) Reiter, T. A.; Rusnak, F. Biochemistry 2004, 43, 782

(137) Zhuo, S.; Clemens, J. C.; Hakes, D. J.; Barford, D.; Dixon, J. E. J. Biol. Chem. 1993, 268, 17754.

(138) Swingle, M. R.; Honkanen, R. E.; Ciszak, E. M. J. Biol. Chem. 2004 279,33992

(139) Pato, M. D.; Kerc, E. Mol. Cell. Biochem. 1991, 101, 31

(140) Chopra, P.; Singh, B.; Singh, R.; Vohra, R.; Koul, A.; Meena, L. S.; Koduri, H.; Ghildiyal, M.; Deol, P.; Das, T. K.; Tyagi, A. K.; Singh, Y. Biochem. Biophys. Res. Commun. 2003, 311, 112.

(141) Hoff, R. H.; Mertz, P.; Rusnak, F.; Hengge, A. C. J. Am. Chem. Soc. 1999, 121, 6382.

(142) Fjeld, C. C.; Denu, J. M. J. Biol. Chem. 1999, 274, 20336

(143) Jackson, M. D.; Fjeld, C. C.; Denu, J. M. Biochemistry 2003, 42, 8513

(144) Reiter, N. J.; White, D. J.; Rusnak, F. Biochemistry 2002, 41, 1051

(145) Crans, D. C.; Simone, C. M.; Holz, R. C.; Que, L., Jr. Biochemistry 1992, 31, 11731

(146) Goldberg, J.; Huang, H. B.; Kwon, Y. G.; Greengard, P.; Nairn, A. C.; Kuriyan, J. Nature 1995, 376, 745 .

(147) Egloff, M.-P.; Cohen, P. T. W.; Reinemer, P.; Barford, D. J. Mol. Biol. 1995, 254, 942.

(148) Griffith, J. P.; Kim, J. L.; Kim, E. E.; Sintchak, M. D.; Thomson, J. A.; Fitzgibbon, M. J.; Fleming, M. A.; Caron, P. R.; Hsiao, K.; Navia, M. A. Cell 1995, 82, 507.

(149) Kissinger, C. R.; Parge, H. E.; Knighton, D. R.; Lewis, C. T.; Pelletier, L. A.; Tempczyk, A.; Kalish, V. J.; Tucker, K. D.; Showalter, R. E. Nature 1995, 378, 641 .

(150) Honkanen, R. E.; Golden, T. Curr. Med. Chem. 2002, 9, 2055

(151) Chen, M. X.; Cohen, P. T. W. FEBS Lett. 1997, 400, 136.

(152) Sinclair, C.; Borchers, C.; Parker, C.; Tomer, K.; Charbonneau, H.; Rossie, S. J. Biol. Chem. 1999, 274, 23666.

(153) Martin, B. L.; Graves, D. J. J. Biol. Chem. 1986, 261, 14545.

(154) Hengge, A. C.; Martin, B. L. Biochemistry 1997, 36, 10185.

(155) Hengge, A. C. Acc. Chem. Res. 2002, 35, 105.

(156) Scheuermann, R. H.; Echols, H. Proc. Natl. Acad. Sci. U.S.A. 1984, 81,7747

(157) Catalano, C. E.; Allen, D. J.; Benkovic, S. J. Biochemistry 1990, 29, 3612

(158) Derbyshire, V.; Pinsonneault, J. K.; Joyce, C. M. EMBO J. 1991, 10,17

(159) Viswanathan, M.; Lovett, S. T. J. Biol. Chem. 1999, 274, 30094

(160) Mazur, D. J.; Perrino, F. W. J. Biol. Chem. 2001, 276, 17022.

(161) Lam, W.-C.; Thompson, E. H. Z.; Potapova, O.; Sun, X. C.; Joyce, C. M.; Millar, D. P. Biochemistry 2002, 41, 3943.

(162) Thompson, E. H. Z.; Bailey, M. F.; van der Schans, E. J. C.; Joyce, C. M.; Millar, D. P. Biochemistry 2002, 41, 713.

(163) Brutlag, D.; Atkinson, M. R.; Setlow, P.; Kornberg, A. Biochem. Biophys. Res. Commun. 1969, 37, 982.

(164) Brutlag, D.; Kornberg, A. J. Biol. Chem. 1972, 247, 241

(165) Mazur, D. J.; Perrino, F. W. J. Biol. Chem. 1999, 274, 19655.

(166) Breyer, W. A.; Matthews, B. W. Nat. Struct. Biol. 2000, 7, 1125

(167) Wood, R. D.; Mitchell, M.; Sgouros, J.; Lindahl, T. Science 2001, 291, 1284.

(168) Hübscher, U.; Maga, G.; Spadari, S. Annu. Rev. Biochem. 2002, 71, 133

(169) Shevelev, I. V.; Hübscher, U. Nat. Rev. Mol. Cell Biol. 2002, 3, 1.

(170) Deutscher, M. P.; Kornberg, A. J. Biol. Chem. 1969, 244, 3029.

(171) Klenow, H.; Overgaard-Hansen, K. FEBS Lett. 1970, 6, 25

(172) Ollis, D. L.; Brick, P.; Hamlin, R.; Xuong, N. G.; Steitz, T. A. Nature $1985,313,762$

(173) Spicer, E. K.; Rush, J.; Fung, C.; Reha-Krantz, L. J.; Karam, J. D.; Könisgberg, W. H. J. Biol. Chem. 1988, 263, 7478

(174) Saiki, R. K.; Faloona, F.; Mullis, K. B.; Horn, G. T.; Erlich, H. A.; Arnheim, N. Science 1985, 230, 1350

(175) Mullis, K. B.; Faloona, F. Methods Enzymol. 1987, 55, 335.

(176) Drake, J. W. Annu. Rev. Genet. 1991, 25, 125.

(177) Drake, J. Proc. Natl. Acad. Sci. U.S.A. 1991, 88, 7160.

(178) Schaaper, R. M. J. Biol. Chem. 1993, 268, 23762.

(179) Fersht, A. R.; Knill-Jones, J. W.; Tsui, W.-C. J. Mol. Biol. 1982 156,37
(180) Filée, J.; Forterre, P.; Sen-Lin, T.; Laurent, J. J. Mol. Evol. 2002, $54,763$.

(181) Ohmori, H.; Friedberg, E. C.; Fuchs, R. P. P.; Goodman, M. F.; Hanaoka, F.; Hinkle, D.; Kunkel, T. A.; Lawrence, C. W.; Livneh, Z.; Nohmi, T.; Prakash, L.; Prakash, S.; Todo, T.; Walker, G. C.; Wang, Z.; Woodgate, R. Mol. Cell 2001, 8, 7.

(182) Kunkel, T. A. Cell 1988, 53, 837.

(183) Welch, M. M.; McHenry, C. S. J. Bacteriol. 1982, 152, 351

(184) Kelman, Z.; O’Donnell, M. Annu. Rev. Biochem. 1995, 64, 171.

(185) Taft-Benz, S. A.; Schaaper, R. M. J. Bacteriol. 1999, 181, 2963.

(186) Perrino, F. W.; Harvey, S.; McNeill, S. M. Biochemistry 1999, 38, 16001.

(187) DeRose, E. F.; Darden, T.; Harvey, S.; Gabel, S.; Perrino, F. W. Schaaper, R. M.; London, R. E. Biochemistry 2003, 42, 3635.

(188) Gupta, R.; Hamdan, S. M.; Dixon, N. E.; Sheil, M. M.; Beck, J. L. Protein Sci. 2004, 13, 2878.

(189) Hamdan, S. M.; Bulloch, E. M.; Thompson, P. R.; Beck, J. L.; Yang J. Y.; Crowther, J. A.; Lilley, P. E.; Carr, P. D.; Ollis, D. L.; Brown, S. E.; Dixon, N. E. Biochemistry 2002, 41, 5266.

(190) Perrino, F. W.; Krol, A.; Harvey, S.; Zheng, S. L.; Horita, D. A Hollis, T.; Meyers, D. A.; Isaacs, W. B.; Xu, J. Adv. Enzyme Regul 2004, 44, 37

(191) Huang, S.; Li, B.; Gray, M. D.; Oshima, J.; Mian, I. S.; Campisi, J. Nat. Genet. 1998, 20, 114

(192) Koonin, E. V. Curr. Biol. 1997, 7, 604.

(193) Kamath-Loeb, A. S.; Shen, J.-C.; Loeb, L. A.; Fry, M. J. Biol. Chem 1998, 273, 34145.

(194) Mummenbrauer, T.; Janus, F.; Müller, B.; Wiesmüller, L.; Deppert, W.; Grosse, F. Cell 1996, 85, 1089.

(195) Ma, D.; McCorkle, J. R.; Kaetzel, D. M. J. Biol. Chem. 2004, 279, 18073.

(196) Yang, D.-H.; de Jong, J. G.; Makhmoudova, A.; Arif, B. M.; Krell, P. J. J. Gen. Virol. 2004, 85, 3569.

(197) Yoshida, A.; Ueda, T. Biochem. Biophys. Res. Comm. 2003, 310, 522 .

(198) Shafritz, K. M.; Sandigursky, M.; Franklin, W. A. Nucleic Acids Res. 1998, 26, 2593.

(199) Viswanathan, M.; Dower, K. W.; Lovett, S. T. J. Biol. Chem. 1998 $273,35126$.

(200) Bessho, T.; Sancar, A. J. Biol. Chem. 2000, 275, 7451

(201) Perrino, F. W.; Harvey, S.; McMillin, S.; Hollis, T. J. Biol. Chem. 2005, 280, 15212.

(202) Bernard, A.; Blanco, L.; Lázaro, J. M.; Martin, G.; Salas, M. Cell 1989, 59, 219

(203) Morrison, A.; Bell, J. B.; Kunkel, T. A.; Sugino, A. Proc. Natl. Acad. Sci. U.S.A. 1991, 88, 9473

(204) Koonin, E. V.; Deutscher, M. P. Nucleic Acids Res. 1993, 21, 2521

(205) Blanco, L.; Bernard, A.; Salas, M. Gene 1992, 112, 139

(206) Blanco, L.; Bernard, A.; Blasco, M. A.; Salas, M. Gene 1991, 100, 27.

(207) Derbyshire, V.; Freemont, P. S.; Sanderson, M. R.; Beese, L. S.; Friedman, J. M.; Joyce, C. M.; Steitz, T. A. Science 1988, 240, 199.

(208) Lehman, I. R.; Richardson, C. C. J. Biol. Chem. 1964, 239, 233.

(209) DNA Replication; Kornberg, A., Ed.; Freeman, W. H.: San Francisco, CA, 1980.

(210) Freemont, P. S.; Friedman, J. M.; Beese, L. S.; Sanderson, M. R.; Steitz, T. A. Proc. Natl. Acad. Sci. U.S.A. 1988, 85, 8924.

(211) Han, H.; Rifkind, J. M.; Mildvan, A. S. Biochemistrv 1991, 30, 11104

(212) Taft-Benz, S. A.; Schaaper, R. M. Nucleic Acids Res. 1998, 26, 4005.

(213) Kühn, F. J. P.; Knopf, C. W. J. Biol. Chem. 1996, 271, 29245.

(214) de Vega, M.; Lázaro, J. M.; Salas, M.; Blanco, L. EMBO J. 1996, 15,1182

(215) Frey, M. W.; Nossal, N. G.; Capson, T. L.; Benkovic, S. J. Proc. Natl. Acad. Sci. U.S.A. 1993, 90, 2579.

(216) Elisseeva, E.; Mandal, S. S.; Reha-Krantz, L. J. J. Biol. Chem. 1999 274, 25151

(217) Esteban, J. A.; Soengas, M. S.; Salas, M.; Blanco, L. J. Biol. Chem. 1994, 269, 31946.

(218) Patel, S. S.; Wong, I.; Johnson, K. A. Biochemistry 1991, 30, 511.

(219) Beese, L. S.; Steitz, T. A. EMBO J. 1991, 10, 25.

(220) Beechem, J. M.; Otto, M. R.; Bloom, L. B.; Eritja, R.; Reha-Krantz, L. J.; Goodman, M. F. Biochemisty 1998, 37, 10144.

(221) Frey, M. W.; Frey, S. T.; Horrocks, W. D., Jr.; Kaboord, B. F.; Benkovic, S. J. Chem. Biol. 1996, 3, 393.

(222) Mullen, G. P.; Serpersu, E. H.; Ferrin, L. J.; Loeb, L. A.; Midvan, A. S. J. Biol. Chem. 1990, 265, 14327.

(223) Maki, H.; Kornberg, A. Proc. Natl. Acad. Sci. U.S.A. 1987, 84, 4389

(224) Miller, H.; Perrino, F. W. Biochemistry 1996, 35, 12919

(225) Kumar, J. K.; Chiu, E. T.; Tabor, S.; Richardson, C. C. J. Biol. Chem. 2004, 279, 42018.

(226) Donlin, M. J.; Patel, S. S.; Johnson, K. A. Biochemistry 1991, 30, 538 
(227) Wang, C. X.; Zakharova, E.; Li, J.; Joyce, C. M.; Wang, J.; Königsberg, W. Biochemistry 2004, 43, 3853.

(228) Kiefer, J. R.; Mao, C.; Hansen, C. J.; Basehore, S. L.; Hogrefe, H. H.; Braman, J. C.; Beese, L. S. Structure 1997, 5, 95

(229) Tabor, S.; Richardson, C. C. Proc. Natl. Acad. Sci. U.S.A. 1995, 92, 6339.

(230) Doublié, S.; Tabor, S.; Long, A. M.; Richardson, C. C.; Ellenberger, T. Nature 1998, 391, 251.

(231) Wang, J.; Yu, P.; Lin, T. C.; Königsberg, W. H.; Steitz, T. A. Biochemistry 1996, 35, 8110.

(232) Wang, J.; Sattar, A. K. M. A.; Wang, C. C.; Karam, J. D.; Königsberg, W. H.; Steitz, T. A. Cell 1997, 89, 1087.

(233) Kamtekar, S.; Berman, A. J.; Wang, J.; Lázaro, J. M.; de Vega, M.; Blanco, L.; Salas, M.; Steitz, T. A. Mol. Cell 2004, 16, 609.

(234) Zhao, Y.; Jeruzalmi, D.; Moarefi, I.; Leighton, L.; Lasken, R.; Kuriyan, J. Structure 1999, 7, 1189.

(235) Savino, C.; Federici, L.; Johnson, K. A.; Vallone, B.; Nastopoulos, V.; Rossi, M.; Pisani, F. M.; Tsernoglou, D. Structure 2004, 12, 2001.

(236) Hashimoto, H.; Nishioka, M.; Fujiwara, S.; Takagi, M.; Imanaka, T.; Inoue, T.; Kai, Y. J. Mol. Biol. 2001, 306, 469

(237) Kuroita, T.; Matsumura, H.; Yokota, N.; Kitabayashi, M.; Hashimoto, H.; Inoue, T.; Imanaka, T.; Kai, Y. J. Mol. Biol. 2005, 351, 291.

(238) Kim, Y.; Eom, S. H.; Wang, J.; Lee, D.-S.; Suh, S. W.; Steitz, T. A Nature 1995, 376, 612

(239) Rodriguez, A. C.; Park, H.-W.; Mao, C.; Beese, L. S. J. Mol. Biol. 2000, 299, 447.

(240) Hopfner, K.-P.; Eichinger, A.; Engh, R. A.; Laue, F.; Ankenbauer, W.; Huber, R.; Angerer, B. Proc. Natl. Acad. Sci. U.S.A. 1999, 96, 3600

(241) Hamdan, S. M.; Carr, P. D.; Brown, S. E.; Ollis, D. L.; Dixon, N. E. Structure 2002, 10, 535.

(242) DeRose, E. F.; Li, D.; Darden, T.; Harvey, S.; Perrino, F. W.; Schaaper, R. M.; London, R. E. Biochemistry 2002, 41, 94.

(243) Jokela, M.; Raki, M.; Heikkinen, K.; Sepponen, K.; Eskelinen, A.; Syväoja, J. E. Protein Expression Purif. 2005, 43, 73

(244) Jokela, M.; Eskelinen, A.; Pospiech, H.; Rouvinen, J.; Syväoja, J. E. Nucleic Acids Res. 2004, 32, 2430.

(245) Shen, Y.; Tang, X.-F.; Yokoyama, H.; Matsui, E.; Matsui, I. Nucleic Acids Res. 2004, 32, 158.

(246) Hopfner, K.-P.; Karcher, A.; Craig, L.; Woo, T. T.; Carney, J. P.; Tainer, J. A. Cell 2001, 105, 473

(247) Horio, T.; Murai, M.; Inoue, T.; Hamasaki, T.; Tanaka, T.; Ohgi, T. FEBS Lett. 2004, 577, 111

(248) Capson, T. L.; Peliska, J. A.; Kaboord, B. F.; Frey, M. W.; Lively, C.; Dahlberg, M.; Benkovic, S. J. Biochemistry 1992, 31, 10984

(249) Cosstick, R.; Vyle, J. S. Nucleic Acids Res. 1990, 8, 2295.

(250) Curley, J. F.; Joyce, C. M.; Piccirilli, J. A. J. Am. Chem. Soc. 1997 119,12691

(251) Brautigam, C. A.; Sun, S.; Piccirilli, J. A.; Steitz, T. A. Biochemistry 1999, 38, 696.

(252) Sträter, N. In Handbook of Metalloproteins; Messerschmidt, A., Bode, W., Cygler, M., Eds.; Wiley: New York, 2001; Vol. 3

(253) Schultz-Heienbrok, R.; Maier, T.; Sträter, N. Biochemistry 2005, 44, 2244

(254) Hunsucker, S. A.; Mitchell, B. S.; Spychala, J. Pharmacol. Ther 2005, 107, 1 .

(255) Bianchi, V.; Spychala, J. J. Biol. Chem. 2003, 278, 46195

(256) Misumi, Y.; Ogata, S.; Ohkubo, K.; Hirose, S.; Ikehara, Y. Eur. J. Biochem. 1990, 191, 563.

(257) Misumi, Y.; Ogata, S.; Hirose, S.; Ikehara, Y. J. Biol. Chem. 1990, $265,2178$.

(258) Zimmermann, H. Biochem. J. 1992, 285, 345.

(259) Dieckhoff, J.; Knebel, H.; Heidemann, M.; Mannherz, H. G. Eur. J. Biochem. 1985, 151, 377.

(260) Liyou, N.; Hamilton, S.; Elvin, C.; Willadsen, P. Insect Mol. Biol. 1999, $8,257$.

(261) Fini, C.; Palmerini, C. A.; Damiani, P.; Stochaj, U.; Mannherz, H. G.; Floridi, A. Biochim. Biophys. Acta 1990, 1038, 18.

(262) Mittal, R.; Das, J.; Sharma, C. B. Plant Sci. 1988, 55, 93.

(263) Ostergaard, J.; Larsen, K.; Jochimsen, B. U. J. Plant Physiol. 1991, 138,387

(264) Neu, H. C. J. Biol. Chem. 1967, 242, 3896.

(265) Mitchel, R. E. J. Biochim. Biophys. Acta 1973, 309, 116

(266) Swartz, M. N.; Kaplan, N. O.; Lamborg, M. F. J. Biol. Chem. 1958, $232,1051$.

(267) Fini, C.; Talamo, F.; Cherri, S.; Coli, M.; Floridi, A.; Ferrara, L.; Scaloni, A. Biochem. J. 2003, 372, 443.

(268) Zimmermann, H. Prog. Neurobiol. 1996, 49, 589

(269) Neu, H. C. J. Biol. Chem. 1967, 242, 3905.

(270) Knöfel, T.; Sträter, N. J. Mol. Biol. 2001, 309, 239.

(271) Dvorak, H. F.; Heppel, L. A. J. Biol. Chem. 1968, 243, 2647.

(272) Glaser, L.; Melo, A.; Paul, R. J. Biol. Chem. 1967, 242, 1944.
(273) Ruiz, A.; Hurtado, C.; Ribeiro, J. M.; Sillero, A.; Sillero, M. A. G. J. Bacteriol. 1989, 171, 6703.

(274) Naito, Y.; Lowenstein, J. M. Biochemistry 1981, 20, 5188.

(275) Le Hir, M.; Gandhi, R.; Dubach, U. C. Enzyme 1989, 41, 87.

(276) Camici, M.; Fini, C.; Ipata, P. L. Biochim. Biophys. Acta 1985, 840 , 6

(277) Tasca, T.; Bonan, C. D.; De Carli, G. A.; Battastini, A. M. O.; Sarkis, J. J. F. Exp. Parasitol. 2003, 105, 167.

(278) Le Hir, M.; Kaissling, B. Am. J. Physiol. Renal Physiol. 1993, 264 , F377.

(279) Garcia, L.; Chayet, L.; Kettlun, A. M.; Collados, L.; Chiong, M.; Traverso-Cori, A.; Mancilla, M.; Valenzuela, M. A. Comp. Biochem. Phvsiol. 1997, 117B, 135.

(280) McMillen, L.; Beacham, I. R.; Burns, D. M. Biochem. J. 2003, 372 625.

(281) Picher, M.; Burch, L. H.; Hirsh, A. J.; Spychala, J.; Boucher, R. C. J. Biol. Chem. 2003, 278, 13468.

(282) Dvorak, H. F.; Anraku, Y.; Heppel, L. A. Biochem. Biophvs. Res. Commun. 1966, 24, 628

(283) Jackson, E. K.; Dubey, R. K. Am. J. Phvsiol. Renal Physiol. 2001, 281, F597.

(284) Lennon, P. F.; Taylor, C. T.; Stahl, G. L.; Colgan, S. P. J. Exp. Med 1998, 188, 1433

(285) Nemoto, E.; Kunii, R.; Tada, H.; Tsubahara, T.; Ishihata, H.; Shimauchi, H. J. Periodontal Res. 2004, 39, 10.

(286) Osborne, F. N.; Kalsi, K. K.; Lawson, C.; Lavitrano, M.; Yacoub, M. H.; Rose, M. L.; Smolenski, R. T. Am. J. Transplant. 2005, 5, 1248.

(287) Knöfel, T.; Sträter, N. Nat. Struct. Biol. 1999, 6, 448.

(288) Knöfel, T.; Sträter, N. J. Mol. Biol. 2001, 309, 255

(289) Schultz-Heienbrok, R.; Maier, T.; Sträter, N. Protein Sci. 2004, 13, 1811

(290) Kimura, E.; Shiota, T.; Koike, T.; Shiro, M.; Kodama, M. J. Am. Chem. Soc. 1990, 112, 5805

(291) Mareque-Rivas, J. C.; Prabaharan, R.; Parsons, S. Dalton Trans. 2004, 1648.

(292) Bauer-Siebenlist, B.; Meyer, F.; Farkas, E.; Vidovic, D.; CuestaSeijo, J. A.; Herbst-Irmer, R.; Pritzkow, H. Inorg. Chem. 2004, 43, 4189.

(293) Ibrahim, M. M.; Ichikawa, K.; Shiro, M. Inorg. Chim. Acta 2003 , 353,187

(294) Ruf, M.; Weis, K.; Vahrenkamp, H. J. Am. Chem. Soc. 1996, 118, 9288

(295) Coates, J. H.; Gentle, G. J.; Lincoln, S. F. Nature 1974, 249, 773

(296) Canary, J. W.; Xu, J.; Castagnetto, J. M.; Rentseperis, D.; Marky, L. A. J. Am. Chem. Soc. 1995, 117, 11545.

(297) Bauer-Siebenlist, B.; Meyer, F.; Farkas, E.; Vidovic, D.; Dechert, S. Chem.-Eur. J. 2005, 11, 4349.

(298) Park, I.-S.; Michel, L. O.; Pearson, M. A.; Jabri, E.; Karplus, P. A.; Wang, S.; Dong, J.; Scott, R. A.; Koehler, B. P.; Johnson, M. K. Hausinger, R. P. J. Biol. Chem. 1996, 271, 18632.

(299) Jabri, E.; Karplus, P. A. Biochemistrv 1996, 35, 10616

(300) Benini, S.; Rypniewski, W. R.; Wilson, K. S.; Miletti, S.; Ciurli, S.; Mangani, S. Structure 1999, 7, 205.

(301) Todd, M. J.; Hausinger, R. P. Biochemistry 2000, 39, 5389.

(302) Aubert, S. D.; Li, Y.; Raushel, F. M. Biochemistry 2004, 43, 5707.

(303) Jackson, C.; Kim, H.-K.; Carr, P. D.; Liu, J.-W.; Ollis, D. L. Biochim. Biophys. Acta 2005, 1752, 56

(304) Wilce, M. C. J.; Bond, C. S.; Dixon, N. E.; Freeman, H. C.; Guss, J. M.; Lilley, P. E.; Wilce, J. A. Proc. Natl. Acad. Sci. U.S.A. 1998 $95,3472$.

(305) Zhang, L.; Crossley, M. J.; Dixon, N. E.; Ellis, P. J.; Fisher, M. L.; King, G. F.; Lilley, P. E.; MacLachlan, D.; Pace, R. J.; Freeman, H. C. J. Biol. Inorg. Chem. 1998, 3, 470 .

(306) Cama, E.; Pethe, S.; Boucher, J.-L.; Han, S.; Emig, F. A.; Ash, D. E.; Viola, R. E.; Mansuy, D.; Christianson, D. W. Biochemistry 2004, 43, 8987

(307) Maher, M. J.; Ghosh, M.; Grunden, A. M.; Menon, A. L.; Adams, M. W. W.; Freeman, H. C.; Guss, J. M. Biochemistry 2004, 43, 2771.

(308) Copik, A. J.; Nocek, B. P.; Swierczek, S. I.; Ruebush, S.; Jang, S. B.; Meng, L.; D'souza, V. M.; Peters, J. W.; Bennett, B.; Holz, R C. Biochemistry 2005, 44, 121.

(309) Arthur, L. M.; Gustausson, K.; Hopfner, K.-P.; Carson, C. T.; Stracker, T. H.; Karcher, A.; Felton, D.; Weitzman, M. D.; Tainer, J.; Carney, J. P. Nucleic Acids Res. 2004, 32, 1886.

(310) Zhang, Y.; Wang, P. G.; Brew, K. J. Biol. Chem. 2001, 276, 11567

(311) Chen, S.; Yakunin, A. F.; Kuznetsova, E.; Busso, D.; Pufan, R. Proudfoot, M.; Kim, R.; Kim, S.-H. J. Biol. Chem. 2004, 279, 31854

(312) Wang, D.; Guo, M.; Liang, Z.; Fan, J.; Zhu, Z.; Zang, J.; Zhu, Z.; Li, X.; Teng, M.; Niu, L.; Dong, Y.; Liu, P. J. Biol. Chem. 2005, 280,22962

(313) Siemann, S.; Evanoff, D. P.; Marrone, L.; Clarke, A. J.; Viswanatha, T.; Dmitrienko, G. I. Antimicrob. Agents Chemother. 2002, 46, 2450. 
(314) Garrity, J. D.; Carenbauer, A. L.; Herron, L. R.; Crowder, M. W. J. Biol. Chem. 2004, 279, 920.

(315) Cameron, A. D.; Ridderstrom, M.; Olin, B. Structure 1999, 7, 1067

(316) Frazão, C.; Silva, G.; Gomes, C. M.; Matias, P.; Coelho, R.; Sieker, L.; Macedo, S.; Liu, M. Y.; Oliveira, S.; Teixeira, M.; Xavier, A. V.; Rodrigues-Pousada, C.; Carrondo, M. A.; Le Gall, J. Nat. Struct. Biol. 2000, 7, 1041.

(317) Garcia-Saez, I.; Mercuri, P. S.; Papamicael, C.; Kahn, R.; Frere, J. M.; Galleni, M.; Rossolini, G. M.; Dideberg, O. J. Mol. Biol. 2003, 325,651 .

(318) de la Sierra-Gallay, I. L.; Pellegrini, O.; Condon, C. Nature 2005, $433,657$.
(319) Garau, G.; Lemaire, D.; Vernet, T.; Dideberg, O.; Di Guilmi, A. M. J. Biol. Chem. 2005, 280, 28591.

(320) Schilling, O.; Wenzel, N.; Naylor, M.; Vogel, A.; Crowder, M.; Makaroff, C.; Meyer-Klaucke, W. Biochemistry 2003, 42, 11777.

(321) Wenzel, N.; Carenbauer, A.; Pfiester, M.; Schilling, O.; MeyerKlaucke, W.; Makaroff, C.; Crowder, M. J. Biol. Inorg. Chem. 2004, 9, 429 .

(322) Holtz, K. M.; Kantrowitz, E. R. FEBS Lett. 1999, 462, 7.

(323) O'Brien, P. J.; Herschlag, D. Biochemistry 2002, 41, 3207. CR050318F 